\title{
PRE-SERVICE TEACHER PROFESSIONAL NOTICING FOR TEACHING MATHEMATICS
}

\author{
A Dissertation \\ presented to \\ the Faculty of the Graduate School \\ at the University of Missouri-Columbia \\ In Partial Fulfillment \\ of the Requirements for the Degree \\ Doctor of Philosophy \\ by \\ Stephanie A. Hopkins \\ Dr. Delinda van Garderen, Dissertation Supervisor \\ MAY 2021
}


The undersigned, appointed by the dean of the Graduate School, have examined the dissertation entitled.

\section{PRE-SERVICE TEACHER PROFESSIONAL NOTICING FOR TEACHING MATHEMATICS}

presented by Stephanie A. Hopkins,

a candidate for the degree of Doctor of Philosophy,

and hereby certify that, in their opinion, it is worthy of acceptance.

Professor Delinda van Garderen

Professor Erica Lembke

Professor Chad Rose

Professor Jessica Rodrigues

Professor Corey Webel 
For Garrett.

"If it were easy everyone would do it." 


\section{ACKNOWLEDGEMENTS}

I have many people to thank who supported me during my doctoral journey and during the process of completing this dissertation. First, I would like to thank my advisor Dr. vG. She spent the last four years pushing me to be the best scholar and teacher I could be. She would comb over my writing and provide insightful and thoughtful feedback to help me develop and continue forward. She gave me tough love and encouragement when needed. Thanks to her I will spend the rest of my career 'grappling' - Thanks vG!

To the special education faculty: thank you for sharing your expertise, advice, time, and mentorship over the past four years. To my dissertation committee, Dr. Rose thank you for being a mentor every day since day one of this journey. Dr. Rose spent countless hours providing advice on navigating this crazy career and life in higher education. Dr. Webel, thank you for welcoming me into the math education family. You taught me so much about teaching in higher education, lessons I will take with me for years to come. Dr. Jrod, you stepped into support me as a doctoral student when you had many other new faculty obligations. I thank you for always been available for brainstorming and support. Finally, Dr. Lembke: you are someone I have admired since I was an undergraduate. You are a friend, mentor, running buddy, total boss, and overall GOAT. You are the reason I returned to pursue my doctoral degree. Thank you!

To my fellow doctoral students, I am so grateful for the constant laughs, support, brainstorming sessions, and memories. I will be forever grateful to Rachel Juergensen and Stacy Hirt who gave their time and expertise to help make this project possible.

To my massive, loud, intrusive, amazing family. I can't thank you enough for the check-ins, support, and pretending to care when I tried to explain my dissertation to you. 
Grammie, I have you to thank for my massive, loud, intrusive, amazing family. The example set by you and Grandpa for our family dynamic provided me with the greatest support system during the last four years.

To my better half in this world, Garrett, you deserve your own novel to properly acknowledge everything you've done for me the past four (or eleven) years. You provided endless reassurance on the tough days and took me for ice-cream to celebrate on the good ones. You've always been so supportive of our adventures - thank you for supporting me on this one and I can't wait to see what's next!

Finally, I would like to thank my parents, Mark and Sue. Twenty years ago, I was a kid in elementary school who was identified with a learning disability. I hated school, learning was frustrating, and I would never had set my dreams this high without the support of my parents. Because of their dedication, sacrifice, time, commitment, support, encouragement, and love, I am now in a position to be able to spend my life supporting kids just like me. This dissertation would not have been possible without their devotion and commitment to my success. Thanks Mom and Dad!

Cheers! 
TABLE OF CONTENTS

ACKNOWLEDGEMENTS _.................................................................. ii

LIST OF TABLES $\quad$............................................................................ vii

LIST OF FIGURES _..................................................................... viii

ABSTRACT

CHAPTER 1

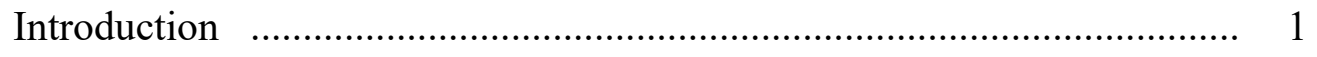

Pedagogical Content Knowledge (PCK) .................................................... 3

Development of PCK ………………............................................... 8

Overarching Concern ........................................................................... 9

CHAPTER 2

Review of the Literature …………………………............................. 11

Professional Noticing $\quad$.......................................................................... 11

Teacher Beliefs

Content Knowledge of Mathematics $\quad$........................................................... $\quad 30$

Professional Noticing, Beliefs, and Content Knowledge $\quad$......................... 33

Summary and Rationale ................................................................ 34

Research Questions .......................................................................... 37

CHAPTER 3

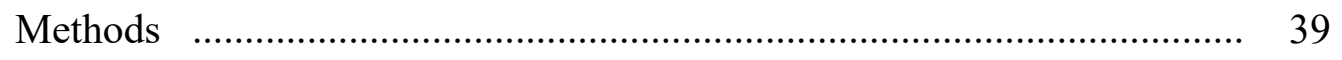

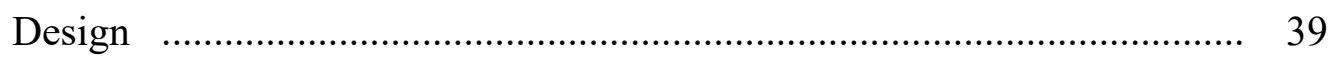

Pre-Service Teacher Participants: Recruitment and Demographics ......... 39 


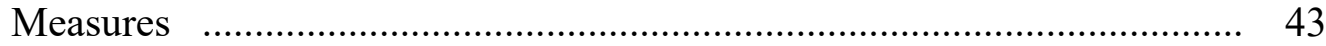

Mathematics Belief Scale .................................................................... 43

Learning Mathematics for Teachers (LMT) ............................................. 44

Professional Noticing ........................................................................... 47

Data Collection Procedures ....................................................................... 50

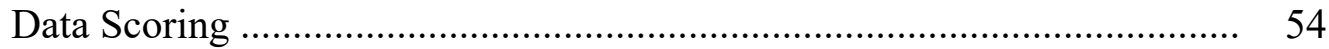

Mathematics Belief Scale ....................................................................... 54

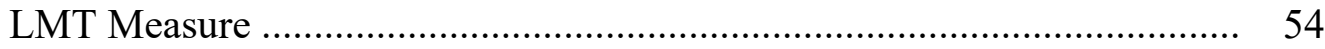

Professional Noticing Scoring Rubric ……………………..................... 55

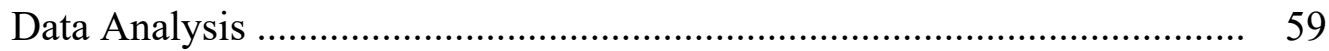

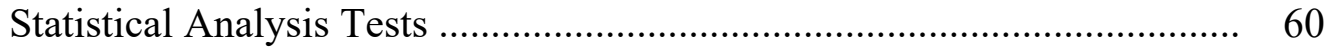

\section{CHAPTER 4}

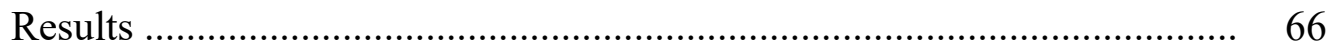

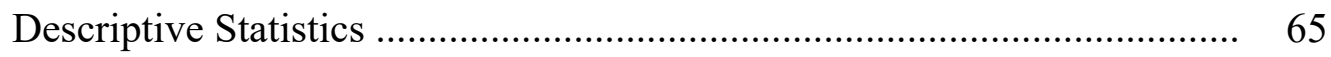

Research Question 1 ............................................................................. 74

Research Question 1a ...................................................................... 75

Research Question 1b ....................................................................... 77

Research Question 2 ...................................................................... 80

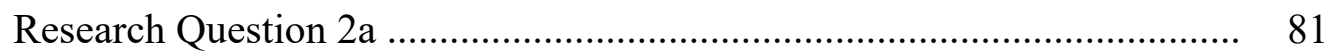

Research Question 2b ..................................................................... 83

Research Question 3 ...................................................................... 85

\section{CHAPTER 5}

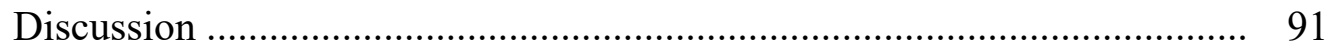


Mathematical Content Knowledge is Essential ...................................... 92

The Importance of a Teacher's Beliefs About Teaching Mathematics....... 94

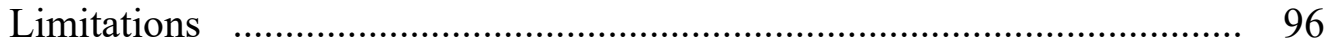

Implications for Practice ....................................................................... 98

Future Research .......................................................................... 103

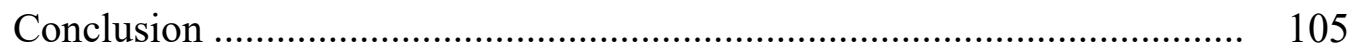

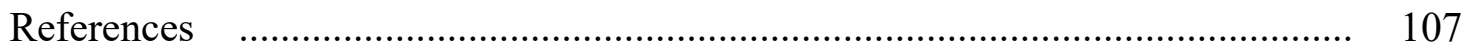

Appendices

A Institutional Review Board Approval ............................................. 138

B Participant Verbal Consent Script ...................................................... 139

C Participant Consent form adapted for online administration ................. 141

D LMT Sample Items .............................................................. 143

E Adaptation of Principles and Standards for School Mathematics ......... 144

F. Professional Noticing Video Clip Descriptions ................................. 146

G. Mathematics Belief Scale ........................................................ 147

H. Noticing Responses Scoring Rubric and Direction ............................ 148

I. Professional Noticing Rubric Scoring Coding Guide .......................... 151

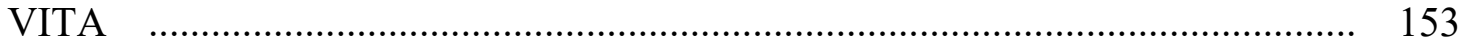




\section{LIST OF TABLES}

Table 1. Cohort Descriptions $\quad$............................................................... 41

Table 2. Demographic Information of Pre-Service Teachers $\quad$ ….................... 42

Table 3. Data Collection Method and Period by Cohort $\quad$.............................. 51

Table 4. Statistical Analyses and Items for Research $\quad 61$

Questions

Table 5. Professional Noticing scores by major and Year in Program.............. 67

Table 6. Professional Noticing Topic by Major .......................................... 68

Table 7. Professional Noticing Topic by Year in Program............................... 68

Table 8. Content Knowledge by Major and Year in Program $\quad$........................ 69

Table 9. $\quad$ LMT Scores by Content Knowledge Groups …............................. 70

Table 10. Teacher Beliefs by Major by Year in Program ................................ 72

Table 11. MBS Mean and Standard Deviation by Teacher Beliefs Subscale....... 73

Table 12. Summary of Hierarchical Multiple Regression for Professional

Noticing 


\section{LIST OF FIGURES}

Figure 1. Domain Map for Mathematical Knowledge for Teaching $\quad$............ 4

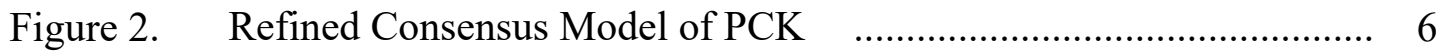

Figure 3. Data Collection Fidelity Checklist $\quad$............................................. 53

Figure 4. Mean of Teacher Professional Sum Scores by Content Knowledge 75

Group.

Figure 5. Estimated Marginal Means of Professional Noticing Sum Scores ..... 76

Figure 6. Professional Noticing Sum Scores by Major by Content Knowledge 78 Groups

Figure 7. Mean of Professional Noticing Sum Scores by Teacher Beliefs ....... 80

Figure 8. Professional Noticing Sum Scores by Year in Program by Teacher 82 Beliefs

Figure 9. Professional Noticing Sum Scores by Major by Teacher Beliefs ....... 84

Figure 10. Professional Noticing Sum Score by Content Knowledge of 86 Mathematics 


\title{
PRE-SERVICE TEACHER PROFESSIONAL NOTICING FOR TEACHING MATHEMATICS
}

Stephanie Hopkins

Dr. Delinda van Garderen, Dissertation Advisor

\begin{abstract}
Students with disabilities and/or those who have difficulty learning mathematical concepts can be found in almost every classroom. Over the last several decades, the responsibilities and roles of general and special education educators have shifted, blurring the conventionally held boundaries between special education and general education teachers and their pedagogical practices. Both special education and general education teachers are expected to provide an optimal mathematical instructional experience to all students. One way to best prepare novice teachers for this task is by increasing their overall Pedagogical Content Knowledge (PCK). The purpose of this study is to contribute to research about specific components of a pre-service teacher's PCK. This research utilized a cross-sectional research design in its study of a representative sample of preservice teachers at specific moments in time during their teacher preparation program. Mathematical content knowledge and teachers' beliefs regarding the teaching of mathematics were found to have a statistically significant impact on professional noticing. Although not statistically significant, the differences the choice of a major had on a teacher's noticing ability requires further investigation. This study addresses an important gap in the research literature on noticing in that it includes special education teachers. Additionally, the study provides concrete recommendations for teacher preparation programing and suggestions for future research.
\end{abstract}




\section{Chapter 1}

\section{Introduction}

Students with disabilities ${ }^{1}$ or those who have difficulty learning mathematical concepts can be found in almost every classroom (Knight et al., 2008). Recent educational reforms and government mandates have had a significant impact on how and in what educational environment students with disabilities receive their daily instruction. The "No Child Left Behind Act" (NCLB) of 2001 and the "Individuals with Disabilities Education Improvement Act" (IDEA) of 2004 mandated that all students, with but a few exceptions, master the general education curriculum, participate in standardized assessments, and attain a passing level of performance. According to recent data, 63 percent of students with disabilities spend 80 percent or more of their time in the general education classroom (National Center for Education Statistics, 2020). Consequently, an increasing number of students with disabilities receive the majority of their core content instruction (e.g., reading, writing, and mathematics) within the general education environment.

Research findings suggest that students with disabilities who receive their core instruction in inclusive classrooms achieve higher course grades in mathematics than students in pullout resource programs (Rea et al., 2002). As inclusive classrooms have become the norm in many schools, the responsibilities and roles of general and special education educators have shifted, blurring the conventionally held boundaries between special education and general education practices (Brownell et al., 2010; Shepherd et al.,

\footnotetext{
${ }^{1}$ The expression "students with disabilities" refers to students who fall into one or more of the categories defined by the "Individuals with Disabilities Education Act" (IDEA, 2004).
} 
2016). As a result, it is likely that increased numbers of students with disabilities will receive their core content instruction, including mathematics, from both general and special education teachers, and in a general education environment. While it seems clear that the more inclusive classroom can be beneficial for students with disabilities, the success of this inclusive model depends on a close collaboration between general and special education teachers in order to ensure that all students who share the same classroom environment are provided an optimal instructional experience (Arthaud et al., 2007; Da Fonte \& Barton-Arwood, 2017; Jordan et al., 2009; Robinson \& Buly, 2007). Although there is much debate regarding the best pedagogical strategies for teaching mathematics (e.g., Boyd \& Bargerhuff, 2009; Munter et al., 2015; Hunt \& Tzur, 2017), research clearly indicates that all prospective instructors need to help students develop a deep and meaningful understanding of the subject matter to ensure their meaningful progress (Miller \& Hudson, 2007; Rittle-Johnson et al., 2015; Rittle-Johnson, et al., 2001). Toward this end, teachers need to provide learning opportunities that add to, build upon, and make connections with prior knowledge. This can be done by incorporating strategies that keep students engaged, probe and assess their preconceptions, create multiple opportunities for students to communicate what they have already learned about the subject matter, and allow ample time for students to reflect on the learning experience (Brownell et al., 2019; Hill et al., 2004; Sezer, 2008). An effective instructor must endeavor always to remain flexible, be prepared to adopt multiple approaches, scaffold new content on a student's knowledge base, and be armed with a solid grounding in the factual and conceptual frameworks of the subject matter (Brownell et al., 2010; Leonard, 2018; Shulman 1987). These components will help 
ensure that the inclusive environment is a welcoming and engaging one where diversity is promoted and respected, where different learning paces are respected, and where errors are transformed into learning opportunities (Donovan, \& Bransford, 2005; Van de Walle, 2003). Effective instruction, however, depends largely on an educator's knowledge of the subject matter.

\section{Pedagogical Content Knowledge}

The teacher plays a critical role in developing a student's fundamental understanding of mathematics in that he/she is responsible for providing a rich and robust educational experience in the classroom. Research has found that a teacher's attributes, particularly his or her expertise in the subject matter, impact significantly the outcomes of students, particularly in the mathematics classroom. For example, Hill and colleagues (2005) reported that a teacher's mathematical knowledge was a significant predictor of a student's mastery of concepts. In other words, a teacher's ability to provide quality instruction depends both on his/her mastery of the subject matter, along with the ability to access a repertoire of pedagogical tools and strategies that allow this knowledge to be communicated to the students (Ball et al., 2008). This essential knowledge base has been identified as a teacher's pedagogical content knowledge (Shulman, 1987).

Pedagogical content knowledge (PCK) refers to a teacher's ability to transform knowledge into accessible components that students can then assimilate and master (Shulman, 1987). In the mathematics education community, a commonly used model of PCK is known as the "Mathematical Knowledge for Teaching" (MKT; Hill et al., 2008). The MKT is divided into two main components: knowledge of subject matter and pedagogical methodology. Knowledge of subject matter includes a teacher's common 
content knowledge (CCK), specialized content knowledge (SCK), and knowledge at the mathematical horizon (HCK). Pedagogical content knowledge is comprised of knowledge of content and students (KCS), knowledge of content and teaching methods (KCT), and knowledge of the overall curriculum (Hill et al., 2008).

\section{Figure 1}

\section{Domain Map for Mathematical Knowledge for Teaching}

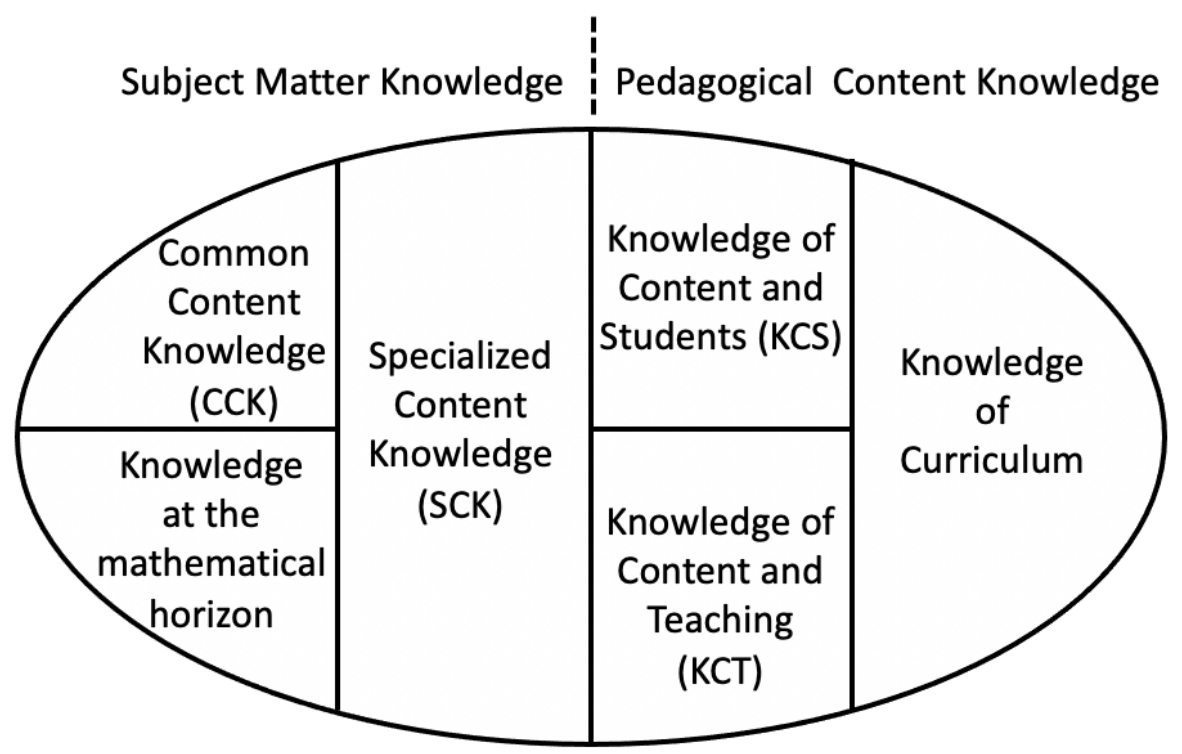

Note. Model of the six teaching strands for mathematical knowledge for teaching.

Reprinted from Unpacking Pedagogical Content Knowledge: Conceptualizing and

Measuring Teachers' Topic-Specific Knowledge of Students by Hill, Ball, and Schilling (2008).

Subject matter knowledge (Figure 1) contains three components (CCK, SCK \& HCK). Common Content Knowledge or CCK is described as "knowledge that is used in the work of teaching in ways in common with how it is used in many other professions or occupations that also use mathematics" (Hill et al., 2008, p. 377). Specialized Content Knowledge or SCK is defined as mathematical knowledge that allows teachers to engage 
in specific teaching tasks, such as the accurate representation of mathematical ideas, the ability to explain mathematical rules and procedures, and the capacity to examine and understand unusual solutions to problems (Hill et al., 2008). The third and final component on the left side of the domain map is knowledge at the mathematical horizon. Knowledge at the mathematical horizon is defined as an awareness of where and how the specific mathematical concepts being taught fit into the structures and hierarchies of shared collective mathematical knowledge (Ball \& Bass, 2009). Knowledge at the mathematical horizon or HCK requires teachers to become familiar with the more sophisticated types of mathematical problems that students might encounter. This will allow teachers to orient their instructional methods so as to take into account the future needs of their students.

Pedagogical content knowledge (Figure 1) includes KCS, KCT and knowledge of curriculum. Knowledge of Content of Students or KCS is defined as "content knowledge intertwined with knowledge of how students think about, know, or learn content" (Hill et al., 2008, p. 378). KCS is used in situations where teachers must not only demonstrate mastery of content but must also develop an awareness of the individual learner. KCS should be viewed as a subset of a teacher's overall PCK. Knowledge of Content and Teaching or KCT is comprised of knowledge of the subject matter that is required for teaching, plus professional expertise that goes beyond the instruction of mathematical concepts. Finally, Knowledge of Curriculum involves understanding the goals of the curriculum, its structures, scope and sequence, and the ability to assess the curriculum. Although the MKT provides a comprehensive overview of the knowledge bases required to teach mathematics, it does not take into account a teacher's perceptions about 
teaching and learning that may contribute to or influence the MKT. As a result, researchers (e.g., Campbell \& Malkus, 2014) have argued that the current model requires modification.

Recently, a new model of PCK, the Refined Consensus Model (see Figure 2, RCM) was developed in order to include not only the specific knowledge bases that contribute to PCK but to also demonstrate how PCK develops over time. It also took into account factors that influenced the development of PCK (Hume et al., 2019).

\section{Figure 2}

Refined Consensus Model of PCK

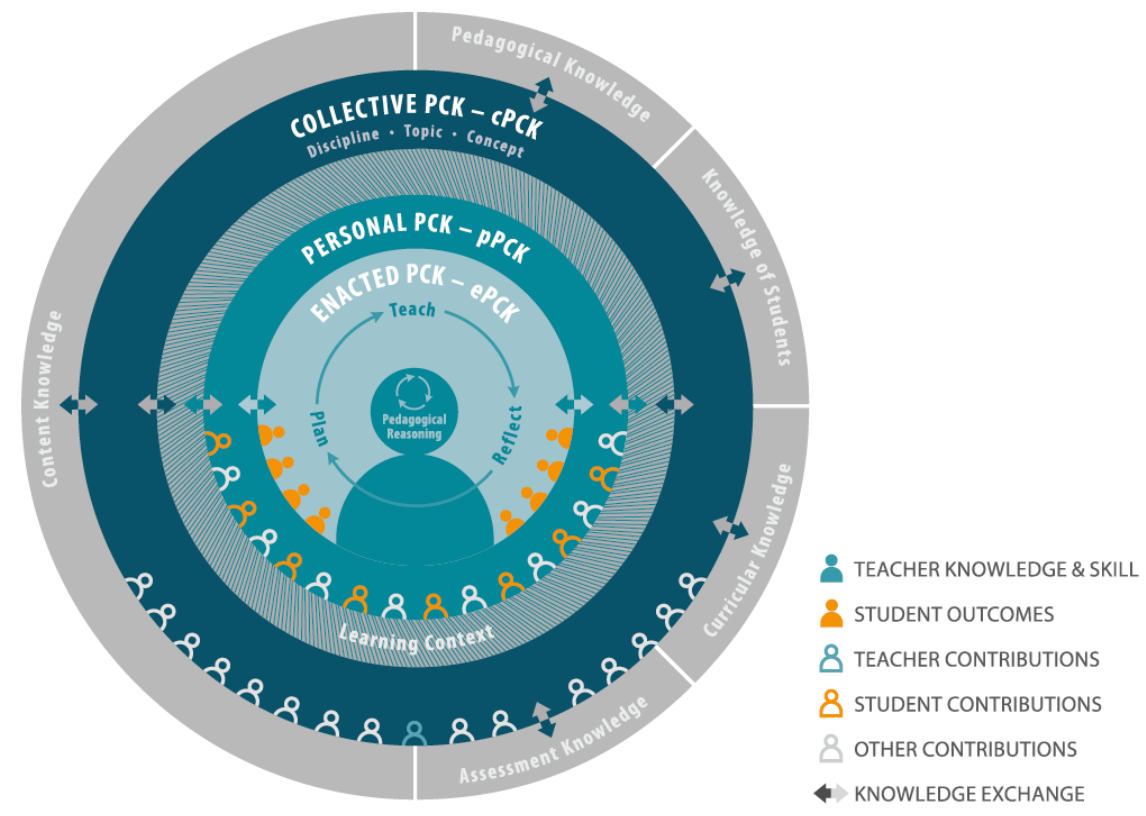

Note. The Refined Consensus Model of PCK resulted from conversations at the $2^{\text {nd }}$ PCK summit and feedback from two conferences in 2017. Reprinted from Repositioning Pedagogical Content Knowledge in Teachers' Knowledge for Teaching Science by Hume, Cooper, and Borowski (2019).

The RCM provides a framework that takes into consideration additional components of a teacher's knowledge base and skill set that were not acknowledged in 
the MKT framework. The RCM sees mastery (or level) of content knowledge as a continuum composed of broad and more narrowly focused ideas that can be found across the spectrum of PCK (Hume et al., 2019). According to the RCM, there are three distinctive components of PCK, each component influencing the other in a bidirectional way (van Garderen et al., 2021). The three components are: enacted PCK (ePCK), personal PCK (pPCK), and collective PCK (cPCK). Hume and colleagues (2019) described the first component, ePCK, as the knowledge and skills used by teachers in particular settings that targeted a particular learning goal for specific students. The second, the pPCK, was defined as the "cumulative and dynamic pedagogical content knowledge and skills of an individual teacher" (Hume et al., 2019, p. 99.) This reformulation takes into account not just the knowledge and skills unique to the teacher but includes his/her experiences with and contributions from others (Carlson \& Daehler, 2019). However, unlike the MKT, the pPCK acknowledges that a teacher's performance is likely to be amplified or filtered by differing attitudes and beliefs “ $\ldots$ about students, the nature of science content knowledge, or the role of the teacher [and these] are examples of beliefs and attitudes that can amplify and/or filter how a teacher develops pPCK for science teaching” (Hume et al., 2019, p. 82). The pPCK continues to develop and take shape over time through unique experiences, individual attitudes, and personal beliefs (Carlson \& Daehler, 2019). As each teacher has a variety of differing experiences, attitudes, and beliefs that impact the pPCK, these factors will influence their ePCK differently (van Garderen et al., 2021). The third component identified by Hume et.al., (2019) cPCK, encompasses knowledge shared by more than one person, that is to say, knowledge that is not private, but rather public and held collectively among researchers, 
teachers, and other education professionals (Hume et al., 2019). This collective knowledge is specific knowledge within a discipline that includes both topic and concept knowledge (Carlson \& Daehler, 2019). Although each component of the RCM framework focuses on a critical component for teaching, this study will focus primarily on $\mathrm{pPCK}$, in particular, personalized knowledge of subject matter and pedagogical knowledge.

\section{Development of PCK}

An important component for optimal utilization of the PCK framework is to understand how it develops over time. Pre-service teachers are often unaware that pedagogical reasoning and action are reinforced by a complex knowledge base that continues to develop from the moment they enter the teaching profession. Experienced teachers draw upon this acquired knowledge as they hone their pedagogical skills (Hume \& Berry, 2011). Some components of PCK are more challenging for pre-service teachers to develop than others. Often, novice teachers fall across a continuum of PCK development (Monte-Sano \& Budano, 2013). Pre-service teachers displayed varying improvements in individual areas of their PCK over a 2-year period. Even over a lengthy period of time, pre-service teachers continued to make improvements in PCK development. It is imperative to remember that this PCK develops over time in each preservice teacher (Monte-Sano \& Budano, 2013).

Academic researchers have found that teaching experience and teacher preparation courses can influence a teachers' PCK (Brown et al., 2013; Lannin et al., 2013; Niess et al., 2010). Pre-service teachers lack extensive classroom experience during their teacher preparation programming, and this has been found to be a limiting factor in 
PCK development. However, intervention through preparation methods courses can be an effective way to encourage and enhance growth (Hume \& Berry, 2011; van Garderen et al., 2021). Kinach and colleagues (2002) described the complexity of PCK development in pre-service teachers. According to the authors, this challenging process should be kickstarted during pre-service preparation in order to internalize dispositions and skills and to encourage stakeholders to examine their own teaching with an eye towards improving their skills over time (Nilsson \& Loughran, 2012). PCK development encompasses knowledge acquisition and content knowledge which are both interwoven within the context of instructional practices (Park \& Oliver, 2008).

As each of the components of PCK are found within individual teachers, it can develop in different ways for each instructor (Monte-Sano \& Budano, 2013; van Garderen et al., 2021). Understanding the differences in knowledge growth for teachers can help clarify the importance of individualizing future education programs for new teachers (Lannin et al., 2013). This will allow pre-service teachers to bring their developing PCK into their first classroom teaching experiences. Armed with a strong knowledge base on which to build their skills, new teachers will have the confidence they need to develop their teaching strategies (Hume \& Berry, 2011). Thus, the desired goal is for teacher preparation programs to play an important role in providing experiences and practices to allow for the development of pre-service teachers' PCK.

\section{Overarching Concern}

It has been well established that teachers play a critical role in student learning and success (e.g., Feng \& Sass, 2010; Rockoff, 2004; Stronge et al., 2011). It is therefore a cause for concern to learn that many teachers feel unprepared to teach mathematics, 
particularly to students with a disability (DeSimone \& Parmar, 2006; Ernst \& Rogers, 2009; Smith \& Smith, 2000). This suggests that we may need to better prepare teachers for this task. As McLesky and colleagues (2019) proposed, the most effective way to improve outcomes for students with disabilities is to improve the effectiveness of their teachers. Teacher preparation programs play an important role in developing future teachers' PCK (van Garderen et al., 2021). Before we can determine how best to prepare pre-service teachers, it is critical to understand what they know and believe in order to provide appropriate and targeted support to develop their professional development and growth as teachers. Therefore, the focus of this study is on the relationship between pre-service teachers' pPCK, which includes beliefs and knowledge about teaching mathematics, coupled with the examination of the pedagogical practice, professional noticing. 


\section{Chapter 2}

\section{Review of the Literature}

This chapter will position the present study within current scholarship on professional noticing, teacher beliefs regarding the teaching of mathematics, and teachers' content knowledge of mathematics. First a detailed review of the practice of noticing will be provided, a principal focus of this study. Next, this chapter will discuss how a teacher's beliefs regarding the teaching of mathematics might affect teaching methodology and how these beliefs might correlate to professional noticing. Finally, this chapter will review current research on a teacher's content knowledge for teaching mathematics in order to determine if there a correlation between content knowledge and professional noticing. This chapter aims to present research both on what is known and on what remains yet to be explored in the fields of mathematics education, special education, and teacher preparation.

\section{Professional Noticing}

Effective pedagogy begins with a solid understanding of the needs and goals of the learner (Hunt \& Little, 2014; Powell \& Fuchs, 2015). The problem is, teachers have typically constructed lesson plans or made interventions using a "one size fits all" model, even though instructional models (e.g., Gersten \& Dimino, 2006; Murray et al., 2004), particularly those pertaining to special education, argue that it is essential to start instructional design with the specific needs of a student in mind (Riccomini et al., 2017). By establishing the learner as the point of departure for developing pedagogical decision making, pre-service teachers can begin to build an effective series of lesson plans for teaching students with disabilities (Boudah et al., 1997; Gersten \& Dimino, 2006). One 
essential pedagogical practice that pre-service teachers need to master in order to better attend to the specific needs of the learner is "teacher noticing" (Jacobs et al., 2010; van Es et al., 2017; Van Es \& Sherin, 2002). Sherin and van Es have offered the broadest body of work on noticing in mathematics education (Sherin, 2007, 2011; Sherin \& van Es, 2005, 2010; van Es \& Sherin, 2002, 2006). They depict noticing as having three main components. The first involves identifying an "event" that is of noteworthy consequence in a classroom situation. Teachers focus on what they believe to be important in the classroom and ignore what seems to be less relevant based on their personal assessment. As they focus on the event, teachers must pay particular attention to what students are doing and saying (Van Es \& Sherin, 2002). Noticing is a nuanced response to behavior, one that observers cannot necessarily evaluate as it is a process that occurs through the thinking progression of the teacher. A second component of noticing is that it uses knowledge about the particular context to make a reasoned interpretation about classroom interactions. The teacher moves beyond a surface level observation to make connections to issues related to teaching and learning. The third component is to make connections between the specific classroom event and the broader principles of teaching and learning. In other words, the teacher can use information gleaned during the observation of the selected "event" and apply techniques derived from known research on teaching practices to improve teaching effectiveness (van Es \& Sherin, 2008).

Jacobs and colleagues (2010) extended this definition and conceptualized its focus to specifically address instances of noticing involving children's mathematical thinking. With this more focused lens, the range of what teachers noticed became less important than the degree to which teachers noticed students' mathematical thinking processes 
(Jacobs et al., 2010). The process was referred to as professional knowledge of children's mathematical thinking. Thus, the term "professional noticing" will be used throughout this study to refer to the pedagogical skill which provides instruction appropriately adapted to the students' immediate needs based on the students' mathematical thinking.

The work done by Jacobs and colleagues (2010) was closely modeled on Sherin and van Es's (2002) depiction of the process of teacher noticing. With the focus on the learner when discussing professional noticing, the notion that students must be the focal point for pedagogical decision making, especially students with disabilities, was further strengthened (Boudah et al., 1997; Gersten \& Dimino, 2006). This study uses the Jacobs et al., 2010 process as the foundation and lens to measure professional noticing throughout this study.

\section{Process of Professional Knowledge of Children's Mathematical Thinking}

Professional noticing, where the focus on the student's mathematical thinking, entails a three-phase process that includes: (a) attending to children's strategies for learning, (b) interpreting children's capacity for mathematical understanding through making connections, and (c) deciding how to respond based on an analysis of children's understandings (Jacobs et al., 2010). Although closely related to van Es and Sherin's (2002) process of teacher noticing, Jacobs and colleagues (2010) made a notable contribution by incorporating the interconnected skill of how to respond to what is being observed based on the child's understanding. Overall, the goal of noticing is to enable teachers to make decisions about where to focus their attention (e.g., a students' misconception, a question, or procedure), the amount of time to be devoted to a particular component of student thinking, and when it is no longer necessary to focus attention on a 
specific strategy or idea. Professional noticing enhances the probability that a teacher will respond rapidly to student mistakes and thus increase success in advancing students' thinking (Anantharajan 2020; Copur-Gencturk \& Rodrigues, 2021). It is important to remember that professional noticing is a process rather than a static description of knowledge (Sherin, Jacobs, \& Philipp, 2011). As teachers move through the various phases of professional noticing, their focus is contingent upon on what is happening inthe-moment. Each phase in the process will be explained further with examples provided.

The first phase of professional noticing is attending to children's learning strategies. As van Es and Sherin (2002) described, the first phase is intended to identify what is important in a teaching situation. Using the concentrated Jacobs et al., (2010) lens, that identification involves identifying a specifically important component related to children's mathematical strategies. Attending to a student means observing and identifying a student's work and actions while engaged in a mathematical activity (Thomas et al., 2020). Allowing the teacher to be in a better position to interpret a student's learning and to make relevant instructional decisions in later phases of the process. For example, 5 th graders learn about comparing fractions by representing fractions on number lines. Towards that end, the students work on a problem that asks them to represent a relay race in which three runners each run an equal distance. During independent work time, the teacher interacts with a student and asks him or her to explain his or her strategy for solving the problem. The student begins to place tick marks on the empty number line provided and places three marks about equal distance apart. When the student goes to count the marks, he/she realizes the last tick mark is at the end of the line (with no more space to "run"). The student rechecks their work and is still unsure why 
there are three tick marks on the line but not three equal distances (example drawn from a video bank, Kersting, 2008; Kersting et al., 2010). The teacher observes and acknowledges this moment as important and works to understand the student's strategy thus moving the teacher to the second phase of professional noticing.

The second phase of professional noticing involves making appropriate connections to knowledge about mathematical strategies and development by interpreting a student's mathematical understanding. A teacher must not only attend to a student's mathematical strategy, but also interpret and reflect on those strategies (Jacobs et al., 2010). When interpreting a student's work, a teacher deliberates upon what is known about knowledge development in mathematics in order to determine what the child understands (Thomas et al., 2020). Similar to what van Es and Sherin (2002) recommend, the teacher must apply his/her own understanding of the details involved in the student's strategy and his/her knowledge about research on student mathematical development in order to enhance the student's success (Jacobs et al., 2010). To continue the example from the first phase, the 5th grade teacher takes the information regarding the student's proposed strategy and then reflects on the student's understanding in order to make appropriate connections to research on children's mathematical development. The student showed a misunderstanding by counting the tick marks that represented a runner, but not the space in between the tick marks that indicated the space covered by the runner. The teacher would then know there are multiple choices in strategies he/she could use to help the student work through this confusion. Some of these strategies include providing immediate and corrective feedback (Powell \& Fuchs, 2015), utilizing a series of 
questions (Mason, 2010; Sahin \& Kulm, 2008), or directly modeling the problem for the student (Bryant et al., 2008; Powell \& Fuchs, 2015).

The third and final phase of professional noticing focuses on the reasoning that teachers use when deciding how to respond (Jacobs et al., 2010). The decision-making process is based on what is noticed (during phase one) and how this is interpreted (during phase two) in order to ensure a student is learning in a way that best fits his or her current understanding of mathematics (Thomas et al., 2020). In this third phase of professional noticing, the teacher from the example would need to make a decision on how to respond. The teacher makes this decision based on his or her mathematical and pedagogical knowledge. A response might involve asking the student questions, such as "what does a tick mark represent?" and "what does the space between the tick marks represent?" The goal is to give the student the opportunity to return to his/her strategy using the teacher's questioning to navigate his/her current thinking (Mason, 2010; Sahin \& Kulm, 2008). It is important to note that there is not one single "correct" way to respond to each situation (Jacobs et al., 2010). Nevertheless, the professional noticing process provides a scaffolding on which to make meaningful instructional decisions (Kilpatrick et al., 2001).

\section{Research Supporting Professional Noticing for Teacher's Knowledge of Student}

Students experiencing difficulty with mathematics may benefit from mathematics instruction that is designed to respond to individual learning needs (Stevens et al.,2018). In order to best meet the needs of struggling students or students with disabilities, mathematics teachers must employ high quality instructional methods (Doabler \& Fien, 2013). One necessary piece of evidence regarding the delivery of high-quality instruction is to assess a teacher's knowledge of students (Ball et al., 2008; Hill \& Chin, 2018, 
Shulman, 1987). To date there is no explicit research study that connects a teacher's use of professional noticing directly to student outcomes. However, professional noticing has been identified as a key skill for a teachers' increased knowledge of a student (Hill \& Chin, 2018). A teacher's knowledge about students increases achievement outcomes because such knowledge may in and of itself facilitate the noticing of a student's ability to understand, learning strategies, and misconceptions. This knowledge in turn influences the instructional process (Hill \& Chin, 2018). A series of studies suggested professional noticing as one aspect of a teacher's skill set that involves attending to students' strategies, interpreting students' understandings, and responding with appropriate instructional strategies (Hill \& Chin, 2018; Jacobs et al., 2010; Sherin et al., 2011). Instructional moves are conducted thoughtfully and with deliberate intention by teachers who both perceive and understand students' thinking and are prepared to respond in ways that meet specific student needs (Barnhart \& van Es, 2015).

\section{Situating Professional Noticing within Special Education}

The practice of "professional noticing" has not been connected specifically to the field of special education. However, there are techniques that embrace the goals of instructional decision making within the field of special education. Examples include Data-Based Individualization (DBI) and Curriculum Based Measurements (CBM). Both DBI and CBM advocate the use of data and direct observation to drive future instructional decisions for students (Jung et al., 2018; Stecker et al., 2005), specifically decisions related to mathematics instruction (Powell et al., 2020; Powell \& Stecker, 2014). 
Within the field of special education, DBI is a systematic method that provides teachers with a process for intensifying intervention at the student level using assessment data to determine how and when an intervention should be initiated or changed (NCII, 2013). One way to monitor progress through the DBI method is by using CBM's. A $\mathrm{CBM}$ is an evidence-based practice used for screening and progress monitoring. It is designed to assess the effects of instruction on student performance (Lembke \& Stecker, 2007). As is the case for professional noticing, the purpose of CBM's is to assist in instructional decision making (VanDerHeyden \& Burns, 2005). An example of a CBM in mathematics is providing the student a math probe that is at the student's academic grade level and ideally represents skills the student will be expected to master by the end of the year (Hosp \& Hosp, 2003). Researchers have found that incorporating the use of CBM's within their instructional methodology increased student achievement in mathematics (Fuchs et al.,1991; VanDerHeyden \& Burns, 2005; Ysseldyke et.al., 2009).

In a similar fashion, professional noticing encourages teachers to use their skills to understand the significance of what they are noticing and respond to it within the classroom (Jacobs et al., 2010). Since teachers cannot preplan in-the-moment responses, this improvisational aspect of teaching requires teachers to constantly analyze and connect specific situations to what they know about children's mathematical development (Jacobs et al., 2010; Franke et al., 2007). This allows teachers to make prompt instructional decisions either for the class as a whole, or for a small group, or even for an individual student. Professional noticing provides teachers with an instructional process that does not require additional support from colleagues or the collection of multiple weeks of data collection to drive decision-making. Due to the process taking place 
between a student and teacher while interacting face-to-face while instruction is occurring.

Although DBI and CBM practices involve elements of professional noticing, there are important differences. For example, while CBMs contribute vital information for academic decision-making in classroom settings, multiple data points are required, and these can take weeks to collect (Stecker \& Fuchs, 2000). Once the data is collected, the decision-making process that is derived from the progress monitoring method or CBM takes place outside the instructional environment. CBM differs from professional noticing in that $\mathrm{CBM}$ data collection for analysis and instructional decision making occurs outside of the instructional process while professional noticing requires in-themoment decision making, while instruction is taking place. CBM provides a vital piece of information for driving instruction but is not, by itself, sufficient to improve student achievement (Stecker et al., 2005).

Incorporating the practice of professional noticing within the DBI systematic process could provide teachers with an additional set of processes to collect daily or more frequent data as a means of monitoring progress to drive instructional decisions. Further, professional noticing could be strengthened if it were used in combination with progress monitoring data from a CBM. This would provide the teacher with noticing observations in addition to academic dialogistic assessments. For example, if a teacher has previously collected CBM data on a student's current computational capability, the data might impact where teachers would choose to focus their attention or the amount of time they needed to devote to a particular student during specific mathematical tasks.

\section{Pre-Service Teacher Professional Noticing}


Researchers have explored professional noticing in mathematics pre-service teachers to understand how they make sense of complex classroom circumstances (Fisher et al., 2018; Jacobs et al., 2010; Star \& Strickland 2011). Therefore, thoughtful decisions must be made (Jacobs et al, 2010). Two common approaches for examining pre-service teacher professional noticing include a comparison of the differences in professional noticing between pre-service and expert teachers (Hogan et al., 2003; Huang \& Li, 2012) and through utilizing teacher preparation methods courses as a means of data collection or instructional intervention (Goldsmith \& Seago, 2011; Jacobs et al., 2010; Star and Strickland, 2008; Tyminski et al., 2015; Ulusoy, 2020) Several themes have emerged from this research.

Overall, a major difference between pre-service teachers and expert teachers are the expert teacher's ability to attend to a broader range of relevant aspects that take place in a classroom. Hogan and colleagues (2003) argued that the difference between novice and expert teachers involved a shift in perspective that allowed an expert teacher to move from attending to a particular student or event to a broader capacity to monitor both the activities of the teacher and the student. Expert teachers typically have a greater understanding of educational practices, and this enables them to identify the most noteworthy features of classroom interactions (van Es et al., 2017). Experienced teachers also have the skills and strategies required for selecting, varying, and reflecting upon their methods. This contributes to the establishment of more meaningful instructional experiences (Russ et al., 2011). Expert teachers have of course had more opportunities to experience different components of noticing, and thus become increasingly aware of what 
constitutes relevant happenings over time. They are thus able to make sense of and better attend to the classroom situations they observe or encounter (Brown et al., 1989).

Although it may be safe to hypothesize that expert teachers would have more robust professional noticing skills than pre-service teachers, two studies have provided documented evidence as such by comparing the two groups of teachers (Huang \& Li, 2012; Schafer \& Seidel, 2015). In both studies, overall findings indicated that expert teachers were able to dedicate more attention to students' mathematical and higher order thinking processes, and less attention to their own instructional behavior. Whereas, preservice teachers, on the other hand, could identify teaching and learning components, but struggled to apply professional knowledge to interpret and make sense of student thinking all while devoting more attention to superficial aspects of the lesson, such as classroom behaviors and time management.

A second process commonly used by researchers to assess professional noticing with pre-service teachers has been through the use of elementary education or secondary pre-service teacher methods courses (Goldsmith \& Seago, 2011; Jacobs et al., 2010; Star and Strickland, 2008; Tyminski et al., 2015 Ulusoy, 2020). Star and Strickland (2008) utilized the methods course to examine professional noticing on a broader level. They found that general education pre-service teachers mainly paid attention to static features of the classroom environment (e.g., student behavior). As research on professional noticing focused increasingly on mathematical content, both Jacobs et al., (2010) and Ulusoy (2020) found that it was beneficial to classify instances of professional noticing using professional noticing response categories such as 1) lack of evidence, 2) low evidence, or 3) robust evidence. It was found that most pre-service teachers fell into the 
low or lack of evidence category. The pattern found in Jacobs and colleagues (2010) and Ulusoy (2020) confirmed findings from Star and Strickland (2009) that revealed preservice teachers often attended to generic moments of instruction, including classroom management, overall climate and student support. They failed to provide any detailed evidence of noticing events linked to the learning process at hand.

\section{Development of Professional Noticing Practice}

Research is undeveloped on the investigation of how pre-service teachers differ in their ability to professionally notice and how they develop their skills throughout their programming. Haltiwanger and Simpson (2014) studied all $2^{\text {nd }}, 3^{\text {rd }}$, and $4^{\text {th }}$ year undergraduate general education pre-service teachers and their capacity for professional noticing in three different areas. Students were assessed in the areas of attending, interpreting and responding to student mathematical thinking. Pre-service teachers' levels of professional noticing were compared at different stages of their pre-service program. Fourth-year participants tended to be more skillful at attending to students' mathematical thinking compared to their second- and third-year counterparts. In the area of interpreting, no pre-service teacher at any stage in the program was able to reveal a rigorous level of noticing. In the area of responding, similar findings regarding attending were found. Fourth-year students outperformed their second- and third-year counterparts. The overall findings indicated that as the students moved through the teacher preparation program, their ability to demonstrate a more rigorous level of professional noticing increased.

\section{Measuring Professional Noticing}


Over time, varied methods for examining professional noticing have emerged. Approaches range from analyzing student artifacts or written documentation, teacher interviews or reflective comments after teaching a lesson, and the use of video clips as a means to measure professional noticing (Amador et al., 2021).

The first approach uses student artifacts as a means of measuring professional noticing. Student artifacts can include work samples or videotaped segments of lessons. The use of classroom artifacts to study professional noticing is a commonly used method because it requires the teacher attend to the mathematical problem at hand as well as the students' mathematical thinking process. Despite the widespread popularity of this approach, artifacts do not inherently produce all of the information teachers need for professional noticing. This method can be difficult when used as a means to measure professional noticing as it provides an "end product" from the student rather than provide a way to examine the student's reasoning process. For example, if a teacher is trying to understand a student's mathematical thinking based on the artifact without watching the student solve the problem, it can be challenging to determine the order of the student's thought process. Thus, artifacts are best used as one of a number of tools designed to examine professional noticing (Goldsmith \& Seago, 2011).

A second approach to measure the practice of professional noticing is to obtain information from teachers via interviews (after instruction takes place). This method asks teachers to recount what they recall seeing and thinking during instruction (Sherin \& van Es, 2010). A variant of this approach is to have teachers view a video of their own teaching and provide their reactions (Rosaen et al., 2008). For example, Rosaen and colleagues (2008) focused on three general education student-teachers. This cross-case 
analysis study required participants to respond and reflect upon videos of themselves teaching in an effort to increase their ability to professionally notice. A concern with the recall method is that teachers may be unable to precisely identify their in-the-moment decisions due to the lengthy passage of time (Sherin \& Russ, 2011).

The third approach to measuring professional noticing, and the focus of this particular study, involves the use of video samples depicting someone else's teaching performance (Carter et al., 1988; Copur-Gencturk \& Rodrigues, 2021; Star et al., 2011; Star \& Strickland, 2008; Ulusoy, 2020; Van Es \& Sherin, 2008; van Es et al., 2017). Star and Strickland (2008) used video samples to measure the professional noticing ability of secondary education mathematics pre-service teachers who were enrolled in a mathematics methods course. The participants watched a video of one entire class period of an 8th grade mathematics class. After the video, they were asked questions to see what they noticed about the class. Participants were encouraged to take notes during the video and were not able to discuss the video with their peers after the video. Similarly, Ulusoy (2020) had participants watch videos and respond to prompts throughout a 13-week methods course. Ulusoy (2020) utilized video clips which included a collection of selectively edited events concerning a learner's thinking on content-related tasks or problem-solving situations in a non-classroom learning environment.

Employing similar methods, Copur-Gencturk \& Rodrigues (2021) utilized inservice mathematics teachers and video clips in order to measure professional noticing. In a large-scale analysis of 496 teachers, participants were asked to watch three video clips from a library of videos (Kersting, 2008; Kersting et al., 2010) and respond to a prompt. 
Responses were then coded on an intensively developed scoring rubric to analyze key components of professional noticing through a categorical scoring system.

With a continued focus on utilizing video samples as a means to study professional noticing, van Es and Sherin (2008) asked seven fourth and fifth grade elementary teachers to provide their own video samples in order to switch and compare professional noticing in a group of select teachers. The teachers were taped during their mathematics instructional times. After taping, the same researcher then reviewed the tapes and identified brief excerpts highlighting mathematical issues that were raised in the lessons. One approximately five-minute excerpt from each classroom was selected. These clips were then shown to their peers (van Es and Sherin, 2008). The advantage of utilizing video clips as an approach to measure professional noticing is that it provides a detailed and focused examination of student thinking (Ulusoy, 2020). It also provides a basis for discussion and reflection on in-the-moment professional noticing versus simply reflecting back on a previous lesson or utilizing an artifact.

Interestingly, professional noticing has been examined using a variety of different methods both with practicing teachers and pre-service teachers. Specifically in the case of pre-service teachers, professional noticing was examined with general education and secondary education majors using a multitude of methods. Methods such as analyzing student work samples (Haltiwanger \& Simpson 2014), reactions to videos a teachers' own teaching while combined with a reflection (Rosaen et al., 2008), as well as the use of video samples depicting someone else's teaching (Star and Strickland, 2008).

\section{In Summary}


Based on the research reviewed, it can be concluded that pre-service teachers did not perform with as robust a degree of professional noticing as experienced teachers. Preservice teachers within a teacher preparation program generally increased their professional noticing skills from year to year. Various approaches exist for examining and measuring professional noticing (e.g., Goldsmith \& Seago, 2011; Jacobs et al., 2010; Star and Strickland, 2008; Tyminski et al., 2015 Ulusoy, 2020). However, the use of video clips is preferred as it allows for a detailed and focused examination of student thinking (Carter et al., 1988; Copur-Gencturk \& Rodrigues, 2021; Star et al., 2011; Star \& Strickland, 2008; Ulusoy, 2020; Van Es \& Sherin, 2008; van Es et al., 2017).

Although the research indicates that noticing is an essential practice for teachers, it is important to recognize that the ability to notice is influenced by several factors (Schoenfeld, 2011 a; Schoenfeld, 2011b; Van Es \& Sherin, 2002, 2008). As Schoenfeld (2011a) writes,"[Teacher] Noticing is essential, but it does not suffice by itself, it takes place within a context of teacher knowledge and orientation (beliefs)" (p. 233). Decisions that result from professional noticing, such as where to focus attention, for how long, and how to respond to students' needs, are closely connected to a teacher's belief system and the mathematical knowledge they have. Therefore, the following sections provide an overview of teacher beliefs and content knowledge, and what is known in the research about pre-service teacher knowledge in connection to these two areas.

\section{Teacher Beliefs}

All teachers possess beliefs about their profession, their students, how students learn, and how subjects should be taught (Summers et al., 2017). As the RCM framework suggests, personal PCK is influenced by personal attitudes and belief systems (Hume et 
al., 2019). Pre-service teachers who enter preparation programs have been characterized as "highly idealistic, loosely formulated, deeply seated and traditional" (Richardson, 2003, p. 6). Evidence suggests that the beliefs held by pre-service teachers at the time they enter their preparation program will impact what and how they learn. This in turn will eventually impact how they approach the instructional process in the classroom (Richardson, 2003).

For the purposes of this study, belief is defined as an understanding about the world that an individual strongly believes is accurate and that derives from his or her personal experiences, whether these be experiences at school, and/or experiences during his or her own formal education (Richardson, 1996, 2003; Urbach et al., 2015). Beliefs are the best indicators as to the type of decisions individuals and individual teachers make (Dewey, 1933; de Vries et al., 2013; Fives, 2003). For example, Richardson and colleagues (1991) found that in a study of 39 teachers, their ideas about how children learn to read and about reading comprehension correlated directly to their classroom practices and their students' outcomes in reading. In another study by Fuchs and colleagues (1994) involving a survey of 121 general educators who taught at least one student with a learning disability, it was found that teachers with strong beliefs in a disciplined work ethic planned their classes with greater attentiveness to student performance. Finally, Carter and Norwood (2010) found a strong correlation between a teacher's beliefs about how students learn mathematics and the way his/her students were likely to view the learning of mathematics. Considering the important role, a teacher's belief system plays in the classroom, and in light of the positive impact it can have on student outcomes, researchers have begun to focus on how the beliefs of pre-service 
teachers develop and evolve over the course of their preparatory program and in their early career.

\section{Pre-Service Teacher Beliefs for Teaching Mathematics}

Although pre-service teachers' beliefs have been studied over the years using a wide range of specific foci, such as inclusion, disability, and diversity, other studies have focused on pre-service teachers' beliefs about teaching and student learning in mathematics (e.g., Civitillo et al., 2018; Silverman, 2007; Sze, 2009). In general, research on pre-service teachers' beliefs has consistently revealed that at the beginning of their preparation program tend to be overly simplistic, optimistic, and grounded in a transmission view of knowledge from teacher to student (Leko et al., 2015). One specific study (Swars et al., 2009) provides an explanatory example of what has commonly been found throughout examination of beliefs for teaching mathematics. Swars and colleagues (2009) conducted research to measure how these beliefs developed during a teacher preparation program in regard to teaching mathematics. The study followed 24 general education pre-service teachers through their first and second mathematics methods courses and during their student teaching. Using the Mathematics Beliefs Inventory, a 48item Likert scale, they found that the pre-service teachers entered their preparation program with well-established beliefs about the teaching and learning of mathematics. These pre-service teachers identified with the belief that students acquire knowledge from another outlet (e.g., school experiences) and that mathematics should be taught through a pre-determined sequence which should be used for instructional purposes.

Although research has been conducted on pre-service teachers' beliefs about teaching mathematics, only a small number of studies have focused on pre-service 
teachers' beliefs about teaching and how these impact student learning in mathematics, specifically as these relate to students with disabilities. Burton and Pace (2009) researched pre-service general education teachers' beliefs about teaching mathematics in an inclusive classroom setting. Interestingly enough, they focused on pre-service teachers at different stages in their teacher preparation programing. The two areas of interest for the current study based on journal research are the teachers' beliefs about mathematics and about teaching mathematics to students with disabilities. Participants in year one and two of their program did not indicate any evidence of a change in their beliefs regarding the subject matter of mathematics or how to teach mathematics to students with disabilities. However, in year three, participants revealed a trend toward increased confidence and more optimism about teaching mathematics to students with disabilities. Esktam and colleagues (2017) aimed to understand how subject knowledge and individual interest might predict the attitude of special education, pre-service teachers toward the efficacy of teaching mathematics. The participants, 57 special education preservice teachers who were between years one and five of their program, responded to an online survey regarding individual interest in mathematics and teacher efficacy beliefs regarding mathematics. Findings suggested that pre-service special education teachers had a low level of confidence in their ability to teach mathematics to struggling students (Ekstam et al., 2017). The number of years in the program was found to have no relation to the outcome variables. Consequently, specific years in the program were not indicated in the results.

Findings are mixed as to whether teacher preparation programs can mold or change pre-service teachers' beliefs (Hall, 2005; Richardson, 2003). Richardson (2003) 
suggested that pre-service teachers bring with them their own set of beliefs that impact what they learn and how they learn it. These individualized beliefs then play an impactful role in future actions within the classroom. Taken together, the studies on pre-service teachers suggested that teachers entered teacher preparation programs armed with a set of pre-formed beliefs for teaching mathematics, but that these continued to evolve and develop over time. These beliefs tend to generally include a low level of confidence for teaching mathematics to students in general (Enochs et al., 2000) and for teaching students who struggle to learn mathematics (Ekstam et al., 2017). Beliefs are important because they impact how teachers will use an instructional practice within their classroom (Polly et al., 2013; Purnomo et al., 2016; Wilkins, 2008). Consequently, research shows that pre-service teachers' beliefs will impact their future instructional practices.

Ideally, pre-service teachers will utilize professional noticing to benefit student learning. However, they may not utilize this practice effectively or at all if they do not believe it is within the scope of their teaching mission or that it has a bearing on their students' ability to learn (Purnomo et al., 2016). Therefore, focusing on understanding teachers' beliefs is an important step, given their ability to impact the effectiveness of instructional practices (Briley, 2012; Klehm, 2014; Richardson, 2003; Yang et al., 2020).

\section{Content Knowledge of Mathematics}

In general it is understood that effective mathematical teaching requires not only knowledge of the subject matter but also knowledge about mathematics that is unique and specific to its instructional delivery (Ren \& Smith, 2018). Mathematical knowledge and knowledge about teaching mathematics play a critical role when teaching students, 
planning lessons and evaluating student's work (Ball et al., 2008). Ball and colleagues (2008) suggested that effective teaching must put an emphasis on the use of knowledge in a classroom setting rather than on the teachers themselves. As previously stated, professional noticing is a practice that can benefit teachers in the act of teaching (Jacobs et al., 2010; Sherin \& van Es, 2010; Thomas et al., 2017). Therefore, in order for teachers to support their students' ability to learn the material, they must have mathematical knowledge that is adequate for instruction. Without a strong foundation of mathematical knowledge, teachers are unable to analyze and understand student thinking, nor can they provide appropriate support and strategies for learning mathematics (Lampert, 2001).

Professional noticing requires teachers to observe and identify an event, and then process, make connections, and respond to that event (Jacobs et al., 2010; Sherin, Jacobs, \& Phillips, 2011). Research has found that content knowledge is an important factor that can increase a teacher's effectiveness in the skill of professional noticing (Hiebert et al., 2017).

\section{Pre-Service Teacher Content Knowledge of Mathematics}

Pre-service teachers' content knowledge is an essential component for the proper training of pre-service teachers (Darling Hammond 2000; Stohlmann et al., 2013). A number of studies have been conducted on what is known about pre-service teachers' content knowledge of mathematics. Three ways to examine this bank of literature are through an examination of literature that focusses on a pre-service teacher's overall content knowledge, through an analysis of differences based on majors or content areas, or through an examination of content knowledge based on a pre-service teacher's stage in a teacher preparation program. 
Several researchers have noted how many pre-service teachers, even those who have completed an extensive array of mathematics courses (Bryan 1999), continue to reveal gaps in their content knowledge or discrepancies in their knowledge of and ability to apply pedagogical methods to mathematical instruction (Ball et al., 2005; Bransford et al., 2000; Fisher et al., 2018). Pre-service teachers have struggled in their own mastery of mathematical knowledge and often have negative attitudes toward mathematics (Beswick 2006; Mays, 2005; Wilkins 2008). Fisher and colleagues (2018) and Beswick and Goos (2012) both examined pre-service teachers' content knowledge. Fisher et al. (2018) examined the mathematics knowledge of pre-service general education teachers and found statistical evidence to indicate that the average score on a mathematical content assessment remained negative from pre to post test. This indicates that below average scores were common among pre-service teachers. Additionally, Beswick and Goos (2012) identified a need for pre-service teachers to acquire more sophisticated mathematical concepts. When general education pre-service teachers were assessed, often over $90 \%$ of the participants could answer questions involving the identification of identifying shapes or pictures correctly, while only $20 \%$ of the pre-service teachers could answer more abstract or complex mathematical problems correctly. This supports the previous finding that pre-service teachers' content knowledge of mathematics has room for improvement.

Researchers often examine differences in the mathematical knowledge of preservice teachers by looking at major or content focus (e.g., special education versus elementary education (Ekstam et al., 2017; Flores et al., 2010). It was found that the content knowledge of special education pre-service teachers was only one standard 
deviation higher than that of an average ninth grade student (Ekstam et al., 2017). Given the importance of content knowledge and its role in student achievement, it is important for special education teachers to have both content knowledge and the pedagogical skills required to assist students with disabilities who are learning mathematics (Griffin et al., 2009; Mageira et al., 2005; Shippen et al., 2011). However, when elementary and special education pre-service teachers were compared, the results demonstrated no significant difference between certification types. Special education teachers performed with a mean score of $81 \%$ for the problem-solving portion, while general education teachers scored $83 \%$.

Although most studies we found examined either pre-service teachers as a single group or distinguished by major (e.g., special education v. elementary education teachers, or secondary education teachers v. elementary education teachers, etc.), one was found that explicitly reported results based on the participants' year in the preparation program (Livy et al., 2012). Examining teachers during three different years in their program indicated that students performed differently depending on their stage in the program. The study did not indicate that students with more years in the program scored higher on a given assessment, but only that students performed differently based on their year in the program (e.g., one-third of fourth year participants exhibited misconceptions about mathematical concepts, while one-fourth of the second-year students couldn't provide justifications for mathematical relationships (Livy et al., 2012).

In sum, research shows that pre-service teachers' mathematical content knowledge is not robust (Fisher et al., 2018; Livy et al., 2012), that there is definitely 
room for improvement (Hine, 2015), and that this content knowledge can vary according to stage in the program (Livy et al., 2012) and according to major (Flores et al., 2010).

\section{Professional Noticing, Beliefs and Content Knowledge}

To date, there is one study that examined the relationships between teacher beliefs, the degree of mathematical knowledge of the teacher, and a teacher's professional noticing skill (Fisher et al., 2018). This study, however, was focused on the impact of an intervention to improve pre-service teacher's ability to use professional noticing in the context of early numeracy development. Data was collected from 224 general education pre-service teachers across five universities engaged in a pre/post study. Of the five universities used in the study, one university served as the comparison group and one as the implementation group. The pre-service teachers who participated in the implementation group engaged in a three-session module. Pre-service teachers who participated in the modules showed growth in their ability to professionally notice children's mathematical thinking processes. Although the goal of the study was to enhance pre-service teacher professional noticing, there was a focus on increasing the relationship between MKT and teacher beliefs. The findings related to this relationship are relevant to the current study. Interestingly, no statistically significant difference in mathematical knowledge scores between the control and intervention group from pre to posttest, which came as a surprise to the reporting authors. While pre-service beliefs regarding attitudes toward mathematics were found statistically significant from pre to posttests, suggesting mathematics methods courses tend to have positive influences on attitudes toward mathematics. This particular research study did not examine the explicit relationship between a pre-service teachers' content knowledge and beliefs, the authors 
suggested more research on these relationships, specifically, teachers' professional noticing and its relationships to varying factors.

\section{Summary and Rationale of Current Study}

Just as current research suggests that effective teaching must take the learner into account (Jenkins et al., 2003), the same idea should extend to those who prepare preservice teachers in teacher preparation programs. Unfortunately, the research suggests that teacher education programs tend to pay little attention to the fact that pre-service teachers acquire their skills and knowledge in different places and at different stages (e.g., the educational stages in his/her teacher preparation program) (Grierson, 2010). Without this information, preparation courses may not be as effective as they could be. As a result, pre-service teachers may not provide quality instruction to their students thus impacting their students' outcomes (DeSimone \& Parmar, 2006; McLesky et al., 2015).

One important instructional practice all teachers should be able to use for implementing effective mathematics instruction with students, including students with disabilities, is professional noticing (Sherin \& Russ, 2011). Professional noticing can help teachers decide where to place their instructional attention and efforts (Sherin et al., 2011). Effective instruction requires that teachers consider the learner as the point of departure for developing pedagogical decision making (Boudah et al., 1997; Gersten \& Dimino, 2006). Professional noticing supports teachers and helps them make meaningful instructional decisions with the learner at the center of that decision making (Jacobs et al., 2010; Kilpatrick et al., 2001).

Although studies exist that examine how pre-service teachers use professional noticing in general and how different stages in teacher education programs affect the 
ability to notice (e.g., Haltiwanger \& Simpson, 2014; Hiebert et al., 2017), the majority of studies on professional noticing have been conducted on general education elementary in-service teachers or secondary education mathematics teachers (Jacobs et al., 2010; Sherin \& Russ, 2011, 2014; Van Es \& Sherin, 2008). A smaller number of studies focused on general education or secondary education mathematics pre-service teachers (Haltiwanger \& Simpson, 2014; Star \& Strickland, 2008; Fisher et al., 2017; van Es et al., 2017). The studies that did focus on noticing by pre-service teachers used general education majors as their subjects (Jacobs et al., 2010; Sherin \& Russ, 2011; Star \& Strickland, 2008; Thomas et al.,2017). Studies have yet to include special education majors. It may be possible that differences exist between those preparing to be special education teachers relative to those preparing to be general education teachers (McHatton \& Parker, 2013). For example, van Garderen et al. (2018) found that special education teachers anticipated positive results from students with disabilities and were confident in these students' ability to use visual representations. On the other hand, Hastings and Oakford (2003) found that general education teachers had fewer positive perspectives regarding successful instruction to students with disabilities, especially students who exhibited challenging behaviors.

Furthermore, to date, only one study has examined the relationship between beliefs (specifically attitudes towards mathematics), mathematics content knowledge and professional noticing practices using an intervention study (Fischer et al., 2017) but questions remain about mitigating factors (i.e., beliefs for teaching mathematics) and the relationship to professional noticing. There has yet to be a descriptive study conducted on a similar topic that utilized general education and special education pre-service teachers. 
The research suggests that both beliefs (Purnomo et al., 2016; Swars et al., 2007;

Thompson, 1984; Wilkins, 2008) and mathematics content knowledge (Ball et al., 2008; Lampert, 2001) can have an impact on teaching effectiveness. Poorer quality instruction may be a result of poor mathematics content knowledge, or a function of beliefs towards teaching mathematics. It is possible then, that content knowledge, differing beliefs about mathematics may influence the practice of professional noticing. These inquires will be examined through the following research questions.

\section{Research Questions}

The current study is designed to address the following questions:

1. What is the relationship between pre-service teachers' mathematics content knowledge and professional noticing?

a. Do different years in the teacher preparation program (e.g., zero, one or two methods courses) have a significant impact on the relationship between a teachers' professional noticing and mathematics content knowledge?

b. Do different majors (special education and general education) in the teacher preparation program have a significant impact on the relationship between a teachers' professional noticing and mathematics content knowledge?

2. What is the relationship between pre-service teachers' beliefs for teaching mathematics and professional noticing?

a. Do different years in the teacher preparation program (e.g., zero, one or two methods courses) have a significant impact on the relationship between a teacher's professional noticing and teacher's beliefs about teaching mathematics? 
b. Do different majors (special education and general education) in the teacher preparation program have a significant impact on the relationship between a teacher's professional noticing and teacher beliefs about teaching mathematics?

3. Is pre-service teacher mathematical content knowledge a predictor of professional noticing? 


\section{Chapter 3}

\section{Methods}

The purpose of this study was three-fold: to examine pre-service teachers' pPCK of content knowledge in mathematics, their beliefs regarding the teaching of mathematics and their implementation of the pedagogical practice of professional noticing. This chapter will outline the research methodology adopted and the methods used for the study, including a detailed explanation of the study design, sampling and participant descriptions, information on measurements and data collection procedures, and a review of the statistical analysis plan.

\section{Design}

This descriptive study utilized a cross-sectional research design (Campbell \& Thompson, 2007). The design involved examining a representative sample of pre-service teachers during different years in their teacher preparation program (e.g., those with zero methods courses, those taking one methods course, and those taking two methods courses) and pre-service teachers in two different programs (e.g., special education and general education).

\section{Pre-Service Teacher Participants: Recruitment and Demographics}

Prior to recruitment and obtaining the consent of participants, the Institutional Review Boards at the University of Missouri (see Appendix A) and the participating university's College of Education Director of Teacher Education approved this study. The participating university is a research-intensive institution located in the Midwest and is currently comprised of approximately 22,616 undergraduate students. Throughout the general education and special education teacher preparation programming, pre-service 
teachers are required to take two mathematics methods courses. These two courses are taken during phase two of the program (commonly during the student's junior year in the program). Pre-service teachers were recruited from those enrolled in either the first or second of the required mathematics methods courses, or phase three of their program, which is during their senior year of onsite field enrollment.

Due to the structure of the course sequencing in the preparation program, and in order to satisfy the desired goal of obtaining data from students at various stages during their academic preparation, the pre-service teachers were divided into three groups. Group one included students who had taken no mathematics courses; Group two was composed of students who had taken one of their two required methods courses; and Group three consisted of students who had taken both required mathematics methods courses. The three main groups were then divided into two based on the students' selected major: elementary or special education, creating six final cohorts. It is important to note that students in both majors take the same initial mathematics methods course, but the second course depends on the selected major. The participants who had yet to receive any instruction (year 1) and participants who have taken one of the two courses would all have received the same mathematics instruction. Therefore, language utilized in the preparation program mathematics courses would be the same up until the third and final group. Elementary education majors take a course provided by the mathematics education department while the special education majors enroll in a course provided through the special education department. From these groups, six final cohorts were established for the purposes of recruitment. For the remainder of this study, the different groups will be referred to by their "year in the program." This researcher acknowledges there is not a 
true "year" separating the groups. The "year in program" is defined by their current placement in the preparation program based on the number of methods courses taken. Table 1 provides the cohort descriptions and total number of participants recruited.

\section{Table 1}

\section{Cohort Descriptions}

\begin{tabular}{ccccc}
\hline $\begin{array}{c}\text { Cohort } \\
\#\end{array}$ & $\begin{array}{c}\text { Number of Methods } \\
\text { Courses }\end{array}$ & $\begin{array}{c}\text { Year in } \\
\text { Program }\end{array}$ & Major & $\begin{array}{c}\text { Total \# of } \\
\text { participants }\end{array}$ \\
\hline 1 & $\begin{array}{c}\text { Zero mathematics } \\
\text { methods courses taken }\end{array}$ & Year 1 & $\begin{array}{c}\text { Elementary } \\
\text { Education }\end{array}$ & 13 \\
2 & $\begin{array}{c}\text { Zero mathematics } \\
\text { methods course taken }\end{array}$ & Year 1 & $\begin{array}{c}\text { Special } \\
\text { Education }\end{array}$ & 21 \\
3 & $\begin{array}{c}\text { One mathematics } \\
\text { methods course taken }\end{array}$ & Year 2 & $\begin{array}{c}\text { Elementary } \\
\text { Education }\end{array}$ & 20 \\
4 & $\begin{array}{c}\text { One mathematics } \\
\text { methods course taken }\end{array}$ & Year 2 & $\begin{array}{c}\text { Special } \\
\text { Education }\end{array}$ & 18 \\
5 & $\begin{array}{c}\text { Two mathematics } \\
\text { methods courses taken }\end{array}$ & Year 3 & $\begin{array}{c}\text { Elementary } \\
\text { Education }\end{array}$ & 20 \\
6 & $\begin{array}{c}\text { Two mathematics } \\
\text { methods courses taken }\end{array}$ & Year 3 & Special \\
& & Education & 28 \\
\hline
\end{tabular}

For cohorts 1, 3, and 5 (elementary major cohorts) the researcher contacted the instructor for permission to either personally recruit participants during class time or, alternatively, to provide a video to be posted on the class website. Students registered their initial interest via email, then purposive criterion sampling was employed (Palinkas et al., 2015). The inclusion criteria were: (a) the pre-service teacher was seeking first time teaching certification, (b) he/she was identified as a general education elementary major, and (c) he/she was enrolled in the designated mathematics methods course for the 
corresponding semester. Data from cohorts 5 and a portion of cohort 3 were collected via an in-person format, while data from cohorts 1 and the remainder of cohort 3 were collected in an online format (due to COVID-19 restrictions).

For cohorts 2, 4, and 6 (the special education cohorts) the researcher contacted the special education practicum seminar instructor to recruit participant volunteers. The instructor provided seminar class time for data collection. All data collection from these cohorts took place during a single data collection period. The inclusion criteria were similar to that established for previous cohorts and were as follows: (a) the pre-service teacher was seeking first time teaching certification, (b) he/she was identified as a special education major, and (c) he/she was enrolled in the designated mathematics methods course for the corresponding semester.

At the time of data collection, online or in-person participants were read aloud or asked to read the provided consent form (Appendix B and Appendix C) and only continue with the Qualtrics if they provided consent. Students were given the choice to opt out of participating or could choose to not allow their data to be used in the study. Table 2 provides pre-service teacher demographics, including those who were first generation college students, those whose first language was English, the number of college level mathematics courses participants had taken, and their selected race and gender affiliation.

\section{Table 2}

Demographic Information of Pre-Service Teachers

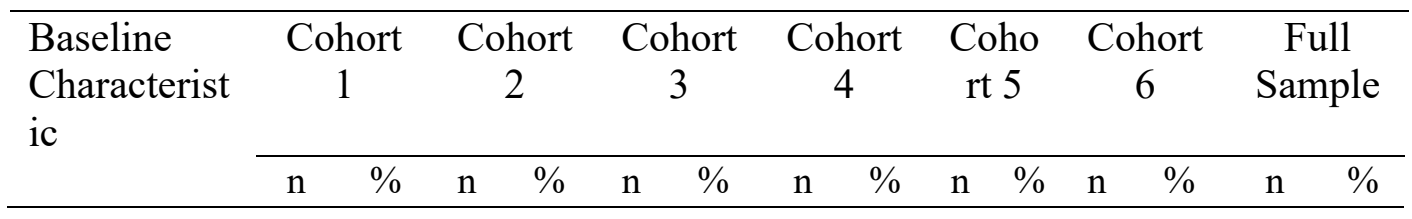




\begin{tabular}{|c|c|c|c|c|c|c|c|c|c|c|c|c|c|c|}
\hline \multicolumn{15}{|l|}{ Gender } \\
\hline \multirow[t]{2}{*}{ Female } & 12 & 92 & 1 & 85 & 1 & 85 & 16 & 89 & 1 & 9 & 2 & 89 & 107 & 89 \\
\hline & & & 8 & & 7 & & & & 9 & 5 & 5 & & & \\
\hline Male & 1 & 8 & 3 & 15 & 3 & 15 & 2 & 11 & 1 & 5 & 3 & 11 & 13 & 11 \\
\hline \multicolumn{15}{|l|}{ Race } \\
\hline Black & 0 & 0 & 0 & 0 & 0 & 0 & 0 & 0 & 0 & 0 & 0 & 0 & 0 & 0 \\
\hline \multirow[t]{2}{*}{ White } & 13 & 100 & 1 & 85 & 2 & 100 & 17 & 95 & 1 & 9 & 2 & 100 & 115 & 95 \\
\hline & & & 8 & & 0 & & & & 9 & 5 & 8 & & & \\
\hline Biracial & 0 & 0 & 1 & 5 & 0 & 0 & 1 & 5 & 1 & 5 & 0 & 0 & 3 & 3 \\
\hline Hispanic & 0 & 0 & 1 & 5 & 0 & 0 & 0 & 0 & 0 & 0 & 0 & 0 & 1 & $>1$ \\
\hline Not & 0 & 0 & 1 & 5 & 0 & 0 & 0 & 0 & 0 & 0 & 0 & 0 & 1 & $>1$ \\
\hline \multicolumn{15}{|l|}{ identify } \\
\hline \multicolumn{15}{|l|}{ English first } \\
\hline \multicolumn{15}{|l|}{ language } \\
\hline \multirow[t]{2}{*}{ Yes } & 12 & 92 & 2 & 100 & 2 & 100 & 16 & 89 & 1 & 9 & 2 & 100 & 116 & 97 \\
\hline & & & 1 & & 0 & & & & 9 & 5 & 8 & & & \\
\hline No & 1 & 8 & 0 & 0 & 0 & 0 & 2 & 11 & 1 & 5 & 0 & 0 & 4 & 3 \\
\hline \multirow{3}{*}{\multicolumn{15}{|c|}{$\begin{array}{l}\text { First } \\
\text { generation } \\
\text { college }\end{array}$}} \\
\hline & & & & & & & & & & & & & & \\
\hline & & & & & & & & & & & & & & \\
\hline Yes & 1 & 8 & 2 & 10 & 3 & 15 & 5 & 27 & 4 & 2 & 4 & 14 & 19 & 16 \\
\hline \multirow[t]{2}{*}{ No } & 12 & 92 & 1 & 90 & 1 & 85 & 13 & 73 & 1 & 8 & 2 & 86 & 101 & 84 \\
\hline & & & 9 & & 7 & & & & 6 & 0 & 4 & & & \\
\hline \multicolumn{15}{|l|}{$\begin{array}{l}\text { College } \\
\text { math }\end{array}$} \\
\hline math & & & & & & & & & & & & & & \\
\hline \multicolumn{15}{|l|}{ courses } \\
\hline \multicolumn{15}{|l|}{ taken } \\
\hline None & 0 & 0 & 1 & 5 & 0 & 0 & 1 & 5 & 0 & 0 & 2 & 7 & 4 & 3 \\
\hline 1 or 2 & 11 & 85 & 1 & 85 & 1 & 85 & 14 & 78 & 1 & 7 & 2 & 75 & 95 & 79 \\
\hline & & & 8 & & 7 & & & & 4 & 0 & 1 & & & \\
\hline 3 to 5 & 2 & 15 & 2 & 10 & 2 & 10 & 3 & 16 & 6 & 3 & 4 & 14 & 19 & 16 \\
\hline 6 or more & 0 & 0 & 0 & 0 & 1 & 5 & 0 & 0 & 0 & $\begin{array}{l}0 \\
0\end{array}$ & 1 & 4 & 2 & 2 \\
\hline
\end{tabular}

\section{Measures}

\section{Mathematics Belief Scale}

The original Mathematics Belief Scale (MBS) was designed to assess teachers' pedagogical beliefs regarding subject matter content (Peterson et al.,1989). This survey contained 48 items designed to assess teachers' beliefs relative to the following four concepts: (1) how children learn mathematics, (2) the relationship between mathematical 
skills and the capacity for understanding and problem solving, (3) the entity who bears responsibility for sequencing topics in the teaching of addition and subtraction, and (4) how addition and subtraction should be taught. Each construct consisted of 12 items using a 5-point Likert scale asking teachers to indicate whether they strongly agreed, agreed, were undecided, disagreed, or strongly disagreed with a given statement. The survey was later modified to an 18- item survey (Capraro, 2001) and has since been used in numerous studies to assess the beliefs of teachers (Cady et al., 2006; Ghazali \& Sinnakaudan, 2014; Kutaka et al., 2017; Ren \& Smith, 2018; Steele, 2001). For the purpose of this study, the shortened version by Capraro (2001) which was later utilized by Ren and Smith (2018) was used. Ren and Smith (2018) performed a factor-analysis confirming two subscales (teacher roles and student learning) within the 18-items measure. Cronbach's alphas were .66 for Student-learning beliefs ( 8 items) and .82 for Teacher-roles (10 items). The total possible score range on the MBS scale is $14-70$. As indicated by researchers Ren and Smith (2018), scores on the MBS would be utilized to identify if participants identified more with "student-centered beliefs" or "teacher-centered beliefs". The first construct, student-centered beliefs, is focused on the idea that students construct their own knowledge through active investigation and that teachers should use strategies and tools that promote students' conceptual understanding (Ren \& Smith, 2018). Therefore, a higher score on this construct indicated a belief that children should construct their own knowledge and that students' innate ability to develop mathematical concepts provided the basis for the sequencing of different content topics. These were identified as having student-centered beliefs (Capraro, 2001;Ren \& Smith, 2018). 
The second construct, teacher-centered beliefs is focused on the idea that students acquired knowledge from the teacher as the source of knowledge (e.g., students need to be told or shown how to do mathematics) and that a mathematically pre-determined sequence should be used for instructional purposes. These were identified as having teacher-centered beliefs (Capraro, 2001; Ren \& Smith, 2018) and were indicated by a lower score on the belief scale.

\section{Learning Mathematics for Teachers: Content Knowledge of Mathematics}

The Learning Mathematics for Teachers (LMT) assessment has been used to study a teacher's content knowledge for teaching mathematics in studies on teacher preparation. The assessment is precise enough to capture the knowledge teachers are likely to use when teaching, but broad enough to apply to a wide range of mathematical content topics (Hiebert et al., 2017). The LMT has previously been used to examine the relationship between professional noticing and an assessment of the overall content knowledge for teaching mathematics (Fisher et al., 2017). The LMT involves assessment across seven content areas (e.g., geometry, number concepts and operations, probability data and statistics, patterns, place value, proportional reasoning, and algebra, rational numbers). The assessment tool is designed to elicit a broad range of responses in order to allow for a comparison between teachers based on their content knowledge for teaching mathematics. The content area that was identified for this study was Elementary Number Concepts and Operations.

According to the LMT training guidelines, Elementary Number Concepts and Operations provides the broadest understanding of a teachers' content knowledge for teaching mathematics based on a sum score (see Appendix D for two sample items from 
the LMT). This content area was chosen after analyzing the syllabi of the three mathematics content courses that are taught during preparation programs. Specifically, the course descriptions and learning goals were examined for similarities and differences in content and teaching practices. The first course in which both general education and special education students enroll focuses on numbers and operations and centers around students' mathematical thinking skills (Lannin, 2018). The second course, taken by general education majors, focuses on geometry and measurement with an emphasis on conducting mathematics discussions in a whole group setting (Empson, 2019). The second course taken by special education majors has a content focus on geometry, measurement, algebra, and probability with an emphasis on connecting these ideas to the teaching of mathematics in a K-12 setting (van Garderen, 2019).

The LMT Elementary Number Concepts and Operations assessment is designed to take about 20-25 minutes and is composed of 34 questions for versions $\mathrm{A}$ and $\mathrm{B}$, respectively. Reliability for items on the number and operation forms is .80 (form A) and .83 (form B) (Hill, 2004). The assumption is made that scores from the LMT can be positively correlated to higher-quality mathematics instruction (Hill et al., 2012; Laursen et al., 2016). Therefore, higher scores are positively related to an improvement in a student's learning of mathematical concepts (Hill et al. 2005). It is important to note that the LMT was designed so that the average teacher would get a correct score on $50 \%$ of the items. The test can be used to compare teachers within a sample or to the normed sample, but cannot compare teachers to an absolute standard (e.g., we cannot determine that if a teacher scored $50 \%$, he or she is not equipped to teach mathematics). The 
assessment is designed to compare teachers on a normed referenced comparison within a sample, which is how it is utilized within this study.

Verifying Focus of Constructs within the LMT. An evaluation of each of the LMT items on both forms A and B was conducted to identify which mathematical construct was to be the focus for each item. The purpose of this process was to confirm that the chosen LMT assessment addressed content that connected to content addressed throughout the methods courses. The process obliged the researcher to examine the item and then identify the mathematical construct a participant would utilize when solving the problem. For example, on form A, item 12, the question asks participants to review students' division homework (see Appendix D item 2 for item 12). Because this would require participants to engage their understanding of division, that item was assigned to the division construct category. Once this process was completed, both the forms and the list of possible constructs were sent to three mathematical experts to determine the interrater reliability of the mathematical construct with which each item was identified. Experts participating in the study included three faculty members in either special education or mathematics education whose research focus was in the area of mathematics. Initial response percentages of agreement and disagreement were calculated, and all discrepancies were discussed with the experts to obtain $100 \%$ agreement. The identified constructs were fractions, division, multiplication, addition, place value, subtraction, integer, and prime/composite. The constructs were then crossreferenced with those listed on the syllabi to determine the mathematical constructs on which we would focus in the professional noticing video clips. Of all the classified 
constructs, multiplication, subtraction, division and place value were those most commonly identified.

\section{Professional Noticing}

To examine a pre-service teacher's professional noticing practice, pre-service teachers were asked to watch a specific set of three video clips and then respond to a prompt after each clip. Watching video clips and responding to a prompt has been used as a means of examining professional noticing by Miller (2011), Sherin et al. (2011), van Es (2011) and many others.

The video clips were selected from a validated and reliable stock of videos (Kersting, 2008; Kersting et al., 2010) that were available for viewing on an interactive, web-based, password-protected software program. These video clips ranged from 1-4 minutes in length and provided a variety of content focuses and instructors. The clips depicted authentic lessons of inclusive general education classrooms and included students with and without disabilities. This video bank has been used by other researchers such as Hiebert et al. (2017) and Copur-Gencturk and Rodrigues (2021).

\section{Video Clip Selection Process and "Problematic Moment" Identification}

The video clips chosen were based on a three-stage selection process. The first stage utilized work done previously when identifying the mathematical content to focus in on the LMT measure. These were identified as numbers and operations, geometry, measurement, and algebra. The selection of videos was narrowed down by the researcher to a set of videos that corresponded to these mathematical content areas.

The narrowed down set of videos then went through a second stage of selection criteria to identify a problematic moment, as done by Copur-Gencturk and Rodrigues 
(2021). The problematic moments were intended to provide a context for pre-service teachers to pay attention to students' thinking or the teacher's mathematical pedagogical actions, or both. Each of the videos included situations where students experienced some confusion or misunderstanding of the mathematical content and the teacher responded in some way. Using the criteria provided by Van de Walle (2003) and Principles and Standards for School Mathematics (NCTM, 2000) regarding standards of meaningful mathematics instruction, the narrowed down set of videos were examined for moments that would be identified as problematic. For example, in video 2, the students learn how to multiply and divide by a "giant 1 " (e.g., $2 / 2,6 / 6$ ) to find equivalent fractions. This term was used by both the student and the teacher in the clip. This was determined to be a problematic moment based on the Van de Walle (2003) process standard of Communication which counsel's teachers "to use precise mathematical language and notations so that the word usage and definitions can act as a foundation for students' future learning” (p. 271). Appendix E contains the full specifics regarding the criteria lens that was used to identify video clips that depicted problematic moments.

The third and final stage for video selection was to verify the remaining videos' problematic moments in consultation with three experts. Six videos met the researcher's idea of content criteria and were identified as having a problematic moment by the researcher. The experts were asked to view the six videos and identify the problematic moment(s) they witnessed in the clip. Moments identified by the experts were compared to those identified by the researcher before being chosen for the study. Utilizing the feedback from the experts, three videos were chosen for the study. Videos were eliminated for a number of reasons. Experts found some video clips to be visually 
blurred, difficult to follow, or too similar to one another; these were thus eliminated. Three of the six videos were agreed upon by the experts as depicting a problematic moment that matched the research criteria, they were clear to follow, and they fit the content included in methods courses. See Appendix E for a full description of the three final videos that were chosen for the study.

\section{Professional Noticing Video Prompt}

The professional noticing protocol that was used for this study was based on research from Copur-Gencturk and Rodrigues (2021). To ensure the protocol was clear and would elicit the desired information, the protocol was sent out to the same expert panel used in the video selection process in order to solicit feedback. The prompt went through three rounds of re-wording and edits in consultation with the experts prior to being finalized.

The protocol involved having pre-service teachers view video clips one at a time on a personal device and then record what they noticed. After watching each video clip, they responded to the following prompt: "Please list the three most significant things that you noticed regarding how the teacher and the students in the clip interacted around the targeted mathematical content." An online Qualtrics survey was used to record responses by typing in three separate text boxes wherein they could indicate one example of noticing in each text box. No length requirements for responses were established and instructions indicated that participants could watch the video more than once.

\section{Data Collection Procedures}

Data collection took place on a single day or over a two-week period for each of the different cohorts (see Table 3). Data collection had to occur during specific timelines 
due to cohorts one through four being actively enrolled in mathematics methods courses. Participants in cohorts one and two (e.g., year 1 in the program) were enrolled in their first methods course during the data collection period. As they were being utilized as the cohort with zero methods courses, it was critical to collect the data before substantial instruction had begun. For these two cohorts, all data was collected by the conclusion of the second week of their first methods course. This same procedure was applied to cohorts three and four who were enrolled in their second methods course, and data collection had to occur before substantial instruction in their first methods course had taken place.

\section{Table 3}

Data Collection Method and Period by Cohort

Cohort \# Collection Method Data Collection Month

$1 * \quad$ Two-week collection period August 2020

$2 \quad$ Single collection August 2020

3 Two-week collection period January 2020

$4 \quad$ Single collection January 2020

5* Two-week collection period March 2020

6* Single collection $\quad$ April 2020

Note. $*$ = Data collection was moved to virtual for some or all the participants due to COVID-19.

During the recruitment stage, the researcher was permitted to use seminar class time for data collection by the cohort instructor. Special Education seminars included all 
special education majors in each cohort. This allowed the data from special education cohorts (cohort two, four, and six) to be collected during one single session. Of the three special education cohorts, two and four were collected in-person, while cohort six was collected in an online session (due to COVID-19 restrictions). The elementary education cohort was much larger and there was no single class that included all elementary majors at one time that the researcher could access. Therefore, data from elementary cohorts (cohorts one, three and five) were collected during a two- week window outside of class time. Recruitment occurred via an e-mail list serve and the researcher personally attended mathematics methods courses to invite pre-service teachers to participate in the study. Data for cohort three, elementary education majors, were collected in-person at the participants' availability on the college campus. Data for cohorts one and five were conducted via Zoom.

During the data collection period, all in-person procedures were conducted in the same manner. Participants were asked to bring headphones and their own technological devices to access the links (if accessing either item was a barrier the researcher worked personally with the participant). Individual notecards were made prior to data collection with QR codes for Qualtrics survey logins and research IDs. Participants were randomly assigned a notecard that would then provide them their de-identified research ID for the remainder of the study. Participants were instructed to use the same research ID on all three of the measures to allow the researcher to later match each participant's measures and demographic data while maintaining the confidentiality of the participants.

Once administration of the procedure began, consent was obtained. Each participant utilized the individualized notecard they were provided that contained the QR 
code to access the three measures. Every participant began by watching the three video clips in a randomized order (based on the notecard they were given) in order to account for the order effect (Strack, 1992). Participants then responded to the prompt, which was provided to them through a Qualtrics link. Participants watched and responded to the videos on their own devices and could re-watch the video clips if needed. The second task was to answer the items from the MBS and provide demographic information. Third, and finally, participants were directed through a second QR link to the LMT Number Concepts and Operations Content Knowledge assessment. The LMT was administered through a secure login system supported by the University of Michigan School of Education. The measure was designed to take 20-25 minutes; on average participants took 15 - 45 minutes to complete the measure. Due to COVID-19, edits were made to mimic the in-person procedures as faithfully as possible. This was done by moving data collection to Zoom meetings in which the participant(s) were emailed their participant notecard and links to the measures once the Zoom meeting started. Once the zoom call was established, procedures were administrated in the same way as the in-person procedures. The participant(s) were asked to mute themselves and complete the measures while on the call to ensure all questions or problems could be answered by the researcher if necessary.

To ensure fidelity of the study and ensure procedures were administered correctly, a special education doctoral student was present for $20 \%$ of the data collection administration and conduct a checklist (Figure 3 ). The $20 \%$ of the data collection that was monitored was done through in-person data collection observations and Zoom video conferencing for online data collection. Fidelity was measured at $100 \%$. 


\section{Figure 3}

\section{Data Collection Fidelity Checklist}

\begin{tabular}{|l|c|c|c|c|}
\hline \multicolumn{5}{|c|}{ Data Collection Checklist } \\
\hline $\begin{array}{l}\text { The degree to which the } \\
\text { researcher implemented the } \\
\text { following... (in order) }\end{array}$ & $\begin{array}{l}\text { Observed in } \\
\text { correct order }\end{array}$ & $\begin{array}{c}\text { Observed out } \\
\text { of order }\end{array}$ & $\begin{array}{c}\text { Not Observed } \\
\text { at all }\end{array}$ & Notes \\
\hline $\begin{array}{l}\text { Participants are } \\
\text { introduced to the study }\end{array}$ & $\square$ & $\square$ & $\square$ & \\
\hline $\begin{array}{l}\text { Verbal Consent is } \\
\text { obtained from each } \\
\text { participant }\end{array}$ & $\square$ & $\square$ & $\square$ & \\
\hline $\begin{array}{l}\text { Participants watched the } \\
\text { videos \& protocol (in } \\
\text { randomized order) }\end{array}$ & $\square$ & $\square$ & $\square$ & \\
\hline $\begin{array}{l}\text { Participants engage in the } \\
\text { Mathematics Belief } \\
\text { Survey }\end{array}$ & $\square$ & $\square$ & $\square$ & \\
\hline $\begin{array}{l}\text { Participants take the } \\
\text { LMT Number Concepts } \\
\text { and Operations Content } \\
\text { Knowledge assessment }\end{array}$ & $\square$ & $\square$ & $\square$ & \\
\hline
\end{tabular}

\section{Data Scoring}

\section{Mathematics Belief Scale}

The MBS was scored using the same procedures outlined by Ren and Smith (2018). Raw data was downloaded from Qualtrics, and Likert-scale responses were coded through Excel. Each response was designated a number for the corresponding answer (e.g., $1=$ "'Strongly Disagree”' through $5=$ "'Strongly Agree”). Reverse coding was necessary on 11 of the 18 items on the survey as was previously done by Ren and Smith (2018). (See Appendix E for full survey and reverse coded items.) Each participant 
received three final scores. The first number was the sum of eight items that focused on the teacher roles sub-scale. A participant's score on the first sub-scale could range from 8 to 40 depending on responses. The second number was the sum of six items that focused on the student learning sub-scale. A participant's score on the second sub-scale could range from 6 to 30. Participants also received a final sum score that added both sub-scales totals together. The overall sum score could range from 14 to 70 depending on responses.

\section{LMT Measure}

The LMT data was collected through a secure login system. The responses were automatically scored through the LMT system as correct/incorrect $(2=$ correct, $1=$ incorrect). The TKAS system provided a standard analysis, descriptive statistics, t-tests, effect sizes and histograms for each administration. Each participant received a sum score for their overall LMT. The measures were composed of 34 questions for versions A and B respectively and the overall sum score could range from 0 to 34 correct items.

\section{Professional Noticing Scoring Rubric}

A rubric (Copur-Gencturk \& Rodrigues, 2021) was used to score pre-service teachers' professional noticing responses. The rubric was developed to capture the degree of noticing and topic of noticing found in the pre-service teacher responses (see Appendix F for rubric used). The adapted 4-point rubric was "created to distinguish among purely descriptive responses, analytical responses, and responses that focused on the significant content-specific issues in each video" (Copur-Gencturk \& Rodrigues, 2021, p. 4). The design was intended to identify professional noticing by category (i.e., category 1 , category 2 , category 3 , and category 4 ) and topic (i.e., teachers' mathematics pedagogy, students' mathematical thinking, or general). 
Each professional noticing response was first scored for a noticing topic. A noticing topic was defined as a subject in the video that caught the teacher's attention. These noticing topics were identified as teacher mathematical pedagogy, student mathematical thinking, or general. An example of a response that would be identified as teacher mathematical pedagogy would be "the teacher allowed the students to share their thinking." This noticing topic was provided because the response focuses on a decision or move made by the teacher. An example of a response that was identified as a professional noticing of student mathematical thinking was "the student is drawing representation of base 100,10, and 1's blocks." This example focuses on what the student is doing or potentially thinking in regard to mathematics. An example of noticing topic, general, is "the student did not seem very comfortable with the teacher." Although the response acknowledges the student's activity, the response did not include a mathematics-specific event, so it was identified as "general."

After a response was scored for a noticing topic, it was then scored by category, which goal was to code responses to ensure capturing of qualitative differences in teachers' responses. Category 1-3 descriptions were kept consistent with those developed by Copur-Gencturk and Rodrigues (2021). A category 1 response was identified as a response that was not specific to mathematics such as, "the student did not seem very comfortable with the teacher." During the coding process one specific participant provided the example "The teacher has a positive attitude when working with the student." Although it could be argued that the attitude of the teacher is important, for the utilized scoring rubric the given response failed to provide any mathematics-specific events or reference to math content. A category 2 response incorporated mathematical 
based responses that were purely descriptive, such as, "the student does not seem to understand fractions." During the coding process one specific participant provided the example "The teacher asked prompting questions like "How do you show that in number form?"'”. The response was coded for depth category. The given example was coded a category 2 as it merely stated facts about what they saw in the clip with no additional information. It was scored a category 2 over 1 because it did acknowledge the mathematics content that was occurring within the clip.

Category 3 responses analyzed an aspect of the student's mathematics thinking or teachers' mathematical pedagogy, such as, "the teacher asked open-ended questions to make sure the student understood the entirety of the problem." During the coding process one specific participant provided the example "the teacher tried to apply mathematical concepts after the problem was already understood. For example, once the student understood how far each person ran, the teacher asked if the student could give a number name or fraction to the tick-mark. However, I wish that the teacher would not have said fraction because I would have liked to see if the student labeled it in three wholes (ex: 1, 2, 3) or into thirds (ex: 1/3, 2/3,3/3)." The response was coded as having a noticing depth of a level 3. This code was given because the response went beyond simply stating what was observed in the clip, the participant provided an example but then took it a step further to provide some analytical reasoning about what about what happening in the clip.

The rubric was adapted sightly for this study in category 4 , the most sophisticated category of professional noticing, as these responses focused on the problematic moments related to students' mathematical thinking or to teachers' mathematical instructional practices. The identified problematic moments were determined through an expert 
panel's assessments that focused on the identified videos used in this study. The adapted scoring rubric was vetted by experts in both special education and mathematics education. Each of the experts were provided the same prompt that was given to the participants along with the three videos in conjunction with a Qualtrics survey. Once initial responses were recorded, individual correspondence took place with each of the three experts - two in special education and one in mathematics education. The mathematics education expert was the author of the original scoring rubric and provided feedback relative to the category 4 problematic professional noticing moment for each of the three chosen videos. The special education experts were established scholars in the area of mathematics for students with disabilities and had knowledge and experience in preparing pre-service teachers. Based on this vetting process, the problematic moments were identified for category 4 on the noticing rubric.

A category 4 problematic moment example that was coded from the participants responses was "the teacher points out to the student that he multiplied the numerator and the denominator by two different numbers, instead of just outwardly telling him that's wrong." The particular response was provided a category 4 since it specifically identified a problematic moment in the students' mathematical thinking specific to the problem. The specific moment identified by the experts were "The student understood he needed to multiply to solve the problem but did not understand the problem." Therefore, the given example identified the problematic moment, and the response was coded as a category 4.

Coding Professional noticing Responses: Interrater Reliability. In order to establish interrater relatability scoring on the professional noticing rubric, the researcher 
engaged in the process of intercoder agreement (Jonsson \& Svingby, 2007). A third-year doctoral candidate in the special education PhD program served as the second coder throughout the agreement and reliability process. To carry out this process, the second coder engaged in a single two-hour training during which she and the researcher read through a researcher-created coding guide (see Appendix H). During that training period, the researcher and second coder discussed the guide and coded responses from 5 participants (15 responses in total). Together they came to a consensus regarding each of the response topics and categories while making notes about the distinctions in each category. Each category was scored on a 1 to 4-point rubric (Copur-Gencturk and Rodrigues, 2021). The categories were assigned point values, for example, more sophisticated professional noticing (as defined in this study) were coded a higher the point value than more general or descriptive responses. It is important to note that the categories were not intended to be leveled as the rubric does not explicitly rank or describe a hierarchy of professional noticing. For example, noticing "general" moments such as student behavior or peers working together has important value for teaching (Sherin et al., 2011). However, within this study the focus is specifically on noticing students' mathematical thinking. Therefore, general or more descriptive noticing responses were coded a lower point value for the purposes of this study. This is not to say they are not valuable noticings for overall teaching. At the conclusion of scoring the responses each participant received four final scores. The first three scores were sum scores of how frequently each topic code was given to each individual participant. For example, a participant could have received a 6 for the topic of Teacher Mathematics Pedagogy which meant that 6 of their 9 overall responses were coded under Teacher 
Mathematics Pedagogy. The fourth and final score was the overall sum total for categories, this score identified the total point value of the noticing depth category. The decision was made to utilize an overall sum score, which differs from Copur-Gencturk and Rodrigues, 2021, due to the guiding research questions of the study. The given study wanted to examine current pre-service teachers overall noticing as it pertains to these differing groups within a preparation program.

Next, the researcher and second scorer independently scored a subset of the dataset and compared coding (15 participants: 45 responses). Initial agreement was $80 \%$ accuracy on scoring the individual response category and $93 \%$ agreement on scoring the individual response topics. Agreement was defined as assigning the same category and topic code to the given noticing response. The researcher and second coder identified discrepancies and discussed their individual rationales for assigning that code. To resolve all initial discrepancies, the second coder and researcher re-examined the professional noticing response and coding guide to come to a final code agreement. During this process, specific distinctions for each category were clarified in the coding guide to provide further clarification for the remainder of coding's. After resolving all initial rounds of scoring discrepancies, the second coder and researcher arrived at 98 to $100 \%$ agreement on both topic and category for scoring.

The second scorer was then randomly assigned 24 more participants (72 responses) for additional double coding. This procedure continued until 20 percent of the professional noticing responses were double coded by the researcher and second scorer for an overall total of 87 participants involving 261 individual responses. During the double coding process, the researcher and second coder achieved $98 \%$ consistency when 
coding for topics, and $91 \%$ accuracy when coding for categories. The researcher and second coder would each code 20 to 30 responses at a time before reconvening to check reliability prior to moving forward. Each specific discrepancy was discussed individually, and a resolution was reached.

\section{Data Analysis}

Following data importation, several analytic procedures were conducted to examine the three proposed research questions (see Table 4 for a summary based on the variables of interest for each research question).

\section{Table 4}

Statistical Analyses and Items for Research Questions

\begin{tabular}{|c|c|c|}
\hline Research Question & Measures & Analysis \\
\hline $\begin{array}{l}\text { 1. Knowledge and } \\
\text { Noticing }\end{array}$ & $\begin{array}{l}\text { Content knowledge (LMT) } \\
\text { Professional noticing Rubric }\end{array}$ & $\begin{array}{l}\text { One-way } \\
\text { ANOVA }\end{array}$ \\
\hline 1a. Year Difference & $\begin{array}{l}\text { Content knowledge (LMT; DV) } \\
\text { Professional noticing rubric } \\
\text { (DV) } \\
\text { Year in program (Factor; IV) }\end{array}$ & $\begin{array}{l}\text { Two-way } \\
\text { ANOVA }\end{array}$ \\
\hline 1b. Major Difference & $\begin{array}{l}\text { Content knowledge } \\
\text { (LMT)(DV) } \\
\text { Professional noticing rubric } \\
\text { (DV) } \\
\text { Major (Factor; IV) }\end{array}$ & $\begin{array}{l}\text { Two-way } \\
\text { ANOVA }\end{array}$ \\
\hline 2. Beliefs and Noticing & $\begin{array}{l}\text { Beliefs (MBS) } \\
\text { Professional noticing Rubric }\end{array}$ & $\begin{array}{l}\text { One-way } \\
\text { ANOVA }\end{array}$ \\
\hline 2a. Year Difference & $\begin{array}{l}\text { Beliefs (MBS; DV) } \\
\text { Professional noticing rubric } \\
\text { (DV) } \\
\text { Year in program (Factor; IV) }\end{array}$ & $\begin{array}{l}\text { Two-way } \\
\text { ANOVA }\end{array}$ \\
\hline 2b. Major Difference & $\begin{array}{l}\text { MBS Survey (DV) } \\
\text { Professional noticing rubric } \\
\text { (DV) } \\
\text { Major (Factor; IV) }\end{array}$ & $\begin{array}{l}\text { Two-way } \\
\text { ANOVA }\end{array}$ \\
\hline
\end{tabular}




\begin{tabular}{lll}
\hline 3. Noticing Predictor & Content Knowledge (LMT; & Linear \\
& PV) & Regression \\
& Professional noticing rubric & Hierarchical \\
& & Multiple \\
& Regression \\
\hline
\end{tabular}

Note. IV = Independent Variable, DV = Dependent Variable, PV = Predictor Variable.

The following will explain the analyses that were used to examine each construct and differing relationships. All assumptions (variable types, linearity, normality, and homoscedasticity) were checked prior to the analyses to make sure that the analyses could be done appropriately. The researcher used the statistical software SPSS to conduct these analyses. To answer the first research question, the following analyses were conducted.

\section{Statistical Analysis Tests}

The decision process for choosing which statistical analysis tests were to be used was made based on the research questions asked and the type of data collected. Below are descriptors of each specific test that was conducted during this study. Also included are assumptions that must be made when running those tests to best understand why certain testes were run during the analysis portion of the study, followed by which test each research question utilized.

\section{Research Question 1}

The focus of this question was to determine the relationship between pre-service teachers' content knowledge and professional noticing. Descriptive data from each cohort were visually analyzed with box plots as well as violin plots to determine the potential for a linear relationship as well as possible outliers that may skew the data set. A two-way analysis of variance (ANOVA) statistical analysis was run in order to establish whether 
there was an interaction effect between the LMT score and the teaching noticing 4-point rubric and to see if a significant difference existed. Cohen's $d$ was used to determine the effect size of LMT scores on professional noticing. Where effect sizes were reported, the following scale was generally used to interpret the magnitude of an effect based on small effect, $0<d<.2$, moderate effect .2 $<d<.5$, large effect $d>.8$ (Cohen, 1998). High sum scores on the LMT measure and high scores on the professional noticing rubric were examined for significance.

To analyze the two sub-research questions, a two-way ANOVA was run for each of the questions to examine the effects of specific variables on the professional noticing rubric. For this study, a two-way ANOVA was chosen because it allows for the testing of a hypothesis regarding the effect of two independent variables (e.g., major, LMT score, and cohort) on a continuous dependent variable (e.g., professional noticing sum score) (Rutherford, 2011). ANOVA tests for significance using the F-test for statistical significance. The F-test provides a groupwise comparison test which compares the variance in each group mean to the overall variance in the dependent variable (e.g., professional noticing; Fox, 2008).

\section{Research Question 2}

The focus of this research question was to determine the relationship between preservice teachers' beliefs on teaching mathematics and professional noticing. A two-way analysis of variance (ANOVA) statistical analysis was run in order to establish whether there was an interaction effect between the MBS and professional noticing and to see if a significant difference existed. The association between the category on the 4-point professional noticing rubric and a low score on the teacher beliefs scale was examined. 
Lower and higher scores on the beliefs scale indicated how participants viewed teachers' roles in the teaching of mathematics and how students learn.

To analyze the two sub-research questions, a two-way ANOVA was run for each of the questions to examine the effects of specific variables on demonstrations on the professional noticing rubric. For this study, a two-way ANOVA was chosen because it allows the testing of a hypothesis regarding the effect of two independent variables (e.g., major, teacher beliefs score, and cohort) on a continuous dependent variable (e.g., professional noticing category sum score) (Rutherford, 2011).

\section{Research Question 3}

To answer research question three, the LMT sum score along with the category sum professional noticing score for all participants was analyzed using a linear regression. The dependent variable for this analysis was the LMT sum score; the independent variable was the sum noticing score. The pre-service teachers' score on the LMT was evaluated as a predictor of a participant's professional noticing. The predication of this analysis is that the higher the LMT score of a pre-service teacher, the more sophisticated the manner of professional noticing when observing mathematics teaching clips. For this study, a linear regression was used to assess teacher content knowledge as a predictive factor associated with professional noticing. Decisively, an advantage to answering research question three is the possibility of continued analysis of a Hierarchical Multiple Regression (HMR). An HMR will serve as a follow-up to a previously conducted ANOVAs as done by Rose and colleagues (2012). The test enables the entry of independent variables into the regression equation in a specific order (v. all independent variables at one time) (Laerd Statistics, 2015). For the purpose of this data 
analysis, the HMR objective will be used to test the additional importance of one or more independent variables in predicting the dependent variable (Laerd Statistics, 2015). 


\section{Chapter Four}

\section{Results}

The purpose of this study was to examine pre-service teachers' $\mathrm{pPCK}$, specifically, their content knowledge of mathematics, mathematics teaching beliefs, their professional noticing of student mathematical thinking, and the relationships among these variables relative to program emphasis - special education versus general education, as well as to their year in the teacher preparation program. This chapter will first report descriptive statistics for the different measures used in the study and then provide findings for each of the specific research questions asked.

\section{Descriptive Statistics}

Provided below is each measure's descriptive statistics. Data was collected on three measures which were previously described in more detail in Chapter 3. Professional noticing data is the sum score participants received based on their written responses to a prompt after having watched three video clips. Mathematical content knowledge for teaching is the sum score for correct item responses derived from the LMT measure. Finally, the MBS is the sum score for participants based on responses to survey items designed to determine how participants believed mathematics should be taught.

\section{Professional Noticing}

The professional noticing rubric reported participants' sum scores from their given responses after watching three video clips where the lowest possible score a participant could receive was 7 , while the highest possible was 24 . A higher score represents a more sophisticated demonstration of professional noticing. 
By Major and Year in Program. Descriptive statistics suggest that elementary education majors demonstrated a more sophisticated degree of professional noticing across all years in the program $(M=12.86, S D=2.68)$ than their special education counterparts $(M=11.54, S D=2.83)$ (see Table 5). Participants in year 2 of the teacher preparation program reported the higher categories of professional noticing $(M=12.84$, $S D=3.27)$ when compared to participants in year 1 of the program $(M=11.70, S D=$ $2.89)$ and those who were in year 3 of the program $(M=11.88, S D=2.65)$.

\section{Table 5}

Professional Noticing Scores by Major and Year in the Program

\begin{tabular}{lc}
\hline \multicolumn{1}{c}{ Major \& Year in Program } & Professional Noticing \\
\hline Year 1 (zero courses) & \\
Sped & $11.60(2.76)$ \\
Elem & $11.85(3.12)$ \\
Combined & $11.72(3.67)$ \\
Year 2 (one course) & \\
Sped & $12.06(3.30)$ \\
Elem & $13.58(3.15)$ \\
Combined & $12.84(3.27)$ \\
Year 3 (all courses) & \\
Sped & $10.96(2.38)$ \\
Elem & $13.15(2.52)$ \\
Combined & $11.83(2.53)$ \\
Years Combined & $12.11(2.83)$ \\
All Elem & $12.86(2.68)$ \\
All Sped & $11.54(2.83)$ \\
\hline
\end{tabular}

Note. Standard deviations are presented in parentheses. Year refers to the number of mathematics methods courses taken; Sped and Elem refer to the participants' major.

By Response. Each participant's professional noticing response was scored for both category and topic of the noticing event. A noticing topic was defined as a response that noticed teacher mathematical pedagogy, student mathematical thinking, or general 
behavior (Copur-Gencturk and Rodrigues, 2021). Based on the mean scores, descriptive statistics indicated that both special and elementary education pre-service teachers scored a much higher mean and frequency of professional noticing in the area of mathematics pedagogy versus student mathematical thinking (see table 6). The participants grouped by major had comparable mean scores in the two areas of noticing topics. Overall, $84 \%$ of the noticing topics were coded as focusing on the teachers' mathematical pedagogy, $14 \%$ on students' mathematical thinking, and $2 \%$ on general topics. Pre-service teachers focused primarily on the teacher's behavior during the video clips rather than on that of the students. The noticing topic did not differ based on the participants' major.

\section{Table 6}

Professional Noticing Topic by Major

\begin{tabular}{|c|c|c|c|c|c|c|}
\hline \multirow[t]{2}{*}{ Major } & \multicolumn{3}{|c|}{$\begin{array}{c}\text { Teachers' Mathematics } \\
\text { Pedagogy }\end{array}$} & \multicolumn{3}{|c|}{$\begin{array}{c}\text { Student's Mathematical } \\
\text { Thinking }\end{array}$} \\
\hline & Mean & $\mathrm{SD}$ & $\begin{array}{l}\text { Frequency } \\
(\%)\end{array}$ & Mean & $\mathrm{SD}$ & Frequency \\
\hline Sped & 7.49 & .191 & 84 & 1.27 & .166 & 14 \\
\hline Elem & 7.62 & .193 & 84 & 1.31 & .185 & 14 \\
\hline Total & 7.55 & 1.48 & 84 & 1.29 & 1.34 & 14 \\
\hline Sample & & & & & & \\
\hline
\end{tabular}

Note. The final $2 \%$ of both major's frequency was identified as noticing a general topic.

An examination of participant coding results based on noticing topics yielded similar results when classified by major. The descriptive statistics suggest pre-service teachers scored much higher mean and frequency scores in the area of noticing teacher mathematics pedagogy versus student mathematical thinking (see Table 7). Based on the year in the program, the frequencies and means differed only slightly.

\section{Table 7}

Professional Noticing Topic by Year in Program 


\begin{tabular}{ccccccc}
\hline $\begin{array}{c}\text { Year in } \\
\text { Program }\end{array}$ & Teachers' Mathematics Pedagogy & \multicolumn{2}{c}{ Student's Mathematical Thinking } \\
\hline & Mean & SD & $\begin{array}{c}\text { Frequency } \\
(\%)\end{array}$ & Mean & SD & $\begin{array}{c}\text { Frequency } \\
(\%)\end{array}$ \\
Year 1 & 7.29 & .279 & 81 & 1.44 & .243 & 16 \\
Year 2 & 7.65 & .209 & 85 & 1.30 & .215 & 14 \\
Year 3 & 7.65 & .222 & 86 & 1.17 & .191 & 14 \\
Combined & 7.55 & 1.48 & 84 & 1.29 & 1.34 & 14 \\
\hline
\end{tabular}

Note. The remaining percentages of frequency of all methods of noticing topics were identified as noticing a general topic.

\section{Pre-Service Teacher Mathematical Content Knowledge}

As noted in Chapter 3, each participant received a sum score for the number of correct items derived from the assessment. Possible scores on the assessment ranged from 0 correct responses to 34 . The participants in the study received scores that spanned the range, from 4 to 26 correct items. The assessment was designed so that the average inservice teacher would score 50 percent, or about 17 items with a correct response (Hill \& Ball, 2004). There was an overall average of 12.37 items correct among all participants; the pre-service teachers answered about 36 percent of the items correctly.

By Major and Year in Program. Similar to the results found in professional noticing, descriptive statistics suggest that elementary majors achieved higher scores on the mathematical knowledge for teaching assessment across all three years of the program when compared with their special education counterparts (see Table 8). The descriptive statistics suggest that participants in year $2(M=13.38, S D=4.40)$ or year 3 $(M=13.04, S D=3.64)$ of the preparation program scored higher than participants who were in year 1 of the program $(M=10.33, S D=4.77)$.

\section{Table 8}

Content Knowledge by Major and Year in Program 


\begin{tabular}{lc}
\hline \multicolumn{1}{c}{ Year in Program \& Major } & LMT \\
\hline Year 1 & \\
Sped & $9.95(3.70)$ \\
Elem & $10.92(6.18)$ \\
Combined & $10.32(4.60)$ \\
Year 2 & \\
Sped & $11.39(3.68)$ \\
Elem & $15.26(4.28)$ \\
Combined & $13.38(4.41)$ \\
Year 3 & \\
Sped & $12.32(3.83)$ \\
Elem & $14.05(3.19)$ \\
Combined & $13.04(3.64)$ \\
Years Combined & $12.37(4.37)$ \\
All Elem & $13.71(4.71)$ \\
All Sped & $11.33(3.80)$ \\
\hline
\end{tabular}

Note. Standard deviations are presented in parentheses. Year refers to the number of mathematics methods courses taken; Sped and Elem represent the participants' major.

Content Knowledge Groups. The continuous values were divided up into categories to allow for the detection of possible non-linear trends (Meyer \& Province, 1988). Three groups were created for the purpose of considering differences between a limited number of groups rather than along a continuum (DeCoster et al., 2011). The three groups were identified as low $(M=11.81, S D=.478)$, average $(M=11.94, S D=$ $.394)$, and high $(M=13.08, S D=.561)$ with the use of Tukey's Hinges (Langford, 2006).

All 120 participants' sum scores were included $(M=12 ; \mathrm{SD}=4.36)$. Tukey's Hinges determined the three inclusive quartiles (see Table 9).

\section{Table 9}

LMT Scores by Content Knowledge Groups

\begin{tabular}{cccc} 
Score & All & Year in Program & Major \\
Range & Participants & & \\
\hline
\end{tabular}




\begin{tabular}{ccccccc}
\hline & & $\mathrm{n}(\%)$ & & $\mathrm{n}(\%)$ & \multicolumn{2}{c}{$\mathrm{n}(\%)$} \\
\hline Low & $4-9$ & $36(30)$ & Year 1 & $18(53)$ & Sped & $26(39)$ \\
LMT & & & Year 2 & $8(21)$ & Elem & $10(19)$ \\
& & & Year 3 & $10(21)$ & & \\
& & & & & & \\
Average & $10-15$ & \multirow{2}{*}{$53(44)$} & Year 1 & $10(29)$ & Sped & $32(48)$ \\
LMT & & & Year 2 & $17(45)$ & Elem & $21(40)$ \\
& & & Year 3 & $26(54)$ & & \\
High & $16-26$ & \multirow{2}{*}{$31(26)$} & Year 1 & $6(18)$ & Sped & $9(13)$ \\
LMT & & & Year 2 & $13(34)$ & Elem & $22(41)$ \\
& & & Year 3 & $12(25)$ & & \\
\hline
\end{tabular}

Note. Percentages of participants in each category are presented in parentheses $(\mathrm{N}=120)$. Score range represents the range of correct sum score items that fall within that category based on Tukey's Hinges.

Tukey's Hinges represent an explanation for three quartiles of a data set, with the upper and lower hinge split into four sections (with three hinges) and the use of the median in the data set (Tukey, 1977). The lower hinge of the $25^{\text {th }}$ percentile was identified as a sum score of 9 correct items and below. The mid-hinge of $50^{\text {th }}$ percentile was identified as a sum of 10 to 15 correct items, and the upper hinge of the $75^{\text {th }}$ percentile was 16 to 26 correct items.

\section{Mathematical Belief Scale (MBS)}

By Major and Year in Program. As with the LMT scores, the continuous scale was then divided up into categories for the purpose of examining the two belief groups of student-centered beliefs versus teacher-centered beliefs (see measures in chapter 2 for definitions of the two groups) along a continuum (DeCoster et al., 2011). Two groups were created in accordance with the original use of the survey (Ren \& Smith, 2018) where higher scores indicated a more student-centered set of beliefs and lower scores 
indicated a more teacher-centered set of beliefs. All 120 participants' sum scores were included $(M=50, \mathrm{SD}=7.43)$. The mean $(\mathrm{M}=50)$ served as the cut off value for determining the two categories.

Table 10 provides descriptive statistics on how the pre-service teachers varied on the beliefs scale for teaching mathematics. Elementary education pre-service teachers identified with more student-centered beliefs $(M=53.00, \mathrm{SD}=7.18)$ than their special education counterparts $(M=47.47, \mathrm{SD}=6.50)$ throughout all three years of preparation programming. Based on means scores, pre-service teachers with more years in the program did reveal a change in their beliefs, but not appreciably. Overall, participants in year $2(M=50.38, \mathrm{SD}=7.74)$ or year $3(M=50.33, \mathrm{SD}=6.69)$ had beliefs which aligned more with student-centered beliefs than participants in year 1 of the program $(M=48.53$, $\mathrm{SD}=7.80)$

\section{Table 10}

Teacher Beliefs by Major by Year in Program

\begin{tabular}{lc}
\hline \multicolumn{1}{c}{ Major \& Year in Program } & MBS \\
\hline Year 1 & \\
Sped & $47.18(5.52)$ \\
Elem & $50.69(10.36)$ \\
Combined & $48.53(7.80)$ \\
Year 2 & \\
Sped & $46.67(7.10)$ \\
Elem & $54.45(7.03)$ \\
Combined & $50.38(7.74)$ \\
Year 3 & \\
Sped & $47.96(6.94)$ \\
Elem & $53.65(4.74)$ \\
Combined & $50.33(6.69)$ \\
All Years & \\
All Sped & $47.47(6.50)$ \\
All Elem & $53.00(7.18)$ \\
Combined & $49.83(7.33)$ \\
\hline
\end{tabular}


Note. Standard deviations are presented in parentheses. Year refers to the number of mathematics methods courses taken; Sped and Elem represent the participants' major.

By MBS subscales. Two subscales (e.g., Ren \& Smith, 2018) were used from the MBS (See Appendix D) to assess mathematical beliefs: Student Learning, and Teacher Roles.

Subscale 1: Student Learning. All pre-service teacher participants exhibited beliefs more aligned with student-centered views for how students learn mathematics, while teacher roles were more aligned with teacher-centered beliefs. Based on mean scores, special education majors had comparable means across all three years of the program $(M=24.58, \mathrm{SD}=4.51)$ and were identified as having a lower rate of studentcentered views (e.g., more teacher-centered beliefs) than their elementary education counterparts $(M=28.08, \mathrm{SD}=5.12)$. Similar results were found for elementary education majors. Student-centered beliefs were comparable across the three years of the program, but their views were more aligned with those who believed in self-centered learning than their special education counterparts.

\section{Table 11}

MBS Mean and Standard Deviation by Teacher Beliefs Subscale

\begin{tabular}{|c|c|c|c|c|}
\hline \multirow[t]{2}{*}{ Group } & \multicolumn{2}{|c|}{ Student Learning Subscale } & \multicolumn{2}{|c|}{ Teacher Roles Subscale } \\
\hline & Mean & SD & Mean & SD \\
\hline \multicolumn{5}{|l|}{ Year 1} \\
\hline Sped & 24.29 & 4.11 & 22.90 & 2.19 \\
\hline Elem & 26.46 & 6.70 & 24.23 & 4.27 \\
\hline Combined & 25.12 & 5.24 & 23.41 & 3.15 \\
\hline \multicolumn{5}{|l|}{ Year 2} \\
\hline Sped & 24.28 & 4.66 & 22.39 & 3.10 \\
\hline Elem & 29.45 & 5.60 & 25.00 & 2.96 \\
\hline Combined & 26.68 & 5.46 & 23.70 & 3.28 \\
\hline \multicolumn{5}{|l|}{ Year 3} \\
\hline Sped & 25.00 & 4.82 & 22.96 & 4.26 \\
\hline
\end{tabular}




\begin{tabular}{lllll} 
Elem & 28.30 & 3.67 & 25.35 & 3.00 \\
Combined & 26.38 & 4.63 & 23.96 & 3.94 \\
All Years & & & & \\
Sped & 24.58 & 4.51 & 22.79 & 3.34 \\
Elem & 28.08 & 5.12 & 24.92 & 3.33 \\
Combined Major & 26.11 & 5.07 & 23.72 & 3.51 \\
\hline
\end{tabular}

Note. The possible range of values is $1-5$ for "'Student-Learning," and “Teacher-Roles".

Subscale 2: Teacher Roles. Based on descriptive statistics, all pre-service teacher participants aligned more with teacher-centered teaching beliefs when the role of the teacher was evaluated compared to that of the student. Special education majors' beliefs remained consistent and depended on the number of years in the program. They were found to hold more teacher-centered beliefs for teaching mathematics $(M=22.79$, $\mathrm{SD}=3.34)$ than their elementary education counterparts $(M=24.92, \mathrm{SD}=3.33)$. Similar results were found for elementary education majors. Their beliefs were consistent based on their years in the program; they also held more student-centered aligned views for the teaching of mathematics.

\section{Research Question 1: What is the relationship between pre-service teachers' content knowledge and professional noticing?}

A series of Analysis of Variance (ANOVA) models were conducted to determine if pre-service teachers' scores for demonstration of professional noticing differed on the LMT relative to the measure for mathematical knowledge for teaching. For the analyses, the pre-service teachers were classified into two final groups: low LMT $(M=11.91, S D=$ $.281, \mathrm{n}=99)$ and high LMT $(M=13.55, S D=.740, \mathrm{n}=21)$. The Low LMT group and Average LMT group had non-significant results, and the two groups were collapsed into one (Langford, 2006) "low LMT" group. Noticing scores increased from low $(M=11.91$, 
$S D=.281)$ to high $(M=13.55, S D=.740)$ for the mathematical knowledge for teaching groups (see Figure 4). The differences between the two LMT groups were statistically significant $F(1,118)=3.989, p=.048$, suggesting that the lower the LMT score, the lower the score in professional noticing, while the higher the LMT score, the higher the score in professional noticing.

\section{Figure 4}

Mean of Teacher Professional Sum Scores by Content Knowledge Group

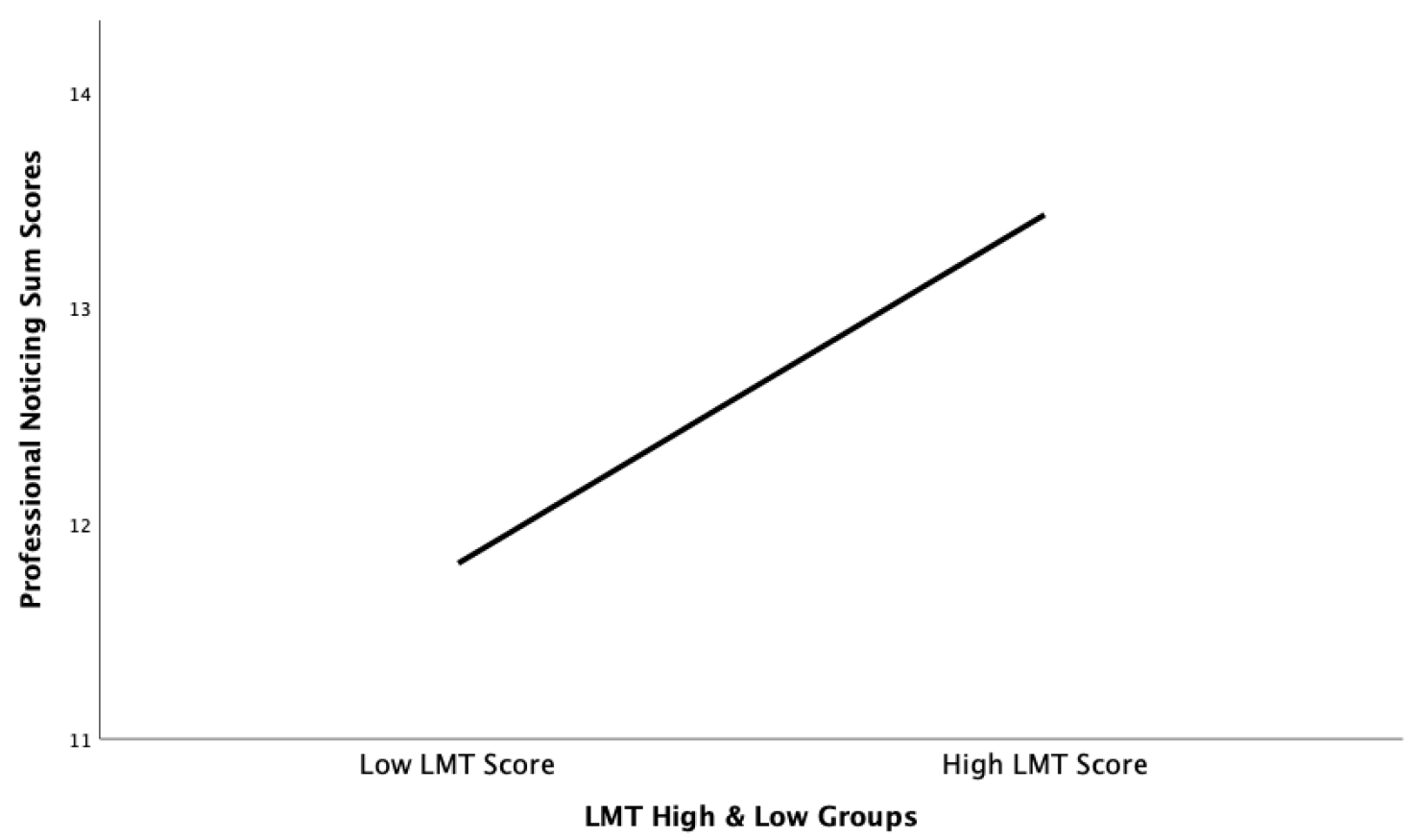

Research Question 1a. Do different years (e.g., zero, one or two methods courses) in the teacher preparation program have a significant impact on the relationship between a teachers' professional noticing and mathematics content knowledge?

A two-way ANOVA was conducted to determine if differing years in the teacher preparation program had a significant impact on professional noticing and LMT scores (see table 8 for LMT sum scores). There was homogeneity of variances, as assessed by 
Levene's test for equality of variances, $p=.154$, suggesting that years in the program do not have equal group variances. The non-statistically significant result indicated there were equal variances, and the assumption of homogeneity of variances has not been violated so no adjustments were needed (Iversen \& Northpole, 1987). There was no statistically significant relationship between mathematical knowledge for teaching and year in the program for the demonstration of professional noticing score $(F(2,114)=$ $.173, p=.842$, partial $\eta^{2}=.003$ ). This suggests that a participant's year in the program does not statistically impact the pre-service teacher's knowledge for teaching mathematics.

\section{Figure 5}

Estimated Marginal Means of Professional Noticing Sum Scores

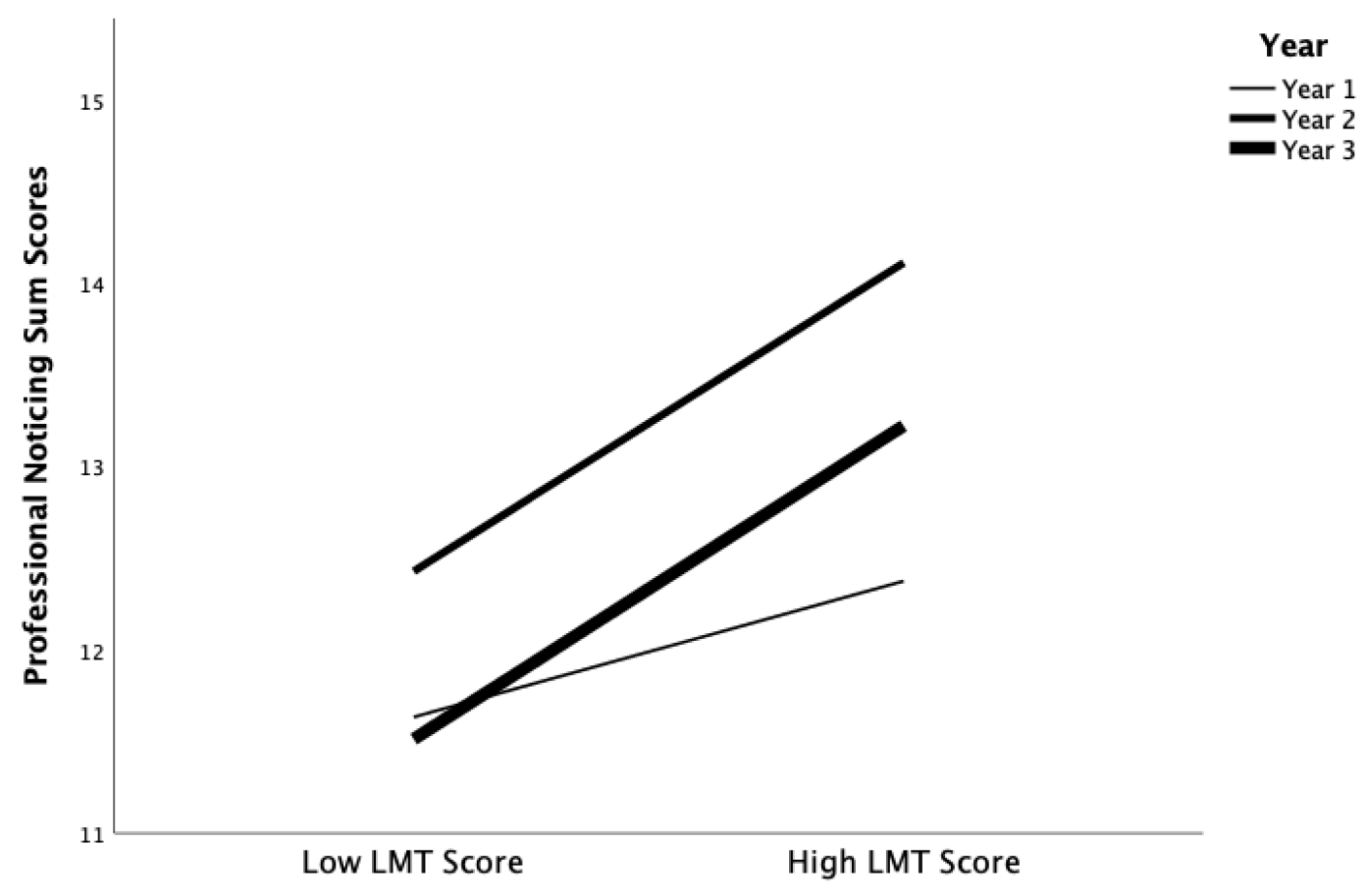

LMT High \& Low Groups

Figure 5 indicates that participants in year 2 of the program had the highest score of professional noticing and LMT while participants in year 3 and year 1 of the program had 
comparable scores. Participants in year 2 scored higher in more sophisticated categories of professional noticing; this increase was higher than those who were in year 1 or those in year 3 of the program.

\section{Research Question 1b. Do different majors (special education and general education) in the teacher preparation program have a significant impact on the relationship between a teachers' professional noticing and mathematics content knowledge?}

A two-way ANOVA was conducted to examine the relationship of a participant's major on the mathematical content score and professional noticing. Residual analysis was performed to test for the assumptions of the two-way ANOVA. Outliers were assessed by inspection of a boxplot; normality was assessed using Shapiro-Wilk's normality test for each cell of the design. Homogeneity of variances was assessed by Levene's test. One outlier was identified and assessed as not being greater than 3 box-lengths from the edge of the box in a boxplot and was, therefore, kept in the data set. Not all data were normally distributed across groups, as assessed by Shapiro-Wilk's test $(p>.05)$. Low LMT for special education and elementary majors were not normally distributed, while high LMT for both special education and elementary majors were normally distributed. The assumption of homogeneity of variances was violated, as assessed by Levene's test for equality of variances, $p=.203$. However, because group sample sizes were approximately equal and large, the two-way ANOVA was conducted as it is a somewhat robust measure of heterogeneity of variance in these circumstances (Jaccard, 1998).

Analysis of the main effect for participant major was performed (Howell, 2010). It indicated that the main effect was not statistically significant $F(1,115)=1.990, p=$ 
.161 , partial $\eta^{2}=.017$. There was a statistically significant main effect of LMT score on professional noticing $F(1,115)=4.547, p<.05$, partial $\eta^{2}=.038$. This finding suggests that as a participant's LMT score increased, so did the professional noticing score. All pairwise comparisons were run where $95 \%$ confidence intervals were reported and pvalues were Bonferroni-adjusted. The unweighted marginal means of professional noticing scores for score on the LMT were $11.93(S E=.283)$ for participants with low LMT and $13.41(S E=.632)$ for participants with high LMT scores respectfully. Afterwards, an analysis of the interaction effect between a participant's major and group identification on the LMT on professional noticing was determined to have no statistical relevance $F(1,115)=.051, p=.822$, partial $\eta^{2}=.000$. Figure 6 indicates that being a special or elementary education major did not significantly influence the pre-service teachers' LMT and professional noticing categories.

\section{Figure 6}

Professional Noticing Sum Scores by Major by Content Knowledge Groups 


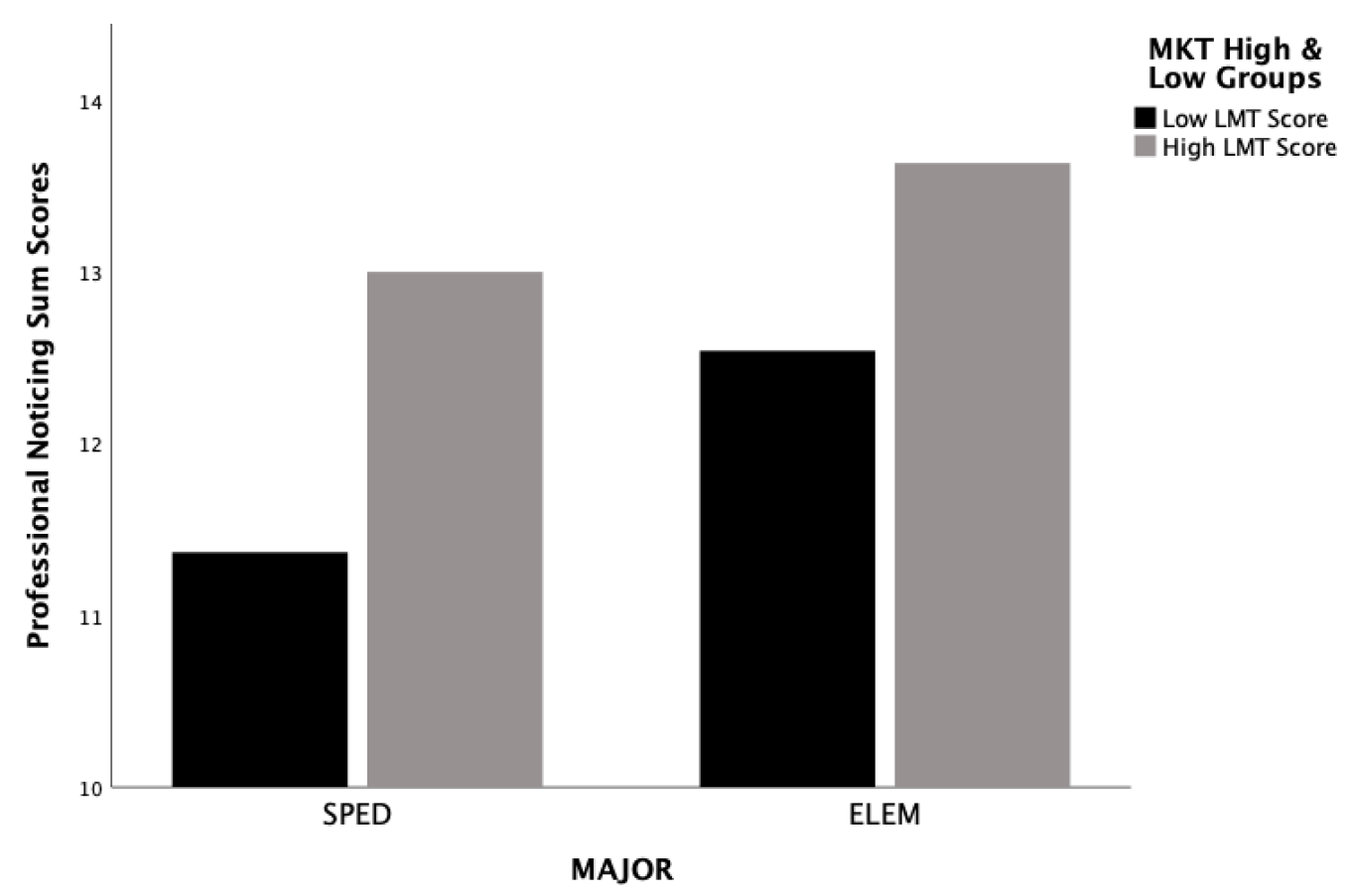

In summary. Research question one focused on pre-service teachers' content knowledge for teaching mathematics and the relationship it has with professional noticing. The researcher acknowledges first, that professional noticing and mathematical content knowledge for teaching have a significant relationship. The statistical analysis signified that students in year 2 or year 3 had better results than those in year 1; however, being a year 2 student in the program is better than being a year 3 student based on these measures. Second, although not significant, there was a trend to suggest that the score on the content knowledge for teaching mathematics may impact the demonstration of professional noticing based on number of years in the program. For example, participants who scored high on the LMT in year 3 of the program scored higher than the LMT in year 1 of the program. However, the data shows participants who scored low on the LMT in year 2 of the program scored better than participants in the high LMT category than participants in year 1 or year 3 of the program. Third, a pre-service teacher's major was not statistically significant in its relationship with content knowledge for teaching 
mathematics and professional noticing. However, the descriptive statistics indicated elementary education pre-service teachers continuously scored higher than their special education counterparts.

\section{Research Question 2. What is the relationship between pre-service teachers' beliefs and professional noticing?}

ANOVA analyses were carried out to determine if pre-service teachers' current demonstration to notice was different based on the teachers' beliefs regarding the teaching of mathematics. Participants' scores on the Mathematical Beliefs Scale (MBS) were divided into two groups with the use of a median split (DeCoster et al., 2011). As the survey was designed to indicate differences in teacher beliefs for teaching mathematics (Ren \& Smith, 2018), the two groups were identified as participants who held more student-centered views of teaching mathematics and participants holding more teacher-centered views regarding the teaching of mathematics. For the analyses, the preservice teachers were classified into two final groups: Teacher-centered $(M=12.14, S D=$ $.384, \mathrm{n}=57)$ and Student-centered $(M=12.25, S D=.382, \mathrm{n}=63)$. Demonstration of professional noticing increased for pre-service teachers holding more teacher-centered viewpoints $(M=12.14, S D=.384)$ relative to student-centered viewpoints $(M=12.25$, $S D=.382)$ (see Figure 7). The differences between the scores for these two groups were statically significant $F(1,118)=7.704, p=.006$. The statistically significant finding suggests that participants who identified more with student-centered viewpoints demonstrated more sophisticated examples of professional noticing.

\section{Figure 7}


Mean of Professional Noticing Sum Scores by Teacher Beliefs

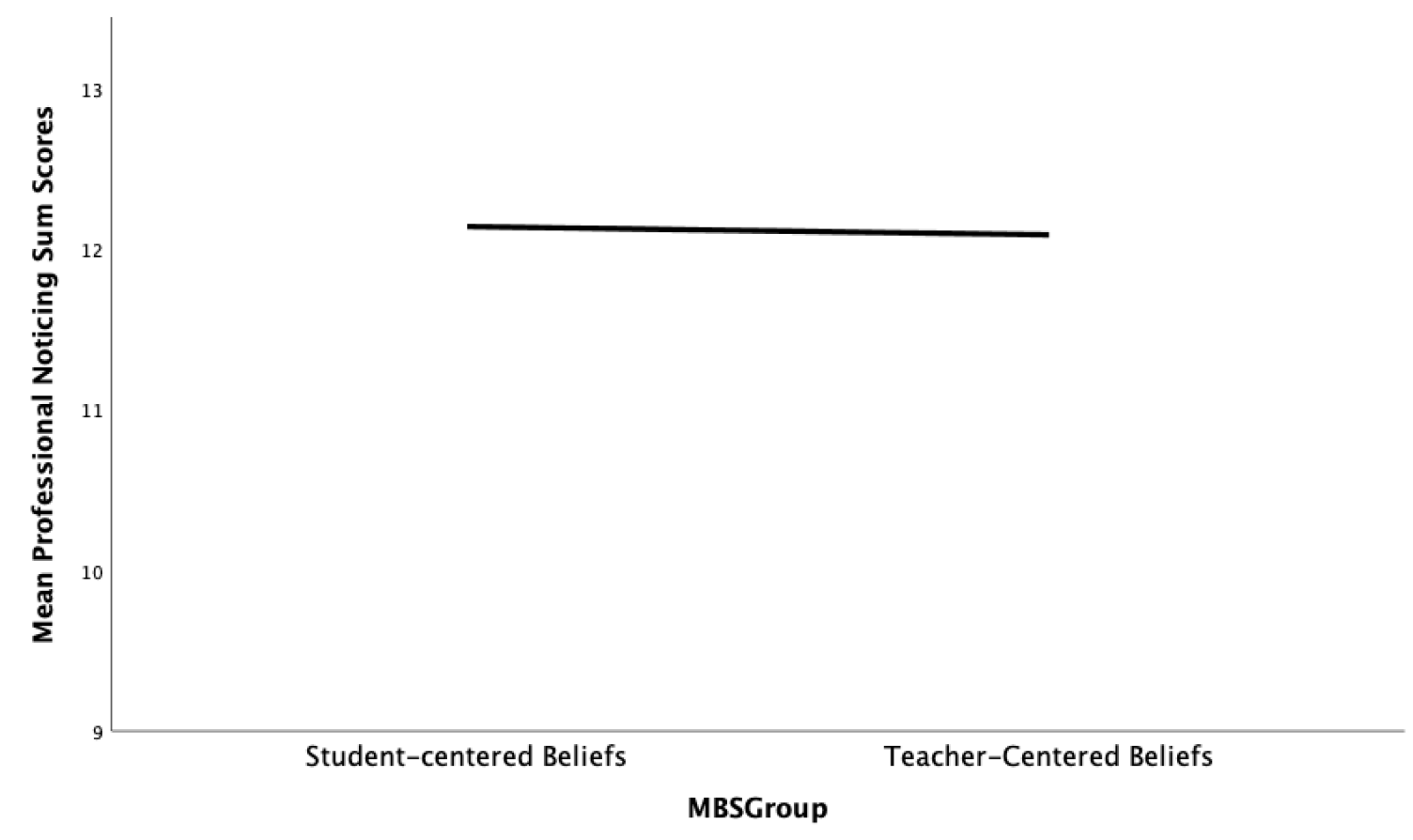

Research Question 2a. Do different years (e.g., zero, one or two methods courses) in the teacher preparation program have a significant impact on the relationship between a teachers' professional noticing and teacher beliefs for teaching mathematics?

A two-way ANOVA was conducted to examine the effects the various years in the teacher preparation program and the impact beliefs about teaching mathematics had on professional noticing. Residual analysis was performed to test for the assumptions of the two-way ANOVA. Outliers were assessed by inspection of a boxplot; normality was assessed using Shapiro-Wilk's normality test for each cell of the design and homogeneity of variances was assessed by Levene's test. There was one outlier, assessed as not being greater than 3 box-lengths from the edge of the box in a boxplot and was, therefore, kept in the data set. For the six groups, all data was normally distributed, as assessed by Shapiro-Wilk's test $(p>.05)$, except for the MBS student-centered year 2 participants ( $\mathrm{p}$ 
$<.05)$. There was homogeneity of variances, as assessed by Levene's test for equality of variances $p=.720$.

An analysis of the main effect for beliefs regarding teaching mathematics was performed (Howell, 2010). This indicated that the main effect was not statistically significant $F(1,113)=.140, p=.709$, partial $\eta^{2}=.001$. All pairwise comparisons were run where $95 \%$ confidence intervals were reported and $p$-values were Bonferroniadjusted. The unweighted marginal means of professional noticing sum scores for varying years of the program were $11.68(\mathrm{SE}=.502)$ for those in year 1 of the program, $12.89(\mathrm{SE}=.461)$ for those in year 2 of the program, and $11.70(\mathrm{SE}=.417)$ for participants in their $3^{\text {rd }}$ and final year of the program. Therefore, the correlation effect during various years in the teacher preparation program linking beliefs for teaching mathematics and professional noticing was not statistically significant $F(2,113)=$ $1.968, p=.144$, partial $\eta^{2}=.034$.

\section{Figure 8}

Professional Noticing Sum Scores by Year in Program by Teacher Beliefs 


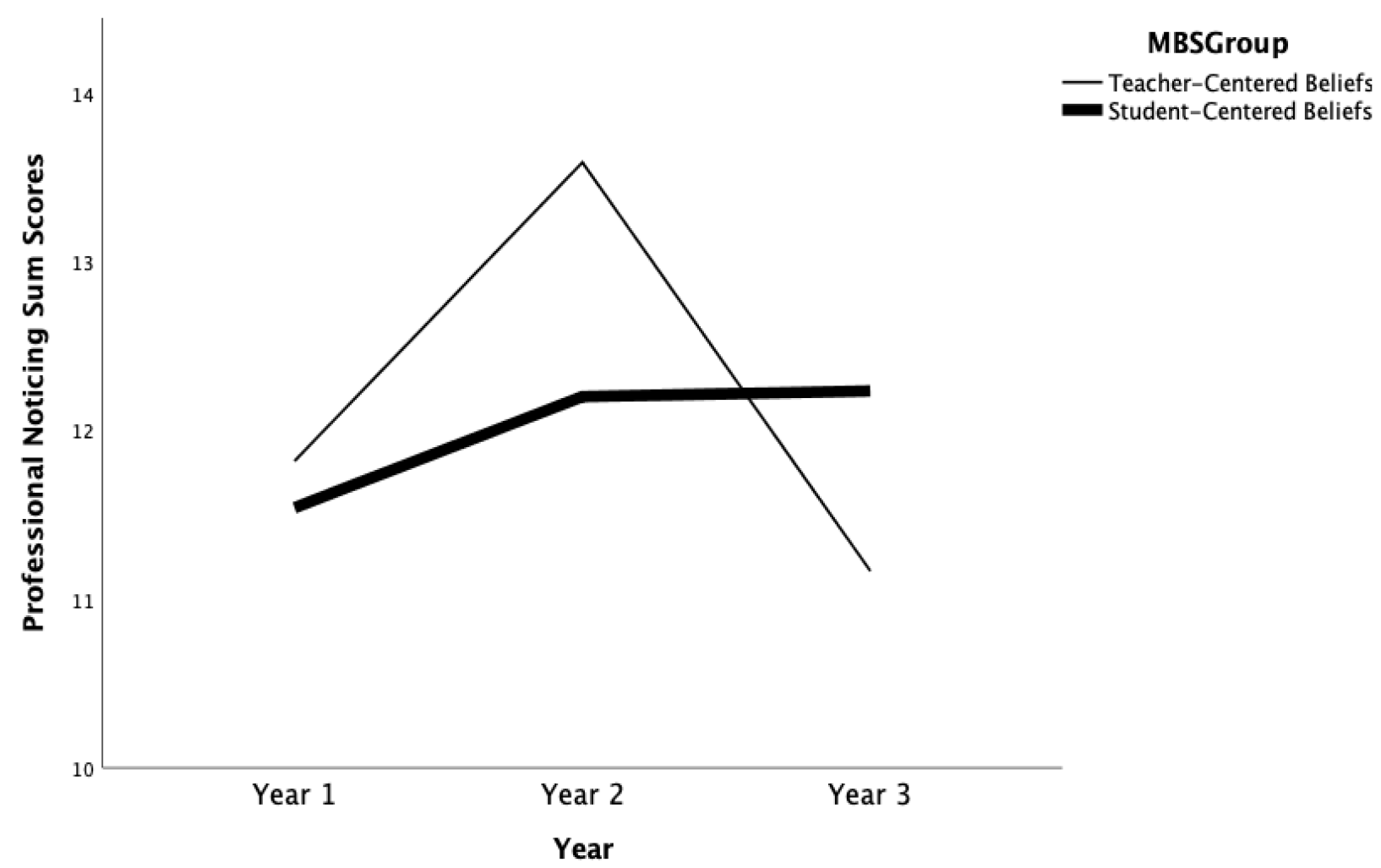

Research Question 2b. Do different majors (special education and general education) in the teacher preparation program have a significant impact on the relationship between a teachers' professional noticing and teacher beliefs for teaching mathematics?

A two-way ANOVA was conducted to examine the effects of participants' majors on their beliefs for teaching mathematics and on professional noticing. Residual analysis was performed to test for the assumptions of the two-way ANOVA. Outliers were assessed by inspection of a boxplot; normality was assessed using Shapiro-Wilk's normality test for each cell of the design and homogeneity of variances was assessed by Levene's test. There was one outlier, which was assessed as not being greater than 3 boxlengths from the edge of the box in a boxplot and was kept in the data set. For the six groups, all data were normally distributed, as assessed by Shapiro-Wilk's test $(p>.05)$ 
except elementary majors who identified as having student-centered beliefs $(p<.05)$. There was homogeneity of variances, as assessed by Levene's test for equality of variances $p=.655$.

An analysis of the main effect for beliefs about teaching mathematics was performed (Howell, 2010). The main effect was statistically significant based on the participant's major $F(1,115)=6.617, p<.05$, partial $\eta^{2}=.054$, suggesting that a participant's major did impact their demonstration of professional noticing. There was no statistically significant main effect regarding beliefs of teaching $F(1,115)=.431$, $p=.513$, partial $\eta^{2}=.004$. This suggests that although a participant's major impacted his/her demonstration of professional noticing, identification with either teacher-centered or student-centered views was not statistically impactful on the capacity for more sophisticated instances of professional noticing (see Figure 9).

\section{Figure 9}

Professional Noticing Sum Scores by Major by Teacher Beliefs

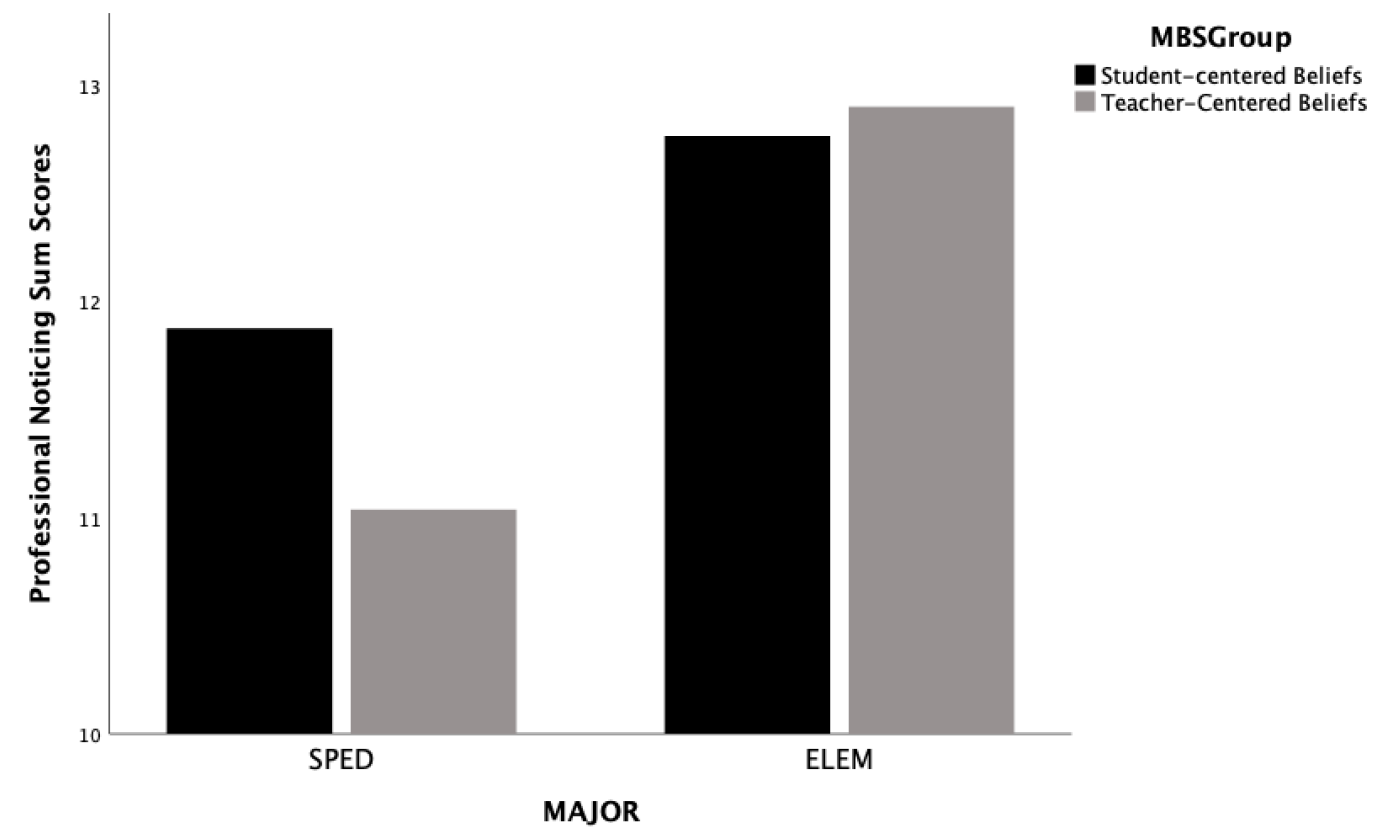


All pairwise comparisons were run where $95 \%$ confidence intervals were reported and $p$-values were Bonferroni-adjusted. The unweighted marginal means of professional noticing sum scores for participant majors were $11.46(\mathrm{SE}=.345)$ for special education majors, and $12.83(\mathrm{SE}=.409)$ for elementary education majors respectively. The interaction effect between participants' majors, beliefs about teaching mathematics and demonstration for professional noticing was not statistically significant $\mathrm{F}(1,115)=$ $.827, \mathrm{p}=.365$, partial $\eta^{2}=.007$

In summary. Research question 2 focused on the relationship between preservice teachers' beliefs on teaching mathematics and professional noticing. We note first that professional noticing scores increased when moving from pre-service teachers with more teacher-centered views to those with student-centered views. Special education majors were identified with more teacher-centered beliefs toward the teaching of mathematics which is congruent with the descriptive statistics indicating that special education majors did not demonstrate as high a level of noticing as their elementary education counterparts.

Second, we found that years in the program and type of major did not significantly impact the relationship between pre-service teachers' beliefs for teaching mathematics and their capacity for professional noticing. However, the results did indicate that participants in year 2 of the program identified the most with studentcentered beliefs on teaching mathematics.

\section{Research Question 3. Is pre-service teacher mathematical content knowledge a predictor of professional noticing?}


A linear regression was run to understand the prediction a pre-service teacher's mathematical knowledge had on professional noticing. To assess linearity, a scatterplot of LMT low and high scores against professional noticing sum scores with superimposed regression line was plotted. Residuals were normally distributed, as assessed by a DurbinWatson statistic of 1.965 . There was homoscedasticity and normality of the residuals. One participant was an outlier with a professional noticing sum score of 22. This participant was removed from the analysis due to being identified as an influential outlier after conducting a Cooks D. The prediction equation was professional noticing $=10.06+$ (1.741*LMT score). The LMT score was statistically significant for predicting professional noticing $F(1,117)=6.885, p<.05$, accounting for $5.6 \%$ of the variation in professional noticing with adjusted $R^{2}=4.8 \%$, a small size effect according to Cohen (1988).

\section{Figure 10}

Professional Noticing Sum Score by Content Knowledge of Mathematics 
Professional Noticing Sum Score by Content Knowledge of Mathematics

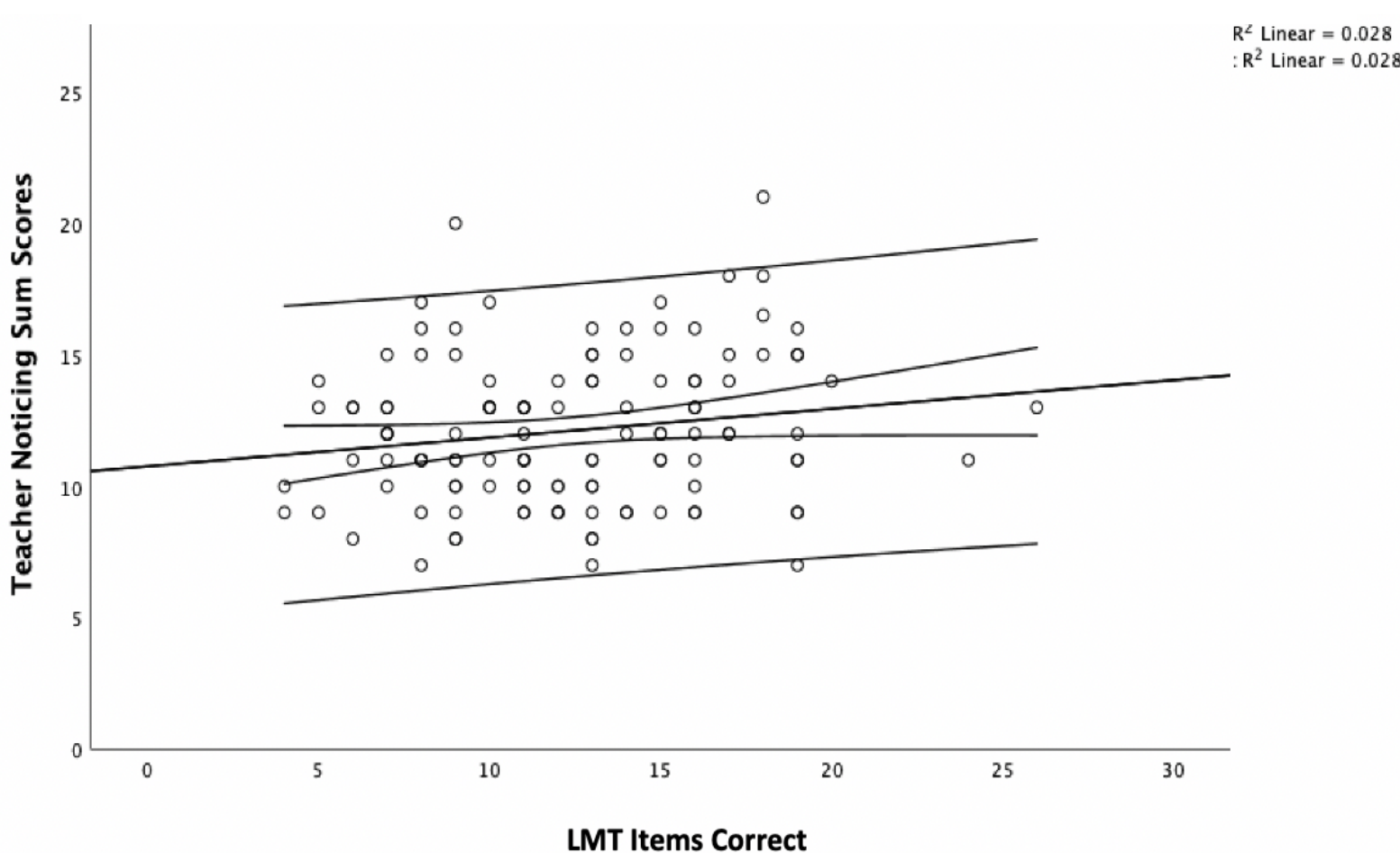

Based on the significant ANOVA results, a hierarchal regression model was calculated to examine the predictive factors associated with professional noticing (Rose $\&$ Espelage, 2012). The purpose of this analysis was to examine the predictive nature of a pre-service teacher's LMT, and MBS, based on both having provided statistically significant ANOVA results. See Table 12 for full details on each regression model. Step 1 included a dummy coded variable representing pre-service teachers' mathematical content knowledge for teaching. Both major and years in the program were included in the first model, even though years in the program did not provide statistical significance when it was included to account for the variance when exploring majors. Step 2 examined the main effect (e.g., LMT and MBS), and step 3 examined the possible interacti 
on terms of pre-service professional noticing.

Table 12.

Summary of Hierarchical Multiple Regression for Professional Noticing

\begin{tabular}{|c|c|c|c|c|}
\hline & \multicolumn{4}{|c|}{ Professional Noticing } \\
\hline & $\mathrm{B}(\mathrm{SE} B)$ & $\beta$ & $\mathrm{R}^{2}$ & $\mathrm{R}^{2} \Delta$ \\
\hline \multicolumn{5}{|l|}{ Model 1} \\
\hline Year in Program & $-.02(.31)$ & .23 & & \\
\hline \multirow[t]{2}{*}{ Major } & $1.32(.51) * *$ & -.01 & & \\
\hline & \multicolumn{2}{|c|}{ Fchange $_{(2,116)}=3.308^{*}$} & .054 & .00 \\
\hline \multicolumn{5}{|l|}{ Model 2} \\
\hline Year in Program & $-.11(.31)$ & -.03 & & \\
\hline Major & $1.49(.55) * *$ & .26 & & \\
\hline MBS & $-.06(-.15) *$ & -.22 & & \\
\hline \multirow[t]{2}{*}{ LMT } & $.13(.07) *$ & .20 & & \\
\hline & \multicolumn{2}{|c|}{ Fchange $_{(2,114)}=3.127^{*}$} & .103 & .008 \\
\hline \multicolumn{5}{|l|}{ Model 3} \\
\hline Year in Program & $-1.24(.95)$ & -.36 & & \\
\hline Major & $-2.51(3.97)$ & -.44 & & \\
\hline MBS & $-.09(.15)$ & -.50 & & \\
\hline LMT & $.01(.38)$ & .01 & & \\
\hline Major x MBS & $.08(.09)$ & .92 & & \\
\hline Year x MBS & $.02(.05)$ & .24 & & \\
\hline Year x LMT & $.09(.08)$ & .35 & & \\
\hline Major x LMT & $.02(.15)$ & .06 & & \\
\hline \multirow[t]{2}{*}{ LMT x MBS } & $.00(.01)$ & -.03 & & \\
\hline & \multicolumn{2}{|c|}{ Fchange $_{(5,109)}=.508$} & .124 & .721 \\
\hline
\end{tabular}

Note. $\mathrm{N}=119 .{ }^{*} p<.05,{ }^{* *} p<.01$

For Model 1 there was linearity as assessed by partial regression plots and a plot of studentized residuals against the predicted values. There was independence of residuals, as assessed by a Durbin-Watson statistic of 1.840. There was homoscedasticity, as assessed by visual inspection of a plot of studentized residuals versus unstandardized predicted values. There was no evidence of multicollinearity, as assessed by tolerance values greater than 0.1 . There were no studentized deleted residuals greater than \pm 3 
standard deviations, no leverage values greater than 0.2 , and values for Cook's distance above 1 . There assumption of normality was met, as assessed by Q-Q Plot.

Within Model 2, the addition of MBS and LMT scores to the prediction of professional noticing did lead to a statistically significant increase from Model 1 of majors and years in program alone in $R^{2}$ of $.073, F(2,114)=3.127 * \mathrm{p}=.014$.

A follow up to Model 2 was Model 3 that was intended to examine the statistical significance of the interaction terms between choice of major and teacher beliefs, year in the program and teacher beliefs, year in the program and mathematical knowledge for teaching, choice of major and mathematical knowledge for teaching, and mathematical knowledge for teaching and teacher beliefs as well as their predictive nature for the capacity for professional noticing. There was not a statistically significant moderator effect of professional noticing as evidenced by the addition of the interaction terms explaining an additional $12.4 \%$ of the total variance $\mathrm{p}<.769$. As such, taking into account the theoretical and practical importance of the data, the interaction terms will be kept in the multiple regression model (Warner, 2013). Model 3 that includes major, year in program, MBS, LMT score and the added interaction terms to predict professional noticing did not yield statistically significant results $R^{2}=.124, F(5,109)=.508, p>.05$; adjusted $R^{2}=.051$. With no significant findings in model 3, all statistical analysis avenues have been followed and no follow up analyses are needed (Aiken \& West, 1991; Warner, 2013).

In summary. Once the follow up research was conducted, the final model accepted for this regression model was Model 2. Model 2 held the most variance and provided the addition of MBS and LMT scores to the prediction of professional noticing. 
Overall, the model supports the idea that a pre-service teachers' major, LMT score, and MBS are all important indicators of professional noticing but that they are independent factors, that is to say, no component depends on the presence of the other. 


\section{Chapter 5}

\section{Discussion}

Students with disabilities and/or those who have difficulty learning mathematical concepts can be found in almost every classroom (Knight et al., 2008). Often, both special education and elementary education teachers are called upon to intervene and assist these struggling students (Arthaud et al., 2007; Da Fonte \& Barton-Arwood, 2017; Jordan et al., 2009). Teacher preparation programs play a vital role in ensuring that teachers are prepared to meet the challenges posed by an increasingly heterogeneous classroom environment. One of the best ways to prepare pre-service teachers for this task is by implementing strategies that support the development of their overall PCK (van Garderen et al., 2021).

The purpose of this study was to examine how professional noticing differs, depending on the teacher's year in the preparation program (measured by number of math methods courses taken), the specific major (elementary education or special education), the teacher's beliefs regarding the teaching of mathematics, and the teacher's knowledge of subject matter. The present study used data collected from elementary and special education pre-service teachers in three different years of their teacher preparation program.

Two key findings from this study have emerged. First, a teacher's mathematical content knowledge correlates positively to the sophistication of professional noticing of student mathematical thinking. Second, identifying with student-centered beliefs regarding the teaching of mathematics correlates positively to the type and sophistication of professional noticing. 


\section{Mathematical Content Knowledge is Essential}

The first significant outcome of this study was the finding there is a relationship between a teacher's content knowledge of mathematics and a heightened sophistication for professional noticing. Further, content knowledge for teaching mathematics was found to be a predictor of professional noticing. Obtained together, knowing a pre-service teachers' year in his/her program, his/her major, his/her beliefs for teaching mathematics, and his/her content knowledge for teaching mathematics all enhance the ability to predict a pre-service teacher's degree of professional noticing of student mathematical thinking.

These findings are consistent with previous literature that found specific mathematical content knowledge is critical for effective mathematics instruction (Ball et al., 2008; Ekstam et al., 2017; Kahan et al., 2003). A solid mathematical knowledge base is important for effectively implementing instructional practices for struggling students in mathematics (Maccini \& Gagnon, 2006). A robust mathematical foundation allows teachers to more accurately identify students' misconceptions and understanding of them in order to provide more targeted intervention (Griffin et al., 2009).

Descriptively, elementary education majors $(M=12.86, S D=2.68)$ and their special education major counterparts $(M=11.54, S D=2.83)$ differed as to how they scored on the 4-point rubric (see Table 5) for professional noticing. In terms of content knowledge, differences were also found. Elementary education majors had a higher number of correct items on the mathematical knowledge for teaching assessment across all three years of the program when compared with their special education counterparts (see Table 8). Although these results are not ideal, these findings reinforce outcomes in the literature that have demonstrated special education programing commonly 
emphasizes knowledge effective interventions more than content area knowledge when compared to general education programs (e.g., Brownell et al., 2005; Flores et al., 2010).

Similarly, there were noted difference not only by major but also by year in the program as well. Based on the findings from this study, more sophisticated professional noticing categories were identified as the participants content knowledge score also increased, however it should not be assumed that being further along in the teacher preparation program will automatically have a notable impact on professional noticing. When the relationship between year in preparation program professional noticing and content knowledge scores were examined, no statistically relevant correlation was found. Nevertheless, there are interesting trends in the data that are noteworthy.

Participants who were in year 2 and 3 had a higher LMT score than participants in the first year of their preparation program. This suggests that overall, years in the program can make a difference in a pre-service teacher's professional noticing (e.g., completing any number of mathematical methods courses is better than having no methods courses). Although more sophisticated categories of professional noticing were found with an increase in the LMT score, there was no evidence that LMT scores necessarily increased progressively after each year in the program. The participant group with the highest LMT and professional noticing scores were pre-service teachers in the second year of their program (e.g., 1 out of 2 methods courses completed) compared to pre-service teachers in year 3 of their program. This finding is not one that we would have anticipated. While it is not possible to determine why the trend occurred based on the data available, it may be possible that year in program had an influence. For example, the pre-service teachers in the third and final year of their program were carrying out 
their student-teaching phase of their program. Their focus may have been more on what or how of their teaching as opposed to their connections with student learning. Previous literature supports this notion in which pre-service teachers could identify teaching and learning components but struggled to apply professional knowledge to interpret and make sense of student thinking (Huang \& Li, 2012; Schafer \& Seidel, 2015). Therefore, additional attention is needed to provide the necessary support to help pre-service teachers learn to focus more on student learning when they are in the act of teaching in the field setting and outside the methods classroom.

\section{The Importance of a Teacher's Beliefs About Teaching Mathematics}

The second significant outcome resulting from the study's findings was the link between a teacher's belief score and the professional noticing score; the more studentcentered of a belief score, the more sophisticated the professional noticing. What is also noteworthy is $84 \%$ of the overall noticing topics were coded as being focused on the teachers' mathematical pedagogy while only $14 \%$ focused on students. This pattern of results is consistent with the literature indicating that the skill of attending specifically to a student's thinking strategies is likely to be the most common skill to be overlooked by pre-service teachers (Jacobs et al., 2010; Star \& Strickland; 2008). Overall, professional noticing response topics focused on the teachers' pedagogy rather than the student's behavior. Therefore, it is suggested that pre-service teachers need additional support to develop a student-centered point of view.

An important distinction found was the relationship between a participant's major and his/her beliefs or his/her sophistication of professional noticing. Although the differences were not found to be statistically significant, descriptive statistics suggested 
that a majority of elementary education majors held more student-centered viewpoints, whereas special education majors identified more with teacher-centered perspectives regarding the teaching of mathematics. These suggested findings support previous literature (Dole et al., 2016; Steele et al., 2005;) and suggest pre-service special education teachers in the current study would benefit from instructional adjustments that increase the focus on student-centered learning (e.g., Brownell et al., 2005).

A deeper investigation into the data revealed another thought-provoking result: pre-service teachers' beliefs did not change dramatically as they moved through the program. A trend was recognized (see Table 10) based on means scores revealing that as pre-service teachers had more years in the program, their beliefs did not change substantially, which differs from that found in a bank of research that affirmed that teaching experience and teacher preparation courses can influence a teachers' pPCK (e.g., Brown et al., 2013; Lannin et al., 2013; Niess et al., 2010). Other studies have also found that many pre-service teachers come to their teacher preparation program armed with a strong set of beliefs that can be difficult to change or mold (Swars et al., 2009). The literature has yielded conflicting results on pre-service teacher beliefs, as Sindelar and colleagues (2010) suggest, using the knowledge about pre-service teacher beliefs (whatever they may be or how they may change) will be important to enable teacher educators to tailor their practices to fit the needs of individual pre-service teachers. This is concerning as, ideally, pre-service teachers will utilize professional noticing to benefit student learning, but they may not utilize this practice effectively or at all if they do not believe it is within the scope of their teaching mission or that it will increase their ability to help students (Purnomo et al., 2016). 


\section{Limitations}

Although several interesting findings emerged in this study, there are limitations that need to be acknowledged. The limitations can be classified into two primary categories: (a) generalizability and (b) claims made about professional noticing. First, the data was collected from one mid-west university with one elementary and special education program. Additionally, the study was based on a relatively small sample size $(N=120)$. Given that the data source was from one university alone, the ability to make generalizations could be limited. Repetitions of this study could benefit from a larger sample size of special education pre-service teachers. A larger sample size would provide opportunities to make broader generalizations about the initial findings presented in the current study, specifically as they apply to special education majors. Although the present results found that elementary education majors outscored their special education counterparts it is appropriate to recognize that professional noticing comes from the mathematics education field and although the first two groups had similar methods courses there is no way to confirm that different experiences (i.e., practicum experiences, instructors etc.) of the participants in each major did not impact their prior knowledge of noticing. A suggestion would be to broaden the scope of special education majors to include participation in a variety of preparation programs and even a variety of certification avenues and options, as similarly done by Fisher et al (2018).

In addition, it is important to acknowledge extenuating circumstances that occurred during the data collection of this study. When making claims about the generalizability of differing years in the program it is important to note the time of data collection. Year 1 participants had data collected at the start of a new academic year in 
August of 2020 while participants in year 2 of the program had data collected in late January early February 2020. While year 3 participants' data collection occurred during the height of COVID-19 lock down. This unforeseen circumstance could have had an impact on the accuracy of the data collection for the year 3 students as well and potentially calls a need for replication of this study. Consequently, it is important to remember that findings cannot be generalized to include all pre-service teachers and should be interpreted cautiously.

Second, this study does not claim that the professional noticing protocol can precisely measure a pre-service teachers' overall ability to notice, but it merely examines pre-service teachers in a specific place and time in their preparation program to determine what they notice. The measures chosen for this study captured the pre-service teachers at stage of their knowledge and beliefs development. The professional noticing rubric measures their current demonstration of noticing. This is not to say they could not develop increased professional noticing skills with explicit instruction on the technique. A participant's current demonstration of noticing could have also been impacted by a change to the given prompt within the noticing measure. The prompt provided in this study asked for participants to examine the interaction between the teacher and student regarding the mathematical content. The prompt could have been more focused in on urging the participants to shift their focus on the student and their mathematical thinking rather than the teacher.

The choice to utilize an overall sum total for categories that identified the total point value of the noticing depth category could also be seen as a limitation to this study as it differs from Copur-Gencturk and Rodrigues, 2021. Choosing to utilize the overall 
sum score suggests that all categories are seen as comparable (e.g., teacher pedagogy $=3$ student thinking=3). Since no instruction or intervention was every provided to the participants on professional noticing the researcher used the guiding research questions to examine what and who the participants were noticing within the clips. The given study wanted to examine current pre-service teachers overall noticing as it pertains to these differing groups within a preparation program. Examining the data as a sum score for this given study could extend into future examinations of this data set by focusing in on categories of noticing based on topic.

The content knowledge measure was used to compare participants within the sample; it does not make claims as to overall teaching effectiveness or ability. Thus, claims should be interpreted cautiously. Further research might consider measuring professional noticing in different ways, such as collecting dual or multiple data points in order to analyze changes in given participants over a duration of time (Amador et al., 2021).

\section{Implications for Practice}

It should be reiterated that the goal of this study was to provide valuable insights into the demonstration of professional noticing and pPCK of different groups of preservice teachers so as to improve teacher preparation programming and better prepare future teachers. Toward this end, four main suggestions for teacher preparation programing arose from this study.

First, findings in this study suggest that the skill of professional noticing should be more explicitly interwoven into the mathematical methods courses that are taught in teacher preparation programs. This recommendation is rooted in the findings that pre- 
service teachers have room to improve their sophistication of noticing student mathematical thinking since the majority of their noticings concentrated on the teacher versus the student. The literature supports this recommendation through previous research which found professional noticing can be taught to pre-service teachers (Amador, 2016; Rooney et al., 2019; Thomas et al., 2014) therefore, incorporating noticing into methods courses can be done and would provide necessary opportunities to develop more robust professional noticing. One important aspect that supports more robust noticing is already underway by higher education course instructors who have been working diligently to incorporate a more sophisticated amount of mathematical pedagogical content knowledge into their courses (Capraro et al., 2005; Kinach, 2002; Quinn, 1997). Similarly, participants who scored higher on the LMT did exhibit a more sophisticated demonstration of professional noticing, it appears that a student's LMT score did not necessarily increase because of taking more than one methods course. This suggests that increasing a pre-service teachers' content knowledge will benefit professional noticing but that alone is not enough, and the explicit integration of professional noticing is also necessary. Thus, combining both mathematical pedagogical content knowledge and explicit opportunities to learn and practice professional noticing in methods courses will benefit the mathematical instruction of those teachers for years to come.

Clearly, a teacher's PCK of specific content knowledge is critical for high quality teaching and it appears to also increase a teacher's professional noticing skills. This suggests that both elementary education and special education methods courses need to be carefully designed so as to support a pre-service teacher's growth both in content 
knowledge for teaching mathematics and for professional noticing. This would allow preservice teachers to become more familiar with the technique, hence increasing their effectiveness with the practice. This would in turn increase the likelihood they would utilize the skill in their classroom. These results are consistent with the assertion that preservice teachers need the opportunity to synthesize professional noticing and content knowledge in order to enhance instructional responsiveness (Thomas et al., 2017). In other words, pre-service teachers need to learn not only how to notice an event (Sherin et al., 2011) using their content knowledge, but they must also learn how to properly make an instructional decision based on what they observe.

A second implication based on the findings is the need to foster increased attention on the learner during mathematics education courses. Both special and elementary education pre-service teachers scored much higher in the area of professional noticing as it related to the pedagogy, the teacher, of mathematics as opposed to the student's mathematical thinking. Given the evidence that the role of attending to children's thinking strategies is a foundational skill for learning how to interpret and respond to pedagogical situations (Sherin et al., 2011), teacher preparation instructors and curriculum designers should consider implementing techniques or placing greater emphasis on techniques that actively develop skills to attend to a student's thinking strategies (Jacobs et al., 2010; Star \& Strickland; 2008).

A third implication revealed in the current study is if we are to improve pedagogical training, we need balanced and focused teacher preparation programs created specifically for special education majors. A closer investigation of the data indicates that elementary education majors in this sample outscored their special education counterparts 
on both the LMT measure and the professional noticing rubric in all three years of the program. The reasons for this difference are somewhat perplexing in that prior to year 3 in the program, students in both majors were enrolled in either no mathematics methods courses or had the same number of mathematics methods courses.

While it is not possible at this juncture to determine the differences between the two types of majors, an initial concern is that most special education pre-service teachers are licensed to teach in $\mathrm{K}-12$ settings and are called upon to respond to a variety of student needs (Geiger et al., 2014). Elementary education majors, on the other hand, focus only on K-5. Leko and colleagues (2015) argue that these broad licensing patterns have resulted in special education preparation programs that are designed to accomplish multiple goals: prepare teachers to provide instruction to students across multiple content areas and grade levels, co-teach with general education teachers, and collaborate with parents. These goals are intended to be accomplished with the same number of courses and years in the program as a general education certification programs that do not entail as broad a scope. Accomplishing high quality instruction while maintaining such a broad focus and staying within the limited time frame of teacher preparation programming presents challenges for any teacher preparation program. This study supports previous recommendations that special education programming needs to be as focused and balanced as possible to meet the needs of our pre-service teachers.

Fourth, and finally, these results support a call made by Brownell et al., (2005) to implement an approach to teacher preparation that supports the collective development of multiple knowledge bases. As elementary participants in this study exhibited more student-centered (as opposed to teacher-centered) beliefs than compared to their special 
education counterparts. Suggesting that elementary pre-service teachers may receive more instruction supporting the notion of obtaining knowledge from multiple outlets. As general education programs commonly focus on specific content pedagogy where students are held as the main source of knowledge, whereas in special education programs focus on more generic pedagogy (e.g., instruction methods, assessment; Brownell et al., 2005) that originates from the teacher as the main source of knowledge. Participants in this sample who identified more with student-centered views toward the teaching of mathematics were more likely to score higher on the professional noticing rubric and LMT. These results are consistent with Swars et al., (2009) who found that those pre-service teachers who had more specialized content knowledge for teaching mathematics were more likely to believe that children could take more responsibility for developing their own mathematical knowledge. These findings may not be surprising as there are often philosophical differences in programs that may contribute to these differences in focus. Both the results from this study along with findings from Swars and colleagues (2009) are consistent with the recommendation from Brownell and colleagues (2005) that teacher preparation programs should view teacher learning as the collective examination of multiple knowledge bases, including, but not limited to, knowledge generated by experts (e.g., the teacher). Brownell et al., (2005) argues for teacher preparation programs that encourage pre-service teachers to reflect on their instruction, integrate prior knowledge with new information provided by coursework, and examine their own beliefs about instruction in addition to the knowledge provided explicitly from the instructor. Therefore, it would perhaps be useful for teacher education programs to incorporate explicit discussions and reflections on the collective 
development of multiple knowledge bases as a means for both receiving and delivering knowledge.

\section{Future Research}

The current study has expanded on current understanding of pre-service teachers' pedagogical formation by expanding the population of pre-service teachers that had been previously investigated (e.g., Jacobs et al., 2010; Thomas et al., 2017). Nonetheless, further research needs to be pursued. Previous researchers have worked to identify critical components of professional noticing (Sherin et al., 2008; Sherin et al., 2011), create scoring rubrics for measuring professional noticing (Copur-Gencturk \& Rodrigues., 2021), and work with in-service teachers to increase professional noticing (van Es and Sherin, 2008). Iterations of the current study could strengthen these previously reported findings in three specific ways.

First, as also suggested by Amador and colleagues (2021), a longitudinal study focusing on the growth of a single group of pre-service teachers and how their ability for professional noticing developed over time are almost absent from the bank of literature. Future longitudinal work would provide an opportunity to incorporate the attention needed to provide necessary supports for pre-service teachers, support that would focus more on student learning while they are engaged in act of teaching. It would also be beneficial to follow one group of pre-service teachers (or the same group) throughout their programing and into their early years in the classroom. By utilizing methods courses as a means to follow the pre-service teachers could be used as done by previous researchers (e.g., Goldsmith \& Seago, 2011; Jacobs et al., 2010; Star and Strickland, 2008; Tyminski et al., 2015; Ulusoy, 2020). 
A longitudinal study would cover a possible cohort group effect from the current study. As it is impossible to claim but could be possible that differing years of the program in the current study just didn't notice as well as other groups throughout the entirety of the program. If this would have been found through a longitudinal study it wouldn't answer the question of if being 'current' in your methods course will assist the pre-service teachers in noticing more robustly or if it was found to be a cohort group effect. A study such as this would also encourage continued research around a preservice/novice teacher's overall PCK by beginning to examine their ePCK of professional noticing while in the classroom with students.

Second, as this study was the first to include special education majors, it would be beneficial to extend the current findings into the special education field by beginning to examine how professional noticing can support special education teachers. As recently suggested by Amador et al., (2021), the professional noticing literature bank is robust in mathematics education and researchers in other disciplines should consider intervention designs to support noticing in their students' coursework. Specifically, we need to examine to what extent professional noticing benefits what is currently taught regarding DBI and use of CBMs. As suggested by several researchers in the field of special education, special education teachers need to have a strong PCK that includes strong knowledge of content and how to teach it, a solid understanding of the specific problems that students with disabilities may experience in the content area, and knowledge of research-based practices for students with disabilities (Brownell et al., 2010; van Garderen et al. 2021). This could be accomplished through an intervention study in a special education mathematics methods course since it has been suggested that this is 
where the development of content and pedagogy are most likely to intersect (Grossman, 1990).

Third, and final, it would be beneficial to provide the ever-growing literature with a study that directly measures a teacher use of professional noticing and student outcomes. A study such as this could be conducted for students with and without disabilities and it is currently missing from the literature. It would continue to strengthen the argument for incorporating the skill within teacher preparation programs and justify the continued use within classrooms.

\section{Conclusion}

Inclusive classrooms have become the norm in many schools (National Center for Education Statistics, 2020). The responsibilities and roles of general and special education educators have shifted, blurring the conventionally held boundaries between special education and general education practices (Brownell et al., 2010; Shepherd et al., 2016). Thus, an increased number of students with disabilities will receive their core content instruction, including mathematical instruction, from both general and special education teachers, and in a general education environment. Preparing all pre-service teachers to have the high-quality skills needed to intervene with students taking mathematics courses is critical for student success. Increasing a pre-service teacher's overall $\mathrm{PCK}$ is a component that can be developed during pre-service preparation (Aydeniz et al., 2014). The current research will stimulate further investigation into ways we can best prepare pre-service teachers in both the special education and elementary education arenas. 
Overall, the present study fills an important gap in the literature by including, for the first-time, special education majors within the sample for measuring professional noticing. Thus, it sheds light on the differing relationship between special education and elementary education majors. Although questions about how professional noticing might be included within already existing special education frameworks still remain, it is clear these skills can be used by special education teachers. Furthermore, the present study provides additional evidence that all pre-service teachers must put the learner at the center of mathematics teaching. While additional work is needed to enhance the ability to make generalizations that would apply to the special education teacher population, this work provides important information relative to the components needed for developing professional noticing in our pre-service teachers. 


\section{References}

Aiken, L. S., \& West, S. G. (1991). Multiple regression: Testing and interpreting interactions. Thousand Oaks, CA: Sage Publications.

Amador, J. (2016). Professional noticing practices of pre-service mathematics teacher educators. International Journal of Science and Mathematics Education, 14(1), 217-241.

Amador, J. M., Bragelman, J., \& Superfine, A. C. (2021). Prospective teachers' noticing: A literature review of methodological approaches to support and analyze noticing. Teaching and Teacher Education, 99, 103256.

Anantharajan, M. (2020). Teacher Noticing of Mathematical Thinking in Young Children's Representations of Counting. Journal for Research in Mathematics Education, 51(3), 268-300. https://doi.org/10.5951/jresemtheduc-2019-0068

Arthaud, T. J., Aram, R. J., Breck, S. E., Doelling, J. E., \& Bushrow, K. M. (2007). Developing collaboration skills in pre-service teachers: A partnership between general and special education. Teacher Education and Special Education, 30(1),

\section{1-12. https://doi.org/10.1177/088840640703000101}

Aydeniz, M., \& Kirbulut, Z. D. (2014). Exploring challenges of assessing pre-service science teachers' pedagogical content knowledge (PCK). Asia-Pacific Journal of Teacher Education, 42(2), 147-166.

\section{https://doi.org/10.1080/1359866X.2014.890696}

Ball, D.L., \& Bass, H. (2009). With an eye on the mathematical horizon: Knowing mathematics for teaching to learners' mathematical futures. Paper presented at the The 2009 Curtis Center Mathematics and Teaching Conference. 
Ball, D. L., Hill, H.C, \& Bass, H. (2005). Knowing mathematics for teaching: Who knows mathematics well enough to teach third grade, and how can we decide? American Educator, 29(1), pp. 14-17, 20-22, 43-46.

Ball, D. L., Sleep, L., Boerst, T. A., \& Bass, H. (2009). Combining the development of practice and the practice of development in teacher education. The Elementary School Journal, 109(5), 458-474.

Ball, D. L., Thames, M. H., \& Phelps, G. (2008). Content knowledge for teaching: What makes it special? Journal for Teacher Education, 59(5), 389-407. https://doi.org/10.1177/0022487108324554

Barnhart, T., \& van Es, E. (2015). Studying teacher noticing: Examining the relationship among pre-service science teachers' ability to attend, analyze and respond to student thinking. Teaching and Teacher Education, 45, 83-93. https://doi.org/10.1016/j.tate.2014.09.005

Beswick, K. (2006). Changes in preservice teachers' attitudes and beliefs: The net impact of two mathematics education units and intervening experiences. School Science and Mathematics, 106(1), 36-47. https://doi.org/10.1111/j.19498594.2006.tb18069.x

Boudah, D. J., Deshler, D. D., Schumaker, J. B., Lenz, B. K., \& Cook, B. (1997). Student-centered or content-centered? A case study of a middle school teacher's lesson planning and instruction in inclusive classes. Teacher Education and Special Education, 20(3), 189-203. https://doi.org/10.1177/088840649702000302 
Boyd, B., \& Bargerhuff, M. E. (2009). Mathematics education and special education: Searching for common ground and the implications for teacher education. Mathematics Teacher Education and Development, 11, 54-67.

Bransford, J. D., Brown, A. L., \& Cocking, R. R. (2000). How people learn: Brain. Mind. Briley, J. S. (2012). The Relationships among Mathematics Teaching Efficacy, Mathematics Self-Efficacy, and Mathematical Beliefs for Elementary Pre-Service Teachers. Issues in the undergraduate mathematics preparation of school teachers, 5 .

Brown, J. S., Collins, A., \& Duguid, P. (1989). Situated cognition and the culture of learning. Educational Researcher, 18(1), 32-42. https://doi.org/10.3102/0013189X018001032

Brown, P., Friedrichsen, P., \& Abell, S. (2013). The development of prospective secondary biology teachers PCK. Journal of Science Teacher Education, 24(1), 133-155. https://doi.org/10.1007/s10972-012-9312-1

Brownell, M. T., Benedict, A. E., Leko, M. M., Peyton, D., Pua, D., \& Richards-Tutor, C. (2019). A continuum of pedagogies for preparing teachers to use high-leverage practices. Remedial and Special Education, 40(6), 338-355. https://doi.org/10.1177/0741932518824990

Brownell, M. T., Ross, D. D., Colón, E. P., \& McCallum, C. L. (2005). Critical features of special education teacher preparation: A comparison with general teacher education. The Journal of Special Education, 38(4), 242-252. https://doi.org/10.1177/00224669050380040601 
Brownell, M. T., Sindelar, P. T., Kiely, M. T., \& Danielson, L. C. (2010). Special education teacher quality and preparation: Exposing foundations, constructing a new model. Exceptional Children, 76(3), 357-377. https://doi.org/10.1177/001440291007600307

Bryan, T. J. (1999). The conceptual knowledge of preservice secondary mathematics teachers: How well do they know the subject matter they will teach. Issues in the undergraduate mathematics preparation of school teachers: The journal, l(January), 1-12.

Bryant, D. P., Bryant, B. R., Gersten, R. M., Scammacca, N. N., Funk, C., Winter, A., ... \& Pool, C. (2008). The effects of tier 2 intervention on the mathematics performance of first-grade students who are at risk for mathematics difficulties. Learning Disability Quarterly, 31(2), 47-63. https://doi.org/10.2307/20528817

Burton, D., \& Pace, D. (2009). Preparing pre-service teachers to teach mathematics in inclusive classrooms: A three-year case study. School Science and Mathematics, 109(2), 108-115. https://doi.org/10.1111/j.1949-8594.2009.tb17943.x

Cady, J., Meier, S. L., \& Lubinski, C. A. (2006). The mathematical tale of two teachers: A longitudinal study relating mathematics instructional practices to level of intellectual development. Mathematics Education Research Journal, 18(1), 3-26. https://doi.org/10.1007/BF03217427 
Campbell, P. F., \& Malkus, N. N. (2014). The mathematical knowledge and beliefs of elementary mathematics specialist-coaches. ZDM, 46(2), 213-225. https://doi.org/10.1007/s11858-013-0559-6

Campbell, M. R., \& Thompson, L. K. (2007). Perceived concerns of preservice music education teachers: A cross-sectional study. Journal of Research in Music Education, 55(2), 162-176. https://doi.org/10.1177/002242940705500206

Capraro, M. M. (2001). Construct Validation and a More Parsimonious Mathematics Beliefs Scales.

Capraro, R. M., Capraro, M. M., Parker, D., Kulm, G., \& Raulerson, T. (2005). The mathematics content knowledge role in developing preservice teachers' pedagogical content knowledge. Journal of Research in Childhood Education, 20(2), 102-118. https://doi.org/10.1080/02568540509594555

Carlson, J., \& Daehler, K. R. (2019). The refined consensus model of pedagogical content knowledge in science education. In Repositioning pedagogical content knowledge in teachers' knowledge for teaching science (pp. 77-92). Springer, Singapore. https://doi.org/10.1007/978-981-13-5898-2_15

Carter, K., Cushing, K., Sabers, D., Stein, P., \& Berliner, D. (1988). Expert-pre-service differences in perceiving and processing visual classroom information. Journal of Teacher Education, 39(3), 25-31. https://doi.org/10.1177/002248718803900306

Carter, G., \& Norwood, K. S. (1997). The relationship between teacher and student beliefs about mathematics. School Science and Mathematics, 97(2), 62-67. https://doi.org/10.1111/j.1949-8594.1997.tb17344.x 
Civitillo, S., Juang, L. P., \& Schachner, M. K. (2018). Challenging beliefs about cultural diversity in education: A synthesis and critical review of trainings with preservice teachers. Educational Research Review, 24, 67-83. https://doi.org/10.1016/j.edurev.2018.01.003

Cohen, J. (1988). Statistical power analysis for the behavioral sciences (2nd ed.). New York: Psychology Press.

Copur-Gencturk, Y., \& Rodrigues, J. (2021). Content-specific noticing: A large-scale survey of mathematics teachers' noticing. Teaching and Teacher Education, 101, 103320. https://doi.org/10.1016/j.tate.2021.103320

Da Fonte, M. A., \& Barton-Arwood, S. M. (2017). Collaboration of general and special education teachers: Perspectives and strategies. Intervention in School and Clinic, 53(2), 99-106. https://doi.org/10.1177/1053451217693370

Darling-Hammond, L. (2000). Teacher quality and student achievement. Education policy analysis archives, 8, 1. https://doi.org/10.14507/epaa.v8n1.2000

DeCoster, J., Gallucci, M., \& Iselin, A. M. R. (2011). Best practices for using median splits, artificial categorization, and their continuous alternatives. Journal of experimental psychopathology, 2(2), 197-209. https://doi.org/10.5127/jep.008310

DeSimone, J. R., \& Parmar, R. S. (2006). Issues and challenges for middle school mathematics teachers in inclusion classrooms. School Science and Mathematics, 106(8), 338-348. https://doi.org/10.1111/j.1949-8594.2006.tb17754.x

Dewey, J. (1933). Philosophy and civilization. 
de Vries, S., Van De Grift, W. J., \& Jansen, E. P. (2013). Teachers' beliefs and continuing professional development. Journal of Educational Administration, 51(2), 213-231. https://doi.org/10.1108/09578231311304715

Doabler, C. T., \& Fien, H. (2013). Explicit mathematics instruction: What teachers can do for teaching students with mathematics difficulties. Intervention in School and Clinic, 48(5), 276-285. https://doi.org/10.1177/1053451212473151

Dole, S., Bloom, L., \& Kowalske, K. (2016). Transforming pedagogy: Changing perspectives from teacher-centered to learner-centered. Interdisciplinary Journal of Problem-Based Learning, 10(1), 1.https://doi.org/10.7771/1541-5015.1538

Donovan, M. S., \& Bransford, J. D. (Eds.) (2005). How students learn. Washington, DC: National Academies Press.

Ekstam, U., Korhonen, J., Linnanmäki, K., \& Aunio, P. (2017). Special education preservice teachers' interest, subject knowledge, and teacher efficacy beliefs in mathematics. Teaching and Teacher Education, 63, 338-345. https://doi.org/10.1016/j.tate.2017.01.009

Empson, S (2019) Learning and Teaching Geometry and Measurement in Elementary Schools [Syllabus]. Mathematics Department, University of Missouri.

Enochs, L. G., Smith, P. L., \& Huinker, D. (2000). Establishing factorial validity of the mathematics teaching efficacy beliefs instrument. School Science and mathematics, 100(4), 194-202. https://doi.org/10.1111/j.1949$\underline{8594.2000 . t b 17256 . x}$

Ernst, C., \& Rogers, M. R. (2009). Development of the inclusion attitude scale for high school teachers. Journal of Applied School Psychology, 25(3), 305-322. 


\section{https://doi.org/10.1080/15377900802487235}

Feng, L., \& Sass, T. R. (2010). What Makes Special Education Teachers Special? Teacher Training and Achievement of Students with Disabilities. Working Paper 49. National Center for Analysis of Longitudinal Data in Education Research.

Fisher, M. H., Thomas, J., Schack, E. O., Jong, C., Tassell, J. (2018, online first). Noticing Numeracy Now! Examining Changes in Preservice Teachers' Noticing, Knowledge, and Attitudes. Mathematics Education Research Journal. https://oi.org/10.1007/s13394-017-0228-0

Fives, H. (2003, April). What is teacher efficacy and how does it relate to teachers' knowledge? A theoretical review. In American Educational Research Association Annual Conference, Chicago.

Flores, M. M., Patterson, D., Shippen, M. E., Hinton, V., \& Franklin, T. M. (2010). Special Education and General Education Teachers' Knowledge and Perceived Teaching Competence in Mathematics. Issues in the Undergraduate Mathematics Preparation of School Teachers, 1.

Fox, J. (2008). Applied regression analysis and generalized linear models (2nd ed.). Thousand Oaks, CA: Sage Publications.

Franke, M. L., Kazemi, E., \& Battey, D. (2007). Mathematics teaching and classroom practice. Second handbook of research on mathematics teaching and learning, 1(1), 225-256.

Fuchs, L. S., Fuchs, D., \& Phillips, N. (1994). The relation between teachers' beliefs about the importance of good student work habits, teacher planning, and student 
achievement. The Elementary School Journal, 94(3), 331-345.

https://doi.org/10.1086/461770

Fuchs, L. S., Hamlett, D. F. C. L., \& Stecker, P. M. (1991). Effects of curriculum-based measurement and consultation on teacher planning and student achievement in mathematics operations. American educational research journal, 28(3), 617-641. https://doi.org/10.3102/00028312028003617

Geiger, W. L., Mickelson, A., McKeown, D., Barton, J., Kleinhammer-Tramill, J., \& Steinbrecher, T. (2014). Patterns of licensure for special education teachers. Handbook of research on special education teacher preparation, 30-46.

Gersten, R., \& Dimino, J. A. (2006). RTI (Response to Intervention): Rethinking special education for students with reading difficulties (yet again). Reading Research Quarterly, 41(1), 99-108. https://doi.org/10.1598/RRQ.41.1.5

Ghazali, M., \& Sinnakaudan, S. (2014). Reasearch on teachers' beliefs about mathematics teaching and learning between Sekolah Kebangsaan (SK), Sekolah Jenis Kebangsaan Cina (SJKC) and Sekolah Jenis Kebangsaan Tamil (SJKT). Journal of Education and Practice, 5(31), 10-19.

Goldsmith, L. T., \& Seago, N. (2011). Using classroom artifacts to focus teachers' noticing. In M. G. Sherin, V. R. Jacobs, \& R. A. Philipp (Eds.), Mathematics teacher noticing: Seeing through teachers' eyes (pp. 169-187). New York, NY: Routledge.

Grierson, A. L. (2010). Changing conceptions of effective teacher education: The journey of a pre-service teacher educator. Studying Teacher Education, 6(1), 3-15. https://doi.org/10.1080/17425961003668898 
Griffin, C. C., Jitendra, A. K., \& League, M. B. (2009). Pre-service special educators' instructional practices, communication patterns, and content knowledge for teaching mathematics. Teacher Education and Special Education, 32(4), 319-336. https://doi.org/10.1177/0888406409343540

Grossman, P. L. (1990). The making of a teacher: Teacher knowledge and teacher education. NewYork: Teachers College Press.

Hall, L. A. (2005). Teachers and content area reading: Attitudes, beliefs and change. Teaching and teacher Education, 21(4), 403-414. https://doi.org/10.1016/j.tate.2005.01.009

Haltiwanger, L., \& Simpson, A. (2014). Secondary mathematics preservice teachers' noticing of students' mathematical thinking. Paper presented at the Proceedings of the 41st annual meeting of the Research Council on Mathematics Learning.

Hastings, R. P., \& Oakford, S. (2003). Student teachers' attitudes towards the inclusion of children with special needs. Educational psychology, 23(1), 87-94. https://doi.org/10.1080/01443410303223

Hiebert, J., Berk, D., \& Miller, E. (2017). Relationships between mathematics teacher preparation and graduates' analyses of classroom teaching. The Elementary School Journal, 117(4), 687-707. https://doi.org/10.1086/691685

Hill, H. C., Ball, D. L., \& Schilling, S. G. (2008). Unpacking pedagogical content knowledge: Conceptualizing and measuring teachers' topic-specific knowledge of students. Journal for Research in Mathematics Education, 372-400. https://doi.org/10.5951/jresematheduc.39.4.0372 
Hill, H. C., Charalambous, C. Y., Blazar, D., McGinn, D., Kraft, M. A., Beisiegel, M., ... \& Lynch, K. (2012). Validating arguments for observational instruments: Attending to multiple sources of variation. Educational Assessment, 17(2-3), 88106. https://doi.org/10.1080/10627197.2012.715019

Hill, H. C., \& Chin, M. (2018). Connections between teachers' knowledge of students, instruction, and achievement outcomes. American Educational Research Journal, 55(5), 1076-1112. https://doi.org/10.3102/0002831218769614

Hill, H. C., Rowan, B., \& Ball, D. L. (2005). Effects of teachers' mathematical knowledge for teaching on student achievement. American Educational Research Journal, 42(2), 371-406.

Hill, H. (2004, February). Summary of Technical Information. Retrieved November 2019, from http://www.umich.edu/ 1mtweb/research.html.

Hill, H. C., Schilling, S. G., \& Ball, D. L. (2004). Developing measures of teachers' mathematics knowledge for teaching. The Elementary School Journal, 105(1), 1130. https://doi.org/10.3102/00028312042002371

Hine, G. S. (2015). Strengthening pre-service teachers' mathematical content knowledge. Journal of University Teaching \& Learning Practice, 12(4), 5.

Hogan, T., Rabinowitz, M., \& Craven III, J. A. (2003). Representation in teaching: Inferences from research of expert and novice teachers. Educational Psychologist, 38(4), 235-247. https://doi.org/10.1207/S15326985EP3804_3

Hosp, M. K., \& Hosp, J. L. (2003). Curriculum-based measurement for reading, spelling, and math: How to do it and why. Preventing School Failure: Alternative Education for Children and Youth, 48(1), 10-17. 
https://doi.org/10.1080/1045988X.2003.10871074

Howell, D. C. (2010). Statistical methods for psychology (7th ed., international edition). Belmont, CA: Wadsworth, Cengage Learning.

Huang, R., \& Li, Y. (2012). What matters most: A comparison of expert and pre-service teachers' noticing of mathematics classroom events. School Science and Mathematics, 112(7), 420-432. https://doi.org/10.1111/j.1949-8594.2012.00161.x

Hume, A., \& Berry, A. (2011). Constructing CoRes - a strategy for building PCK in preservice science teacher education. Research in Science Education, 41(3), 341-355. https://doi.org/10.1007/s11165-010-9168-3

Hume, A., Cooper, R., \& Borowski, A. (2019). Repositioning Pedagogical Content Knowledge in Teachers' Knowledge for Teaching Science. Springer.

Hunt, J. H., \& Little, M. E. (2014). Intensifying interventions for students by identifying and remediating conceptual understandings in mathematics. Teaching Exceptional Children, 46(6), 187-196. https://doi.org/10.1177/0040059914534617

Hunt, J., \& Tzur, R. (2017). Where is difference? Processes of mathematical remediation through a constructivist lens. The Journal of Mathematical Behavior, 48, 62-76. https://doi.org/10.1016/j.jmathb.2017.06.007

Individuals with Disabilities Education Act, 20 U.S.C. §§ 1400-1482 (2004).

Iversen, G. R., \& Norpoth, H. (1987). Analysis of variance. Thousand Oaks, CA: Sage Publications.

OSEP Center on Positive Behavioral Interventions, Sugai, G., Horner, R. H., Dunlap, G., Hieneman, M., Lewis, T. J., . . Sailor, W. (2000). Applying positive behavior support and functional behavioral assessment in schools. Journal of Positive 
Behavior Interventions, 2(3), 131-143.

https://doi.org/10.1177/109830070000200302

Jaccard, J. (1998). Interaction effects in factorial analysis of variance. Thousand Oaks, CA: Sage Publications.

Jacobs, V. R., Lamb, L. L., \& Philipp, R. A. (2010). Professional noticing of children's mathematical thinking. Journal for Research in Mathematics Education, 169-202. https://doi.org/10.5951/jresematheduc.41.2.0169

Jenkins, J. R., Antil, L. R., Wayne, S. K., \& Vadasy, P. F. (2003). How cooperative learning works for special education and remedial students. Exceptional children, 69(3), 279-292. https://doi.org/10.1177/001440290306900302

Jonsson, A., \& Svingby, G. (2007). The use of scoring rubrics: Reliability, validity and educational consequences. Educational research review, 2(2), 130-144. https://doi.org/10.1016/j.edurev.2007.05.002

Jordan, A., Schwartz, E., \& McGhie-Richmond, D. (2009). Preparing teachers for inclusive classrooms. Teaching and Teacher Education, 25(4), 535-542. https://doi.org/10.1016/j.tate.2009.02.010

Jung, P. G., McMaster, K. L., Kunkel, A. K., Shin, J., \& Stecker, P. M. (2018). Effects of data-based individualization for students with intensive learning needs: A metaanalysis. Learning Disabilities Research \& Practice, 33(3), 144-155. https://doi.org/10.1111/ldrp.12172

Kahan, J. A., Cooper, D. A., \& Bethea, K. A. (2003). The role of mathematics teachers' content knowledge in their teaching: A framework for research applied to a study of student teachers. Journal of mathematics teacher education, 6(3), 223-252. 
https://doi.org/10.1023/A:1025175812582

Kersting, N. (2008). Using video clips of mathematics classroom instruction as item prompts to measure teachers' knowledge of teaching mathematics. Educational and Psychological Measurement, 68(5), 845-861. https://oi.org/10.1177/0013164407313369

Kersting, N. B., Givvin, K. B., Sotelo, F. L., \& Stigler, J. W. (2010). Teachers' analyses of classroom video predict student learning of mathematics: Further explorations of a novel measure of teacher knowledge. Journal of Teacher Education, 61(1-2), 172-181. https://doi.org/10.1177/0022487109347875

Kilpatrick, J., Swafford, J., \& Findell, B. (Eds.). (2001). Adding it up: Helping children learn mathematics. Washington, DC: National Academy Press

Kinach, B. M. (2002). A cognitive strategy for developing pedagogical content knowledge in the secondary mathematics methods course: Toward a model of effective practice. Teaching and teacher education, 18(1), 51-71. https://doi.org/10.1016/S0742-051X(01)00050-6

Klehm, M. (2014). The effects of teacher beliefs on teaching practices and achievement of students with disabilities. Teacher Education and Special Education, 37(3), 216-240. https://doi.org/10.1177/0888406414525050

Knight, B. A., Bellert, A., \& Graham, L. (2008). General classroom strategies to enhance the inclusion of students with learning difficulties. In C. Forlin \& M.-G. J. Lian (Eds.), Reform, inclusion \& teacher education: Towards a new era of special \& inclusive education in Asia-Pacific Regions (pp. 169-186). New York, NY: Routledge. 
Kutaka, T. S., Smith, W. M., Albano, A. D., Edwards, C. P., Ren, L., Beattie, H. L., . . . Stroup, W. W. (2017). Connecting teacher professional development and student mathematics achievement: A 4-year study of an elementary mathematics specialist program. Journal of Teacher Education, 68(2), 140-154. https://doi.org/10.1177/0022487116687551

Laerd Statistics (2015)a. Hierarchical multiple regression using SPSS Statistics. Statistical tutorials and software guides. Retrieved from https://statistics.laerd.com/

Lampert, M. (2001). Teaching problems and the problems of teaching. New Haven, CT: Yale University Press.

Langford, E. (2006). Quartiles in elementary statistics. Journal of Statistics Education, 14(3). https://doi.org/10.1080/10691898.2006.11910589

Lannin, J (2018) Learning and Teaching Number and Operations in the Elementary School [Syllabus]. Mathematics Department, University of Missouri.

Lannin, J. K., Webb, M., Chval, K., Arbaugh, F., Hicks, S., Taylor, C., \& Bruton, R. (2013). The development of beginning mathematics teacher pedagogical content knowledge. Journal of Mathematics Teacher Education, 16(6), 403-426. https://doi.org/10.1007/s10857-013-9244-5

Laursen, S. L., Hassi, M. L., \& Hough, S. (2016). Implementation and outcomes of inquiry-based learning in mathematics content courses for pre-service teachers. International Journal of Mathematical Education in Science and Technology, 47(2), 256-275. https://doi.org/10.1080/0020739X.2015.1068390 
Leko, M. M., Kulkarni, S., Lin, M.-C., \& Smith, S. A. (2015). Delving deeper into the construct of preservice teacher beliefs about reading instruction for students with disabilities. Teacher Education and Special Education, 38(3), 186-206.

\section{https://doi.org/10.1177/0888406414557677}

Lembke, E. S., \& Stecker, P. M. (2007). Curriculum-based measurement in mathematics: An evidence-based formative assessment procedure. Center on Instruction.

Leonard, J. (2018). Culturally specific pedagogy in the mathematics classroom: Strategies for teachers and students. Routledge.

Livy, S., Muir, T., \& Maher, N. (2012). How Do They Measure Up? Primary Pre-Service Teachers' Mathematical Knowledge of Area and Perimeter. Mathematics Teacher Education and Development, 14(2), 91-112.

Maccini, P., \& Gagnon, J. C. (2006). Mathematics instructional practices and assessment accommodations by secondary special and general educators. Exceptional children, 72(2), 217-234. https://doi.org/10.1177/001440290607200206

Magiera, K., Smith, C., Zigmond, N., \& Gebauer, K. (2005). Benefits of co-teaching in secondary mathematics classes. Teaching exceptional children, 37(3), 20-24.

Magiera, K., \& Zigmond, N. (2005). Co-teaching in middle school classrooms under routine conditions: does the instructional experience differ for students with disabilities in co-taught and solo-taught classes?. Learning Disabilities Research \& Practice, 20(2), 79-85. https://doi.org/10.1111/j.1540-5826.2005.00123.x

Mahmud, M. S. (2019). The role of wait time in the process of oral questioning in the teaching and learning process of mathematics. International Journal of Advanced Science and Technology, 28(16), 691-697. 
Mason, J. (2010). Effective questioning and responding in the mathematics classroom'reworked and updated from: Mason, J. 2002, 'Minding Your Qs and Rs: effective questioning and responding in the mathematics classroom'. Aspects of teaching secondary mathematics: perspectives on practice. London, 16.

Mays, H. (2005). Mathematical knowledge of some entrants to a pre-service education course. Review process, 186.

McHatton, P. A., \& Parker, A. (2013). Purposeful preparation: Longitudinally exploring inclusion attitudes of general and special education pre-service teachers. Teacher Education and Special Education, 36(3), 186-203. https://doi.org/10.1177/0888406413491611

McLeskey, J., Billingsley, B., Brownell, M. T., Maheady, L., \& Lewis, T. J. (2019). What are high-leverage practices for special education teachers and why are they important?. Remedial and Special Education, 40(6), 331-337. https://doi.org/10.1177/0741932518773477

Meyer, J. S., \& Province, M. (1988). Proliferative index of breast carcinoma by thymidine labeling: prognostic power independent of stage, estrogen and progesterone receptors. Breast cancer research and treatment, 12(2), 191-204. https://doi.org/10.1007/BF01805940

Miller, K. (2011). Situation awareness in teaching. Mathematics teacher noticing: Seeing through teachers' eyes. New York, NY: Routledge.

Miller, S. P., \& Hudson, P. J. (2007). Using evidence-based practices to build mathematics competence related to conceptual, procedural, and declarative knowledge. Learning Disabilities Research \& Practice, 22(1), 47-57. 
https://doi.org/10.1111/j.1540-5826.2007.00230.x

MKT INSTRUMENT PUBLICATIONS. (2015, October 27). Retrieved October 25, 2019, from http://www.umich.edu/ 1mtweb/research.html.

Monte-Sano, C., \& Budano, C. (2013). Developing and enacting pedagogical content knowledge for teaching history: An exploration of two novice teachers' growth over three years. Journal of the Learning Sciences, 22(2), 171-211. https://doi.org/10.1080/10508406.2012.742016

Munter, C., Stein, M. K., \& Smith, M. A. (2015). Dialogic and direct instruction: Two distinct models of mathematics instruction and the debate(s) surrounding them. Teachers College Record, 117(11), n11.

Murray, R., Shea, M., Shea, B., \& Harlin, R. (2004). Issues in education: Avoiding the one-size-fits-all curriculum: Textsets, inquiry, and differentiating instruction. Childhood education, 81(1), 33-35. https://doi.org/10.1080/00094056.2004.10521291

National Center for Education Statistics. (2020, May). The condition of education Preprimary, elementary, and secondary education - Elementary and secondary enrollment - Students with disabilities - Indicator may (2020). National Center for Education Statistics (NCES), a part of the U.S. Department of Education. https://nces.ed.gov/programs/coe/indicator_cgg.asp

National Center on Intensive Intervention (NCII) at American Institutes for Research. (2013). Data-based individualization: A framework for intensive intervention. ERIC Clearinghouse. 
National Council of Teachers of Mathematics. (2000). Principles and standards for school mathematics. Reston, VA.

National Mathematics Advisory Panel. (2008). The Final Report of the National Mathematics Advisory Panel. The Final Report of the National Mathematics Advisory Panel.

Niess, M. L., van Zee, E. H., \& Gillow-Wiles, H. (2010). Knowledge growth in teaching mathematics/science with spreadsheets: Moving PCK to TPACK through online professional development. Journal of Digital Learning in Teacher Education, 27(2), 42-52. https://doi.org/10.1080/21532974.2010.10784657

Nilsson, P., \& Loughran, J. (2012). Exploring the development of pre-service science elementary teachers' pedagogical content knowledge. Journal of Science Teacher Education, 23(7), 699-721. https://doi.org/10.1007/s10972-011-9239-y

No Child Left Behind Act of 2001, P.L. 107-110, 20 U.S.C. $§ 6319$ (2002).

Palinkas, L. A., Horwitz, S. M., Green, C. A., Wisdom, J. P., Duan, N., \& Hoagwood, K. (2015). Purposeful sampling for qualitative data collection and analysis in mixed method implementation research. Administration and policy in mental health and mental health services research, 42(5), 533-544. https://doi.org/10.1007/s10488-013-0528-y

Park, S., \& Oliver, J. S. (2008). Revisiting the conceptualisation of pedagogical content knowledge (PCK): PCK as a conceptual tool to understand teachers as professionals. Research in science Education, 38(3), 261-284. https://doi.org/10.1007/s11165-007-9049-6 
Peterson, P. L., Fennema, E., Carpenter, T. P., \& Loef, M. (1989). Teacher's pedagogical content beliefs in mathematics. Cognition and Instruction, 6(1), 1-40. https://doi.org/10.1207/s1532690xci0601_1

Polly, D., McGee, J. R., Wang, C., Lambert, R. G., Pugalee, D. K., \& Johnson, S. (2013). The association between teachers' beliefs, enacted practices, and student learning in mathematics. The Mathematics Educator, 22(2).

Powell, S. R., \& Fuchs, L. S. (2015). Intensive intervention in mathematics. Learning Disabilities Research \& Practice, 30(4), 182-192. https://doi.org/10.1111/1drp.12087

Powell, S. R., Lembke, E. S., Ketterlin-Geller, L. R., Petscher, Y., Hwang, J., Bos, S. E., ... \& Hopkins, S. (2020). Data-based individualization in mathematics to support middle school teachers and their students with mathematics learning difficulty. Studies in Educational Evaluation, 100897. https://doi.org/10.1016/j.stueduc.2020.100897

Powell, S. R., \& Stecker, P. M. (2014). Using data-based individualization to intensify mathematics intervention for students with disabilities. Teaching Exceptional Children, 46(4), 31-37. https://doi.org/10.1177/0040059914523735

Purnomo, Y. W., Suryadi, D., \& Darwish, S. (2016). Examining pre-service elementary school teacher beliefs and instructional practices in mathematics class. International Electronic Journal of Elementary Education, 8(4), 629-642.

Quinn, R. J. (1997). Effects of mathematics methods courses on the mathematical attitudes and content knowledge of preservice teachers. The Journal of 
educational research, 91(2), 108-114.

https://doi.org/10.1080/00220679709597528

Rea, P. J., McLaughlin, V. L., \& Walther-Thomas, C. (2002). Outcomes for students with learning disabilities in inclusive and pullout programs. Exceptional children, 68(2), 203-222. https://doi.org/10.1177/001440290206800204

Ren, L., \& Smith, W. M. (2018). Teacher characteristics and contextual factors: Links to early primary teachers' mathematical beliefs and attitudes. Journal of Mathematics Teacher Education, 21(4), 321-350. https://doi.org/10.1007/s10857$\underline{017-9365-3}$

Riccomini, P. J., Morano, S., \& Hughes, C. A. (2017). Big ideas in special education: Specially designed instruction, high-leverage practices, explicit instruction, and intensive instruction. Teaching Exceptional Children, 50(1), 20-27. https://oi.org/10.1177/0040059917724412

Richardson, V. (1996). The role of attitudes and beliefs in learning to teach. In J. P. Sikula, T. J. Buttery, E. Guyton, \& Association of Teacher Educators (Eds.), Handbook of research on teacher education, $2^{\text {nd }}$ ed. (pp. 102-119). Macmillan Library Reference.

Richardson, V. (2003). Preservice teachers' beliefs. In J. Raths (Ed.), Teacher beliefs and classroom performance: The impact of teacher education, $6^{\text {th }}$ ed (pp. 1-22). Information Age Pub.

Richardson, V., Anders, P., Tidwell, D., \& Lloyd, C. (1991). The relationship between teachers' beliefs and practices in reading comprehension instruction. American 
Educational Research Journal, 28(3), 559-586.

https://doi.org/10.3102/00028312028003559

Rittle-Johnson, B., Schneider, M., \& Star, J. R. (2015). Not a one-way street:

Bidirectional relations between procedural and conceptual knowledge of mathematics. Educational Psychology Review, 27(4), 587-597. https://doi.org/10.1007/s10648-015-9302-x

Rittle-Johnson, B., Siegler, R. S., \& Alibali, M. W. (2001). Developing conceptual understanding and procedural skill in mathematics: An iterative process. Journal of Educational Psychology, 93(2), 346. https://doi.org/10.1037/0022$\underline{0663.93 .2 .346}$

Rockoff, J. E. (2004). The impact of individual teachers on student achievement: Evidence from panel data. American economic review, 94(2), 247-252. https://doi.org/10.1257/0002828041302244

Robinson, L., \& Buly, M. R. (2007). Breaking the language barrier: Promoting collaboration between general and special educators. Teacher Education Quarterly, 34(3), 83-94.

Rooney, D., \& Boud, D. (2019). Toward a pedagogy for professional noticing: learning through observation. Vocations and Learning, 12(3), 441-457. https://doi.org/10.1007/s12186-019-09222-3

Rosaen, C. L., Lundeberg, M., Cooper, M., Fritzen, A., \& Terpstra, M. (2008). Noticing noticing: How does investigation of video records change how teachers reflect on their experiences? Journal of Teacher Education, 59(4), 347-360. https://doi.org/10.1177/0022487108322128 
Rose, C. A., \& Espelage, D. L. (2012). Risk and protective factors associated with the bullying involvement of students with emotional and behavioral disorders. Behavioral Disorders, 37(3), 133-148. https://doi.org/10.1177/019874291203700302

Russ, R. S., Sherin, B., \& Sherin, M. G. (2011). Images of expertise in mathematics teaching. In Y. Li \& G. Kaiser (Eds.), Expertise in mathematics instruction (pp. 41-60). Springer.

Rutherford, A. (2011). ANOVA and ANCOVA: A GLM approach (2nd ed.). Hoboken, NJ: John Wiley \& Sons.

Sahin, A., \& Kulm, G. (2008). Sixth grade mathematics teachers' intentions and use of probing, guiding, and factual questions. Journal of mathematics teacher education, 11(3), 221-241. https://doi.org/10.1007/s10857-008-9071-2

Santagata, R. (2011). From teacher noticing to a framework for analyzing and improving classroom lessons. In M. G. Sherin, V. R. Jacobs, \& R. A. Philipp (Eds.), Mathematics teacher noticing (pp. 152-168). New York, NY: Routledge.

Schäfer, S., \& Seidel, T. (2015). Noticing and reasoning of teaching and learning components by pre-service teachers. Journal for educational research online, 7(2), 34-58.

Schifter, D. (2011). Examining the behavior of operations: Noticing early algebraic ideas. In M. G. Sherin, V. R. Jacobs, \& R. A. Philipp (Eds.), Mathematics teacher noticing (pp. 204-220). New York, NY: Routledge.

Schoenfeld, A. H. (2011). Toward professional development for teachers grounded in a theory of decision making. ZDM, 43(4), 457-469. 


\section{https://doi.org/10.1007/s11858-011-0307-8}

Schoenfeld, A. H. (2011a). Noticing Matters. A lot. Now What?. In Mathematics Teacher Noticing: Seeing through Teachers Eyes (pp. 223-238). London: Routledge.

Schulman, L. (1986). Paradigms and research programs in the study of teaching. Handbook of research on teaching, 3-36.

Shippen, M. E., Flores, M. M., Crites, S. A., Patterson, D., Ramsey, M. L., Houchins, D. E., \& Jolivette, K. (2011). Classroom Structure and Teacher Efficacy in Serving Students with Disabilities: Differences in Elementary and Secondary Teachers. International Journal of Special Education, 26(3), 36-44.

Shulman, L. S. (1987). Those who understand: Knowledge and growth in teaching. Educational Researcher, 15(2), 4-14. https://doi.org/10. 3102/0013189X015002004

Sezer, R. (2008). Integration of critical thinking skills into elementary school teacher education courses in mathematics. Education, 128(3), 349-363.

Shepherd, K. G., Fowler, S., McCormick, J., Wilson, C. L., \& Morgan, D. (2016). The search for role clarity: Challenges and implications for special education teacher preparation. Teacher Education and Special Education, 39(2), 83-97. https://doi.org/10.1177/0888406416637904

Sherin, M. G. (2007). The development of teachers' professional vision in video clubs. Video research in the learning sciences, 383-395.

Sherin, M. G., Jacobs, V. R., \& Philipp, R. A. (Eds.) (2011). Mathematics teacher noticing: Seeing through teachers' eyes. New York, NY: Routledge. 
Sherin, M. G., \& Jacobs, V. R. (2011). Situating the study of teacher noticing. In M. G. Sherin, V. R. Jacobs, \& R. A. Philipp (Eds.), Mathematics teacher noticing (pp. 33-44). New York, NY: Routledge.

Sherin, M. G., \& Russ, R. S. (2011). Accessing mathematics teachers'in-the-moment noticing. In M. G. Sherin, V. R. Jacobs, \& R. A. Philipp (Eds.), Mathematics teacher noticing (pp. 109-124). New York, NY: Routledge.

Sherin, M. G., \& Russ, R. S. (2014). Teacher noticing via video: The role of interpretive frames. In B. Calandra \& P. J. Rich (Eds.), Digital video for teacher education (pp. 11-28). New York, NY: Routledge.

Sherin, M., \& van Es, E. (2005). Using video to support teachers' ability to notice classroom interactions. Journal of technology and teacher education, 13(3), 475491.

Sherin, M. G. ed., Jacobs, V. R., \& Philipp, R. A. (2011). Situating the Study of Teacher Noticing. In Mathematics Teacher Noticing: Seeing through Teachers Eyes (pp. 3-13). London: Routledge.

Shulman, L. (1987). Knowledge and teaching: Foundations of the new reform. Harvard Educational Review, 57(1), 1-23. https://doi.org/10.17763/haer.57.1.j463w79r56455411

Shulman, L. (2012). Pedagogical content knowledge. American Educational Research Association.

Sindelar, P. T., Brownell, M. T., \& Billingsley, B. (2010). Special education teacher education research: Current status and future directions. Teacher Education and Special Education, 33(1), 8-24. https://doi.org/10.1177/0888406409358593 
Silverman, J. C. (2007). Epistemological beliefs and attitudes toward inclusion in preservice teachers. Teacher Education and Special Education, 30(1), 42-51. https://doi.org/10.1177/088840640703000105

Smith, M. K., \& Smith, K. E. (2000). “I believe in inclusion, but...”: Regular education early childhood teachers' perceptions of successful inclusion. Journal of Research in Childhood Education, 14,161-180. https://doi.org/10.1080/02568540009594761

Star, J. R., Lynch, K. H., \& Perova, N. (2011). Using video to improve mathematics' teachers' abilities to attend to classroom features: A replication study.

Star, J. R., \& Strickland, S. K. (2008). Learning to observe: Using video to improve preservice mathematics teachers' ability to notice. Journal of Mathematics Teacher Education, 11(2), 107-125. https://doi.org/10.1007/s10857-007-9063-7

Stecker, P. M., \& Fuchs, L. S. (2000). Effecting superior achievement using curriculumbased measurement: The importance of individual progress monitoring. Learning Disabilities Research \& Practice, 15(3), 128-134. https://doi.org/10.1207/SLDRP1503_2

Stecker, P. M., Fuchs, L. S., \& Fuchs, D. (2005). Using curriculum-based measurement to improve student achievement: Review of research. Psychology in the Schools, 42(8), 795-819. https://doi.org/10.1002/pits.20113

Steele, D. F. (2001). The interfacing of preservice and inservice experiences of reformbased teaching: A longitudinal study. Journal of Mathematics Teacher Education, 4(2), 139-172. https://doi.org/10.1023/A:1011436116480 
Steele, M. M. (2005). Teaching students with learning disabilities: Constructivism or Behaviorism?. Current Issues in Education, 8.

Stevens, E. A., Rodgers, M. A., \& Powell, S. R. (2018). Mathematics interventions for upper elementary and secondary students: A meta-analysis of research. Remedial and Special Education, 39(6), 327-340. https://doi.org/10.1177/0741932517731887

Stohlmann, M. S., Moore, T. J., \& Cramer, K. (2013). Preservice elementary teachers' mathematical content knowledge from an integrated STEM modelling activity. Journal of Mathematical Modelling and Application, 1(8), 18-31.

Strack, F. (1992). “Order effects” in survey research: Activation and information functions of preceding questions. In Context effects in social and psychological research (pp. 23-34). Springer, New York, NY. https://doi.org/10.1007/978-1$\underline{4612-2848-6 \quad 3}$

Stronge, J. H., Ward, T. J., \& Grant, L. W. (2011). What makes good teachers good? A cross-case analysis of the connection between teacher effectiveness and student achievement. Journal of teacher Education, 62(4), 339-355. https://doi.org/10.1177/0022487111404241

Summers, J. J., Davis, H. A., \& Hoy, A. W. (2017). The effects of teachers' efficacy beliefs on students' perceptions of teacher relationship quality. Learning and Individual Differences, 53, 17-25. https://doi.org/10.1016/j.lindif.2016.10.004

Swars, S., Hart, L. C., Smith, S. Z., Smith, M. E., \& Tolar, T. (2007). A longitudinal study of elementary pre-service teachers' mathematics beliefs and content knowledge. School Science and Mathematics, 107(8), 325-335. 
https://doi.org/10.1111/j.1949-8594.2007.tb17797.x

Swars, S. L., Smith, S. Z., Smith, M. E., \& Hart, L. C. (2009). A longitudinal study of effects of a developmental teacher preparation program on elementary prospective teachers' mathematics beliefs. Journal of Mathematics Teacher Education, 12(1), 47-66. https://doi.org/10.1007/s10857-008-9092-x

Sze, S. (2009). A literature review: Pre-service teachers' attitudes toward students with disabilities. Education, 130(1), 53-57.

Thomas, J. N., Eisenhardt, S., Fisher, M. H., Schack, E. O., Tassell, J., \& Yoder, M. (2014). Professional noticing: Developing responsive mathematics teaching. Teaching Children Mathematics, 21(5), 294-303. https://doi.org/10.5951/teacchilmath.21.5.0294

Thomas, J., Jong, C., Fisher, M. H., \& Schack, E. O. (2017). Noticing and knowledge: Exploring theoretical connections between professional noticing and mathematical knowledge for teaching. The Mathematics Educator, 26(2).

Thomas, J., Marzilli, T., Sawyer, B., Jong, C., Schack, E. O., \& Fisher, M. H. (2020). Investigating the Manifestations of Bias in Professional Noticing of Mathematical Thinking among Preservice Teachers. Journal of Mathematics Education at Teachers College, 11(1).

Thompson, A. G. (1984). The relationship of teachers' conceptions of mathematics and mathematics teaching to instructional practice. Educational studies in mathematics, 15(2), 105-127. https://doi.org/10.1007/BF00305892

Tukey, J. W. (1977). Exploratory data analysis (Vol. 2, pp. 131-160). 
Tyminski, A. M., Simpson, A. J., Land, T. J., Drake, C., \& Dede, E. (2020). Prospective elementary mathematics teachers' noticing of childrens' mathematics: a focus on extending moves. Journal of Mathematics Teacher Education, 1-29. https://doi.org/10.1007/s10857-020-09472-2

Ulusoy, F. (2020). Prospective teachers' skills of attending, interpreting and responding to content-specific characteristics of mathematics instruction in classroom videos. Teaching and Teacher Education, 94, 103103.

https://doi.org/10.1016/j.tate.2020.103103

Urbach, J., Moore, B. A., Klingner, J. K., Galman, S., Haager, D., Brownell, M. T., \& Dingle, M. (2015). "That's my job": Comparing the beliefs of more and less accomplished special educators related to their roles and responsibilities. Teacher Education and Special Education, 38(4), 323-336.

\section{https://doi.org/10.1177/0888406415591220}

VanDerHeyden, A. M., \& Burns, M. K. (2005). Using curriculum-based assessment and curriculum-based measurement to guide elementary mathematics instruction: Effect on individual and group accountability scores. Assessment for Effective Intervention, 30(3), 15-31. https://doi.org/10.1177/073724770503000302

Van de Walle, J. A. (2003). Elementary and middle school mathematics. New York. van Es, E. A., Cashen, M., Barnhart, T., \& Auger, A. (2017). Learning to notice mathematics instruction: Using video to develop preservice teachers' vision of ambitious pedagogy. Cognition and Instruction, 35(3), 165-187. https://doi.org/10.1080/07370008.2017.1317125 
van Es, E. A., \& Sherin, M. G. (2002). Learning to notice: Scaffolding new teachers' interpretations of classroom interactions. Journal of Technology and Teacher Education, 10(4), 571-596.

van Es, E. A., \& Sherin, M. G. (2006). How different video club designs support teachers in "learning to notice". Journal of computing in teacher education, 22(4), 125135.

van Es, E. A., \& Sherin, M. G. (2008). Mathematics teachers"'learning to notice" in the context of a video club. Teaching and Teacher Education, 24(2), 244-276. https://doi.org/10.1016/j.tate.2006.11.005

van Es, E. A., \& Sherin, M. G. (2010). The influence of video clubs on teachers' thinking and practice. Journal of mathematics teacher Education, 13(2), 155-176.

van Garderen, D. (2019) Diagnosis and Remediation of Learning Problems in Math [Syllabus]. Special Education Department, University of Missouri.

van Garderen, D., Scheuermann, A., Poch, A., \& Murray, M. M. (2018). Visual representation in mathematics: Special education teachers' knowledge and emphasis for instruction. Teacher Education and Special Education, 41(1), 7-23. https://doi.org/10.1177/0888406416665448

van Garderen, D., Scheuermann, A., Sadler, K., Hopkins, S., \& Hirt, S. M. (2021). Preparing Pre-Service Teachers to Use Visual Representations as an Instructional Strategy to Solve Mathematics Problems: What Did They Learn? Teacher Education and Special Education. https://doi.org/10.1177/0888406421996070

Warner, R. M. (2013). Applied statistics: From bivariate through multivariate techniques (2nd ed.). Thousand Oaks, CA: Sage. 
Wilkins, J. L. (2008). The relationship among elementary teachers' content knowledge, attitudes, beliefs, and practices. Journal of Mathematics Teacher Education, 11(2), 139-164. https://doi.org/10.1007/s10857-007-9068-2

Yang, X., Kaiser, G., König, J., \& Blömeke, S. (2019). Professional noticing of mathematics teachers: A comparative study between Germany and China. International Journal of Science and Mathematics Education, 17(5), 943963. https://doi.org/10.1007/s10763-018-9907-x

Yang, X., Kaiser, G., König, J., \& Blömeke, S. (2020). Relationship between pre-service mathematics teachers' knowledge, beliefs and instructional practices in China. ZDM, 1-14. https://doi.org/10.1007/s11858-020-01145-X

Ysseldyke, J., Spicuzza, R., Kosciolek, S., Teelucksingh, E., Boys, C., \& Lemkuil, A. (2003). Using a curriculum-based instructional management system to enhance math achievement in urban schools. Journal of Education for Students Placed at Risk, 8(2), 247-265. https://doi.org/10.1207/S15327671ESPR0802_4 
Appendix A

\section{Institutional Review Board Approval}

田 Institutional Review Board University of Missouri-Columbia

FWA Number: 00002876

IRB Registration Numbers: 00000731,00009014
482 McReynolds Hall

Columbia, MO 65211

573-882-3181

irb@missouri.edu

November 25, 2019

Principal Investigator: Stephanie Aurora Hopkins

Department: Special Education

Your IRB Application to project entitled Examining the Relationship of Noticing, Mathematics Knowledge for Teaching, and Beliefs in Novice Teachers was reviewed and approved by the MU Institutional Review Board according to the terms and conditions described below:

$\begin{array}{ll}\text { IRB Project Number } & 2017865 \\ \text { IRB Review Number } & 255031 \\ \text { Initial Application Approval Date } & \text { November 25, 2019 } \\ \text { IRB Expiration Date } & \text { November 25, 2020 } \\ \text { Level of Review } & \text { Exempt } \\ \text { Project Status } & \text { Active - Exempt } \\ \text { Exempt Categories (Revised Common Rule) } & 45 \text { CFR 46.104d(1) } \\ \text { Risk Level } & \text { Minimal Risk }\end{array}$

The principal investigator (PI) is responsible for all aspects and conduct of this study. The PI must comply with the following conditions of the approval:

1. No subjects may be involved in any study procedure prior to the IRB approval date or after the expiration date.

2. All changes must be IRB approved prior to implementation utilizing the Exempt Amendment Form.

3. The Annual Exempt Form must be submitted to the IRB for review and approval at least 30 days prior to the project expiration date to keep the study active or to close it.

4. Maintain all research records for a period of seven years from the project completion date.

If you are offering subject payments and would like more information about research participant payments, please click here to view the MU Business Policy and Procedure: $\underline{\mathrm{htt}} \mathrm{:} / /$

bppm.missouri.edu/chapter2/2_250.html

If you have any questions or concerns, please contact the MU IRB Office at 573-882-3181 or email to muresearchirb@missouri.edu.

Thank you,

MU Institutional Review Board 


\section{Appendix B}

\section{Consent Script:}

\section{Participant Verbal Consent Script}

My name is Stephanie Hopkins, and I am doctoral candidate at the University of Missouri. I am the principal investigator of this project. I am going to go through some questions and answers about information about participation in this study. As I go through the different components, please let me know if you have any questions about participation.

At the end of the information, I will ask for your verbal consent to participate in the study.

I am asking you to take part in this research study because you are a special education or general education (elementary) pre-service teacher who is either taking the first or second mathematics methods course or have already completed both.

For questions about research appointments, the research study, research results, or other concerns, call the study team at: (have this written on a slide for participants to see)

Researcher Name: Stephanie Hopkins

Researcher Affiliation: University of Missouri

Phone Number: 248-881-3507

Email Address: sand54@mail.missouri.edu

If you have any questions regarding your rights as a participant in this research study and/or concerns about the research study, or if you feel under any pressure to enroll or to continue to participate in this research study, you may contact the University of Missouri Institutional Review Board (which is a group of people who review the research studies to protect participants' rights) at (573) 882-3181 or irb@missouri.edu.

\section{What happens if I say "Yes, I want to participate in this research study"?}

To participate in this study, I would ask you to do the following within the research study:

- Engage in three tasks during one data collection period (1-1.5 hours)

- Answer survey items from Mathematics Knowledge of Teaching

- Answer items from a Beliefs about Teaching Mathematics scale

- Watch three video clips (3-5 minutes in length) and responds to the open-ended questions

Participation of this research study is completely voluntary, and you can withdraw participation within the research study at any time and it will not be held against you.

\section{What happens to the information collected for the research?}

Efforts will be made to limit the use and disclosure of your personal information, including research study records, to people who have a need to review this information. 
We cannot promise complete secrecy. Organizations that may inspect and copy your information include the IRB and other representatives of this institution.

The records of this study will be kept private. In any sort of report, we might publish, we will not include any information that will make it possible to identify a participant. Research records will be stored securely and only researchers will have access to the records.

\section{Will I be compensated for my participation?}

If you agree to take part in this research study outside of any designated classroom time, you will be compensated with a 10-dollar gift card for your time and effort spent on study activities. Payment will be provided following the conclusion of the interview.

If you are participating through class time your completion of the activities, whether you choose to participate in the study or not, will be given 20 completion points for your class.

Now is your opportunity to provide verbal consent to participate in the study. [receive consent from participants at this time] 


\section{Appendix C}

\section{Participant Consent Form Adapted for Online Administration Due to COVID-19}

My name is Stephanie Hopkins, and I am doctoral candidate at the University of Missouri and am the principal investigator of this project. Below is some information about the study you have the opportunity to participate in. As you read through the different components, please let me know if you have any questions about participation.

At the end of the information, you will be given the open to begin the survey. By clicking onto the next page, you have providing consent to participate in the survey. If you do not choose to be a part of the study, simply click out of the survey.

You have been asked to take part in this research study because you are a special education or general education (elementary) pre-service teacher who is either taking the first or second mathematics methods course or have already completed both.

For questions about research appointments, the research study, research results, or other concerns, call the study team at: (have this written on a slide for participants to see)

Researcher Name: Stephanie Hopkins

Researcher Affiliation: University of Missouri

Phone Number: 248-881-3507

Email Address: sand54@mail.missouri.edu

If you have any questions regarding your rights as a participant in this research study and/or concerns about the research study, or if you feel under any pressure to enroll or to continue to participate in this research study, you may contact the University of Missouri Institutional Review Board (which is a group of people who review the research studies to protect participants' rights) at (573) 882-3181 or irb@missouri.edu.

\section{What happens if I say "Yes, I want to participate in this research study"?}

To participate in this study, I would ask you to do the following within the research study:

- Engage in three tasks during one data collection period (1-1.5 hours)

- Answer survey items from Mathematics Knowledge of Teaching

- Answer items from a Beliefs about Teaching Mathematics scale

- Watch three video clips (3-5 minutes in length) and responds to the open-ended questions

Participation of this research study is completely voluntary, and you can withdraw participation within the research study at any time and it will not be held against you. 


\section{What happens to the information collected for the research?}

Efforts will be made to limit the use and disclosure of your personal information, including research study records, to people who have a need to review this information. We cannot promise complete secrecy. Organizations that may inspect and copy your information include the IRB and other representatives of this institution.

The records of this study will be kept private. In any sort of report, we might publish, we will not include any information that will make it possible to identify a participant. Research records will be stored securely and only researchers will have access to the records.

\section{Will I be compensated for my participation?}

If you agree to take part in this research study outside of any designated classroom time, you will be compensated with a 10-dollar gift card for your time and effort spent on study activities. Payment will be provided following the conclusion of the interview.

If you are participating through class time your completion of the activities, whether you choose to participate in the study or not, will be given 20 completion points for your class.

Now is your opportunity to provide consent to participate in the study. By clicking onto the next page, you have providing consent to participate in the survey. If you do not choose to be a part of the study, simply click out of the survey. 


\section{Appendix D}

\section{LMT Sample Items}

1. Ms. Harris was working with her class on divisibility rules. She told her class that a number is divisible by 4 if and only if the number formed by the last two digits is divisible by 4 ; for example, 7,548 is divisible by 4 because 48 is. She asked her students why the rule works, and several possible reasons were proposed.

Which of the following reasons comes closest to explaining the divisibility rule for 4 ? (Circle ONE answer.)

a) Four is an even number, and odd numbers are not divisible by even numbers.

b) Once you subtract the number formed by the last two digits, the number that remains (e.g., 7,500 in the example above) is a multiple of 100, and any multiple of 100 is divisible by 4 .

c) Alternating even numbers are divisible by 4 , for example, 24 and 28 but not 26 .

d) It only works when the sum of the last two digits is divisible by $4(4+8=12$, in this example), just like the rule for divisibility by 3 .

2.

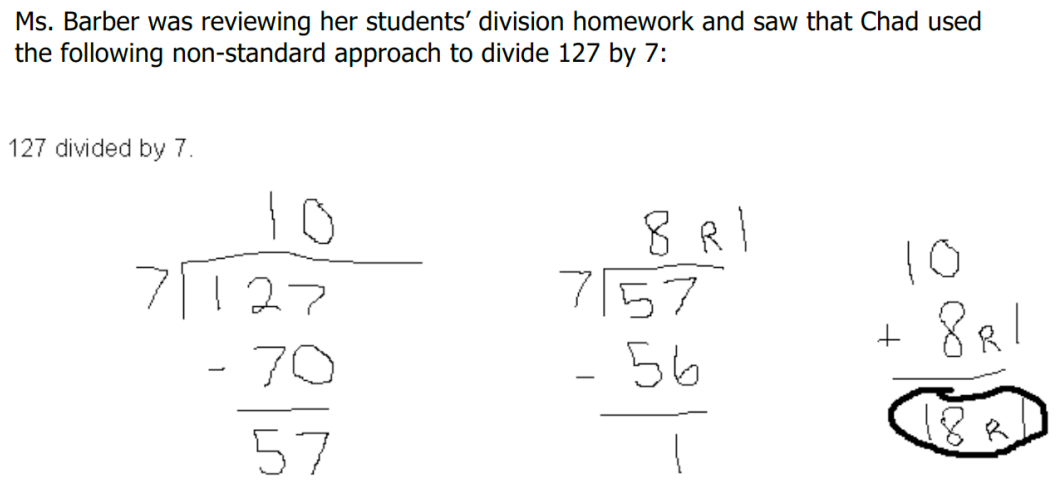

What is true about Chad's approach? (Circle ONE answer.)

a) His approach is not mathematically valid; it is a coincidence that his answer is correct.

b) His approach is not mathematically valid because he subtracted 70 from 127 instead of subtracting 7 from 12 .

c) His approach is mathematically valid, but could be inefficient with large dividends.

d) His approach is mathematically valid, but only works with single-digit divisors. 


\section{Appendix E}

\section{Adaptation of Principles and Standards for School Mathematics Van de Walle (2003)}

\begin{tabular}{|c|c|}
\hline Process Standard & How Can You Develop These Processes in Your Students? \\
\hline Problem Solving & $\begin{array}{l}\text { - Start instruction with a problem to solve-as problem solving is the vehicle for developing mathematical ideas. } \\
\text { Select meaningful mathematical tasks. } \\
\text { Set problems in a situation to which students can relate. } \\
\text { - Use a variety of strategies to solve problems. } \\
\text { Have students self-assess their understanding of the problem and their strategy use. }\end{array}$ \\
\hline Reasoning and Proof & $\begin{array}{l}\text { - Have students consider evidence of why something is true or not. } \\
\text { - Create opportunities for students to evaluate conjectures-do they hold true? } \\
\text { - Encourage students to use logical reasoning to see if something always works or their answers make sense. } \\
\text { comonstrate a variety of ways for students to justify their thinking through fincing examples and } \\
\text { counterexamples to use in a logical argument. }\end{array}$ \\
\hline Communication & $\begin{array}{l}\text { - Invite students to talk about, write about, describe, and explain their mathematical ideas as a way to } \\
\text { examine their thinking. } \\
\text { - Give students opportunities to share ideas so that others can understand and actively discuss their } \\
\text { reasoning. } \\
\text { - Share examples of student work, so students can compare and assess others' thinking. } \\
\text { - Present precise mathematical language and notation so that the word usage and definitions can act as a } \\
\text { foundation for students' future learning. }\end{array}$ \\
\hline Connections & $\begin{array}{l}\text { Emphasize how mathematical ideas explicitly connect to students' prior mathematical knowledge and future } \\
\text { learning. } \\
\text { - Assist students in developing the relationships between the mathematics being learned and real world } \\
\text { contexts and in other subject areas. }\end{array}$ \\
\hline Representation & $\begin{array}{l}\text { - Encourage students to use multiple representations to explore relationships and communicate their thinking. } \\
\text { - Create opportunities for students to move from one representation of an mathematical concept or idea to } \\
\text { another to add depth of understanding. } \\
\text { - Provide problems where students can use mathematical models to clarify or represent a situation. }\end{array}$ \\
\hline
\end{tabular}

Source: Adapted with permission from NCTM (National Council of Teachers of Mathematics). (2000). Principles and standards for school mathematics. Reston, VA: NCTM. Copyright 2000 by the National Council of Teachers of Mathematics. All rights reserved. 
TABLE 1.3 THE SIX GUIDING PRINCIPLES FROM THE PRINCIPLES TO ACTIONS

\begin{tabular}{|c|c|}
\hline Guiding Principle & Suggestions for Classroom Actions That Align with the Principles \\
\hline Teaching and Learning & $\begin{array}{l}\text { - Select focused mathematics goals. } \\
\text { - Use meaningful instructional tasks that develop reasoning, sense making, and problem solving strategies. } \\
\text { Present and encourage a variety of mathematical representations that connect the same ideas or concepts. } \\
\text { - Facilitate student discussions and conversations about important mathematical ideas. } \\
\text { - Ask essential questions that are planned to be a catalyst for deeper levels of thinking. } \\
\text { - Use a strong foundation of conceptual understanding as a foundation for procedural fluency. } \\
\text { Encourage productive struggle-as it is a way to deepen understanding and move toward student application } \\
\text { of their learning. } \\
\text { - Generate ways for students to provide evidence of their thinking through discussions, illustrations, and } \\
\text { written responses. }\end{array}$ \\
\hline Access and Equity & $\begin{array}{l}\text { - Establish high expectations for all students. } \\
\text { - Provide supports targeted to student needs (equity not equality). } \\
\text { - Provide instructional opportunities for students to demonstrate their competence in different ways-creating } \\
\text { tasks with easy entry points for students who struggle and extension options for those who finish quickly. } \\
\text { - Identify obstacles to students' success and find ways to bridge or eliminate those barriers. } \\
\text { - Develop all students' confidence that they can do mathematics. } \\
\text { - Enhance the learning of all by celebrating students' diversity. }\end{array}$ \\
\hline Curriculum & $\begin{array}{l}\text { Build connections across mathematics topics to capitalize on broad themes and big ideas. } \\
\text { - Look for both horizontal and vertical alignment to build coherence. } \\
\text { Avoid thinking of a curriculum as a checklist or disconnected set of daily lessons. }\end{array}$ \\
\hline Tools and Technology & $\begin{array}{l}\text { - Include an array of technological tools and manipulatives to support the exploration of mathematical } \\
\text { concepts, structures, and relationships. } \\
\text { - Think beyond computation when considering the integration of technology. } \\
\text { Explore connections to how technology use for problem solving links to career readiness. }\end{array}$ \\
\hline Assessment & $\begin{array}{l}\text { Incorporate a continuous assessment plan to follow how students are performing and how instruction can be } \\
\text { modified and thereby improved. } \\
\text { - Move beyond test results that just look at overall increases and decreases to pinpoint specific student needs. } \\
\text { - Ensider the use of multiple assessments to capture a variety of student performance. } \\
\text { - Encourage students to self-assess sometimes by evaluating the work of others to enhance their own } \\
\text { Teach students how to check their work. }\end{array}$ \\
\hline Professionalism & $\begin{array}{l}\text { Develop a longterm plan for building your expertise. } \\
\text { - Build collaborations that will enhance the work of the group of collaborators as you enhance the performance } \\
\text { of the students in the school. } \\
\text { - Take acvantage of all coaching, mentoring and professional development opportunities and be a life-long learner. } \\
\text { - Structure in time to reflect on and analyze your instructional practices. }\end{array}$ \\
\hline
\end{tabular}




\section{Appendix F}

\section{Professional Noticing Video Clip Descriptions}

\begin{tabular}{|c|c|c|}
\hline Video Name & Video Length & Description of Video \\
\hline $\begin{array}{l}\text { CVA-M } \\
\text { Fractions } \\
\text { Comparing } 1 \\
\text { TQ ST }\end{array}$ & $02: 21$ & $\begin{array}{l}\text { In this clip, 5th graders are learning about } \\
\text { comparing fractions by representing } \\
\text { fractions on number lines. To that end, the } \\
\text { students work on a problem that asks them } \\
\text { to represent a relay race in which schools } \\
\text { with different numbers of runners } \\
\text { participate. The clip is from the student } \\
\text { independent work phase. }\end{array}$ \\
\hline $\begin{array}{l}\text { CVA-M } 2 \text { - } \\
\text { Fractions - } \\
\text { Equivalence - } \\
2\end{array}$ & 01:06 & $\begin{array}{l}\text { In this clip, 6th graders are learning about } \\
\text { equivalent fractions. In the first part of the } \\
\text { lesson, the students learn how to multiply } \\
\text { and divide by a "giant } 1 \text { " (e.g., } 2 / 2,6 / 6) \text { to } \\
\text { find equivalent fractions. Then students are } \\
\text { asked to find sets of equivalent fractions, } \\
\text { working independently. This clip shows a } \\
\text { teacher student interaction during this } \\
\text { independent work phase. }\end{array}$ \\
\hline $\begin{array}{l}\text { Whole } \\
\text { Numbers - } \\
\text { Subtraction } 8\end{array}$ & $03: 15$ & $\begin{array}{l}\text { In this clip, 3rd grade students are } \\
\text { exploring, modeling, and solving } \\
\text { subtraction problems. Leading up to the } \\
\text { clip, the students are working on several } \\
\text { subtraction problems using place value } \\
\text { blocks (e.g., 100s (flats), 10s (longs), and } \\
\text { 1s (units) and worksheets designed to } \\
\text { show their work with the blocks. The } \\
\text { teacher is going around the room, and the } \\
\text { clip begins when she starts to talk with a } \\
\text { student about her work on solving } 281 \text { - } \\
169\end{array}$ \\
\hline
\end{tabular}


Appendix G

Mathematics Belief Scale

\begin{tabular}{|c|c|c|}
\hline Student Learning & Stages of Learning & Teacher Practices \\
\hline $\begin{array}{l}\text { Q1: Recall of } \\
\text { number facts should } \\
\text { precede the } \\
\text { development of an } \\
\text { understanding of the } \\
\text { related operation }\end{array}$ & $\begin{array}{l}\text { Q7: Most students } \\
\text { have to be shown } \\
\text { how to solve simple } \\
\text { word problems }\end{array}$ & $\begin{array}{l}\text { Q13: Teachers should } \\
\text { encourage students to } \\
\text { find their own } \\
\text { solutions to math } \\
\text { problems even if they } \\
\text { are inefficient }\end{array}$ \\
\hline $\begin{array}{l}\text { Q2: Students should } \\
\text { master } \\
\text { computational } \\
\text { procedures before } \\
\text { they are expected to } \\
\text { understand how } \\
\text { those procedures } \\
\text { work }\end{array}$ & $\begin{array}{l}\text { Q8: Students need } \\
\text { explicit instruction } \\
\text { on how to solve word } \\
\text { problems }\end{array}$ & $\begin{array}{l}\text { Q14: Teachers should } \\
\text { allow students to } \\
\text { figure out their own } \\
\text { ways to solve simple } \\
\text { word problems }\end{array}$ \\
\hline $\begin{array}{l}\text { Q3: Time should be } \\
\text { spend practicing } \\
\text { computational } \\
\text { procedures before } \\
\text { children are } \\
\text { expected to } \\
\text { understand the } \\
\text { procedures }\end{array}$ & $\begin{array}{l}\text { Q9: Most students can } \\
\text { figure out a way to } \\
\text { solve many } \\
\text { mathematics problems } \\
\text { without any adult help }\end{array}$ & $\begin{array}{l}\text { Q15: The goals of } \\
\text { instruction in } \\
\text { mathematics are best } \\
\text { achieved when } \\
\text { students find their } \\
\text { own methods for } \\
\text { solving problems. }\end{array}$ \\
\hline $\begin{array}{l}\text { Q4: Students should } \\
\text { not solve simple } \\
\text { word problems until } \\
\text { they have mastered } \\
\text { some number facts }\end{array}$ & $\begin{array}{l}\text { Q10: Students learn } \\
\text { math best by } \\
\text { attending to the } \\
\text { teacher's } \\
\text { explanations }\end{array}$ & $\begin{array}{l}\text { Q16: Teachers } \\
\text { should teach exact } \\
\text { procedures for } \\
\text { solving word } \\
\text { problems }\end{array}$ \\
\hline $\begin{array}{l}\text { Q5: Time should be } \\
\text { spent practicing } \\
\text { computational } \\
\text { procedures before } \\
\text { students spend much } \\
\text { time solving } \\
\text { problems }\end{array}$ & $\begin{array}{l}\text { Q11: To be } \\
\text { successful in } \\
\text { mathematics, a } \\
\text { student must be a } \\
\text { good listener }\end{array}$ & $\begin{array}{l}\text { Q17: Mathematics } \\
\text { should be presented to } \\
\text { children in such a way } \\
\text { that they can discover } \\
\text { relationships for } \\
\text { themselves }\end{array}$ \\
\hline $\begin{array}{l}\text { Q6: Students will not } \\
\text { understand an } \\
\text { operation until they } \\
\text { have mastered some } \\
\text { of the relevant } \\
\text { number facts }\end{array}$ & $\begin{array}{l}\text { Q12: Students should } \\
\text { understand } \\
\text { computational } \\
\text { procedures before } \\
\text { they master them }\end{array}$ & $\begin{array}{l}\text { Q18: Teachers should } \\
\text { allow students who } \\
\text { are having difficulty } \\
\text { solving a word } \\
\text { problem to continue to } \\
\text { try to find a solution }\end{array}$ \\
\hline
\end{tabular}

*bolded items were reverse coded per Ren \& Smith 2018 


\section{Appendix H}

\section{Noticing Responses Scoring Rubric \& Directions}

After watching a clip of mathematics instruction, pre-service teachers responded to the following prompt: "Please list the three most significant aspects that you noticed regarding how the teacher and/or the student(s) engaged with each other and the targeted mathematical content."

\begin{tabular}{|c|c|c|c|}
\hline & & Noticing Topic & \\
\hline $\begin{array}{l}\text { Noticing } \\
\text { Depth }\end{array}$ & $\begin{array}{c}\text { Teachers' } \\
\text { Mathematics } \\
\text { Pedagogy }\end{array}$ & $\begin{array}{c}\text { Students' } \\
\text { Mathematical } \\
\text { Thinking }\end{array}$ & General \\
\hline $\begin{array}{l}\text { Category } 1 \\
\text { responses that } \\
\text { are not specific } \\
\text { to mathematics }\end{array}$ & -- & -- & $\begin{array}{l}\text { The student } \\
\text { didn't seem } \\
\text { very } \\
\text { comfortable } \\
\text { with the } \\
\text { teacher }\end{array}$ \\
\hline $\begin{array}{l}\text { Category } 2 \\
\text { noticing that } \\
\text { incorporates } \\
\text { mathematical } \\
\text { issues that were } \\
\text { purely descriptive }\end{array}$ & $\begin{array}{l}\text { Teacher Breaks } \\
\text { down the task } \\
\text { Allowed the } \\
\text { student to share } \\
\text { their thinking }\end{array}$ & $\begin{array}{l}\text { The student does not } \\
\text { seem to understand } \\
\text { fractions }\end{array}$ & -- \\
\hline $\begin{array}{l}\text { Category } 3 \\
\text { analyze an aspect } \\
\text { of students, } \\
\text { mathematical } \\
\text { thinking or } \\
\text { teachers, } \\
\text { mathematical } \\
\text { pedagogy }\end{array}$ & $\begin{array}{l}\text { The teacher asked } \\
\text { open ended } \\
\text { questions to make } \\
\text { sure he understood } \\
\text { the entirety of the } \\
\text { problem }\end{array}$ & $\begin{array}{l}\text { The student is } \\
\text { drawing } \\
\text { representation of } \\
\text { base } 100,10 \text {, and } \\
1 \text { 's blocks. } \\
\text { However, they are } \\
\text { represented as } \\
\text { squares, rectangles, } \\
\text { and circles, and are } \\
\text { not broken down } \\
\text { into their many } \\
\text { parts. }\end{array}$ & -- \\
\hline $\begin{array}{l}\text { Category } 4 \\
\text { Noticing of key } \\
\text { problematic } \\
\text { issues }\end{array}$ & $\begin{array}{l}\text { Video } 1 \text { : Teacher } \\
\text { provides the } \\
\text { student with the } \\
\text { questions instead } \\
\text { of asking } \\
\text { questions to }\end{array}$ & $\begin{array}{l}\text { Video 1: Student } \\
\text { focuses on the tick } \\
\text { marks instead of the } \\
\text { space between the } \\
\text { tick marks }\end{array}$ & -- \\
\hline
\end{tabular}




$$
\begin{aligned}
& \text { understand the } \\
& \text { students' } \\
& \text { knowledge of an } \\
& \text { equal distance }
\end{aligned}
$$

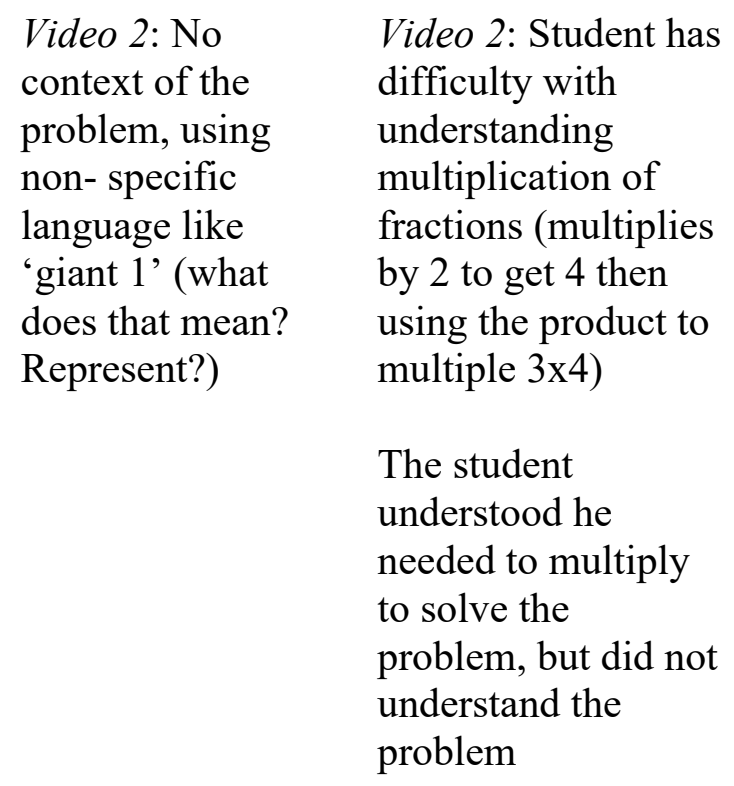

Video 3: Jumping between types of representations (drawing and manipulatives)

Language use of "borrowing" is procedural
Video 3: Place value understanding, regrouping

Students use of how to use visual representations/ drawings as a tool for subtraction

Note. Blank cells indicate combinations of category and topic that are no included in the rubric. Category 1 is captured by the general code; categories 2, 3, and 4 are captured by Mathematics Pedagogy and Mathematical Thinking codes (Copur-Gencturk and Rodrigues, 2021)

\section{Distinctions created as the scorers work through initial scoring:}

Distinctions between Category for Teachers' Mathematics Pedagogy:

- Difference between a 1 and 2: Category 1 responses failed to notice mathematicsspecific events; Category 1 does not contain a specific reference to math content. Even if the Teacher is mentioned, the response is a 1 if math is not discussed. (e.g., describing seating arrangements, describing the teacher's tone of voice); to earn a 1 the teacher needs to be discussed in regard to mathematics.

- Difference between a 2 and a 3: Category 2 rubric contained responses that did mention mathematics but merely in a descriptive or evaluative way; to become a Category 3 the response must describe a 'why' or teacher move in addition to the description. 
- Difference between a 3 and a 4: To become a category 4 the response must specifically identify the mathematical problem that is being addressed.

Distinctions between Category for Students' Mathematics Pedagogy:

- Difference between a 1 and a 2: Category 1 responses failed to notice mathematics-specific events; Category 1 does not contain a specific reference to math content. Even if the Teacher is mentioned, the response is a 1 if math is not discussed. The student must be mentioned in terms of mathematics to become a Category 2.

- Difference between a 2 and a 3: The response must go beyond simply stating facts about what they see (Category 2); to become a Category 3 the response must make an analytical or reasoning statement.

- Difference between a 3 and a 4: For a category 3 it must include analytical or interpretive statements about the mathematics content in the video- to become a category 4 the problematic mathematics of the student thinking must be specifically identified. 


\section{Appendix I}

\section{Scoring Steps:}

\section{Professional Noticing Rubric Scoring Coding Guide}

1. Each response will be coded for CATEGORY and TOPIC

2. Score for the TOPIC first

-(1) Teachers Mathematical Pedagogy (responses focusing on teaching actions and strategies)

-(2) Student Mathematical Thinking (responses that focused on students' thinking)

-(3) General (identify responses that are not related to the math)

3. Score for the CATEGORY second

(0) Category 1 responses failed to notice mathematics-specific events (e.g., describing seating arrangements)

(1) Category 2 responses focused on content specific issues that were either purely descriptive or contained a binary judgement (e.g., restating the problem, stating that the lesson was good)

(2) Category 3 responses analyzed some aspect of students' mathematical thinking or teachers' mathematics pedagogy

(3) Category 4 responses notice an identified key problematic issue which was identified by the panel of math experts (see rubric)

4. Complete the Excel Document identifying CATEGORY and TOPIC for each noticing response Excel Scoring CODES

\begin{tabular}{|l|l|}
\hline TOPIC & $\begin{array}{l}\text { Teachers Mathematical Pedagogy }=\mathbf{T} \\
\text { Student Mathematical Thinking }=\mathbf{S} \\
\text { General }=\mathbf{G}\end{array}$ \\
\hline CATEGORY & Category $1=1$ \\
& Category $2=2$ \\
& Category $3=3$ \\
& Category4 $=4$ \\
\hline TOTAL & $\begin{array}{l}\text { Add up all of the CATEGORY and } \\
\text { create a sum total }(\text { lowest possible }=0 ; \\
\text { highest possible }=27)\end{array}$ \\
\hline
\end{tabular}

\section{Interrater reliability Plan}

1. Train about the rubric and scoring procedures

2. Code responses from 5 pre-service teachers (15 responses) together and come to a consensus on each response's topic and category (making distinguishing notes about category differences)

3. Code 15 responses independently and check interrater reliability (needs to be near $80-90 \%$ )

4. Discuss each item where disagreement is found 
5. Code additional responses independently again if needed

6. Code the remaining of the $20 \%$ double coding ( 71 responses total) in batches of $20-30$ and then check reliability

7. Once $90 \%$ agreement is reached the rest of the individual coding can continue

8. Total of 1,080 responses

- Double code $20 \%=216$ responses

- 864 total responses left

- 432 responses to each score independently after agreement is met 


\section{VITA}

Stephanie Hopkins is originally from outside of Detroit Michigan. She received her bachelors and initial teacher certification in special education from the University of Missouri - Columbia in 2012 and her master's degree in Curriculum and Instruction through the Fellows program at the University of Missouri in 2013. Prior to pursuing her initial teacher certification, Stephanie was a student labeled with a learning disability in written language due to thought processing and sequencing of events. The experience of being a student with an IEP in the school system ignited the interest in becoming an educator. Stephanie was then a special education classroom teacher at the elementary school level in both Missouri and Wisconsin. These experiences were in both inclusive general education classrooms and as self-contained environments to support students perceived as having significant behavioral challenges (both labeled with disabilities and not). These experiences both as a student and teacher have driven her primary research interests - preparing our novice teachers to be prepared for an ever-changing field and arm them with the skills needed to best meet the needs of a classroom's most struggling learner. Outside of the classroom, Stephanie loves to spend time with her husband, golden retriever, Harpo, friends, and family. She is currently living abroad in Bristol England as she completes her Ph.D. 